\title{
WIDEBAND, LOW-LOSS, HIGH-POWER HANDLING DIPLEXER FOR AIRBORNE EARLY WARNING (AEW) SYSTEMS
}

\author{
A Thesis \\ Presented to \\ the Faculty of California Polytechnic State University \\ San Luis Obispo
}

\author{
In Partial Fulfillment \\ of the Requirements for the Degree \\ Master of Science
}

in

Electrical Engineering

By

Awrang M. J. Taiby 


\section{(C) 2007}

Awrang M. J. Taiby

ALL RIGHTS RESERVED 


\section{COMMITTEE MEMBERSHIP}

TITLE: Wideband, Low-loss, High-Power Handling Diplexer for Airborne Early Warning (AEW) Systems

AUTHOR: Awrang M. J. Taiby

DATE SUBMITTED: 11/02/2007

Dr. Dean Y. Arakaki, Associate Professor of Electrical Engineering Committee Chair

Dr. Dennis Derickson, Associate Professor of Electrical Engineering Committee Member

Dr. Xiaomin Jin, Associate Professor of Electrical Engineering

Committee Member 


\title{
ABSTRACT \\ WIDEBAND, LOW-LOSS, HIGH-POWER HANDLING DIPLEXER FOR AIRBORNE EARLY WARNING (AEW) SYSTEMS
}

\author{
by Awrang Taiby \\ Supervisory Committee Chairperson: Dr. Dean Arakaki \\ Department of Electrical Engineering
}

Airborne Early Warning (AEW) systems rely on rotary couplers (RC) to interface rotating antenna elements on aircraft exteriors with stationary onboard systems. The demand for additional channels in new generation AEW systems increases the complexity of rotary couplers significantly. On the other hand, if signals in separate frequency bands use the same channel, existing AEW designs could incorporate additional channels with only minor changes. Passive RF diplexers can accomplish this task. Required characteristics include low-loss $(<0.5 \mathrm{~dB})$, wideband (4.4:1), and high-power $(>6 \mathrm{~kW})$ handling capability. Two diplexer candidates are synthesized and characterized with the aid of a commercial circuit simulation package that includes a 3D full-wave EM solver. A semi-lumped coaxial and a digital elliptic diplexer are proposed, both of which have theoretically low-loss and acceptable VSWR characteristics. However, only the latter diplexer meets operating requirements without the excessive tuning or analysis required by the former. Further studies of the semi-lumped diplexer characteristics may make it useful in other applications.

This thesis defines diplexer design goals, provides a brief introduction to filter theory, and compares performance characteristics of the semi-lumped and digital elliptic diplexers. Simulation results for both designs demonstrate that the digital elliptic diplexer is an optimum solution. 


\section{ACKNOWLEDGMENTS}

The author wishes to thank his advisor, Dr. Dean Arakaki, for the opportunity to work on this project, for all the thoughtful questions he asked, for the constructive criticisms and editions he provided on reports, and for his great generosity and incredible patience.

The author also wishes to thank Randtron Antenna Systems (RAS) for sponsoring this collaborative effort with Cal Poly and providing the facilities, the computers, the simulation software, and for making the author feel welcome at their location in Menlo Park, California.

Finally, the author wishes to thank his parents for all their support, encouragement, and understanding. 


\section{TABLE OF CONTENTS}

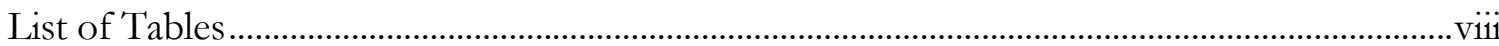

List of Figures ......................................................................................................................

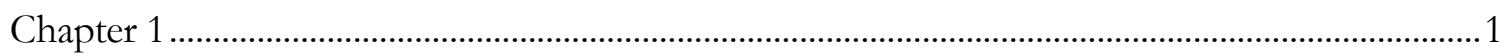

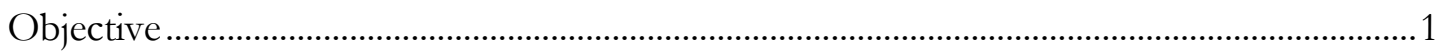

Chapter Organization ...........................................................................................................

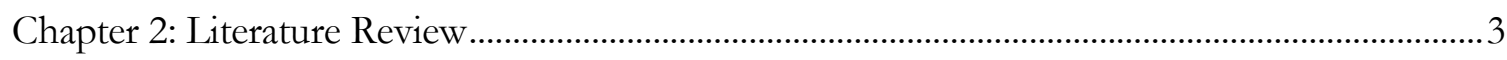

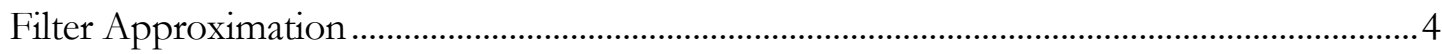

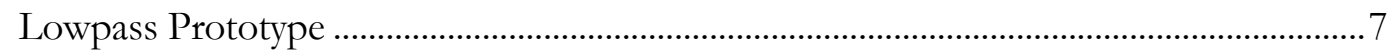

Filter Implementation.................................................................................................... 10

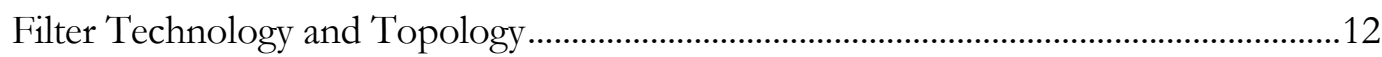

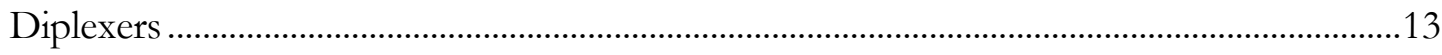

Chapter 3: The Semi-lumped Coaxial Diplexer.......................................................................14

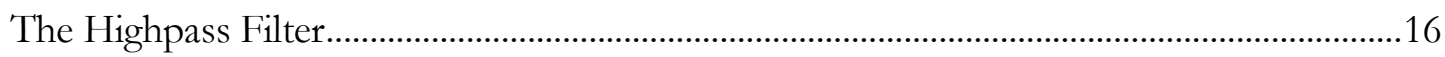

The Diplexer ……….......................................................................................................

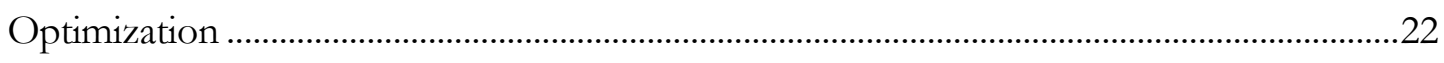

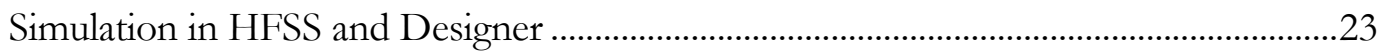

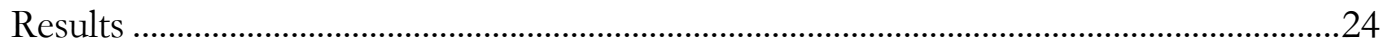

Chapter 4: The Digital Elliptic Diplexer ..................................................................................28

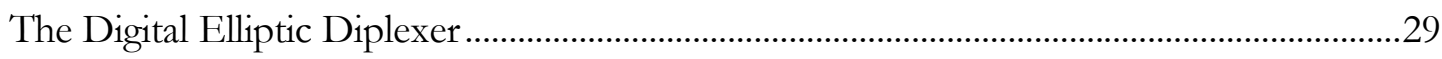

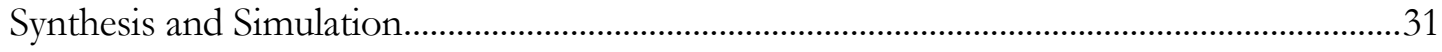

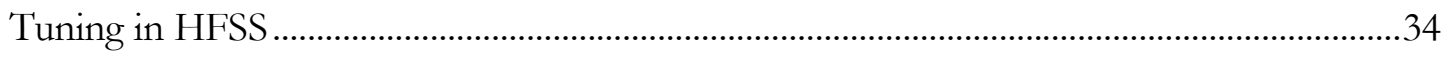




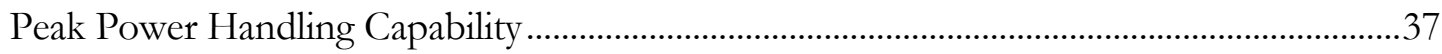

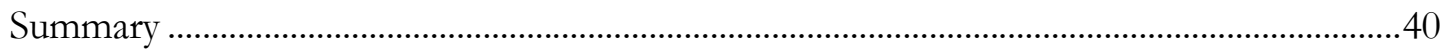

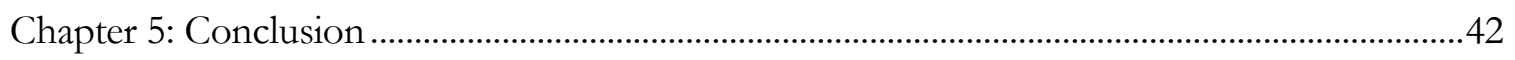

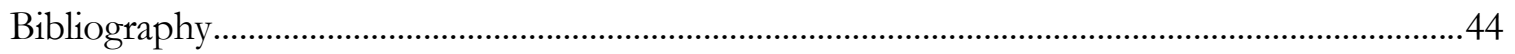

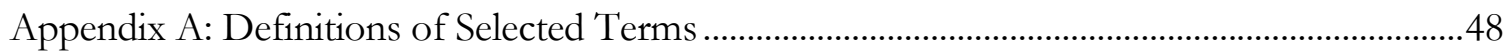

Appendix B: Some Filter Technologies/Topologies ......................................................................50

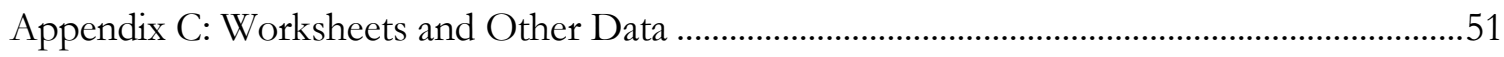




\section{LIST OF TABLES}

Number

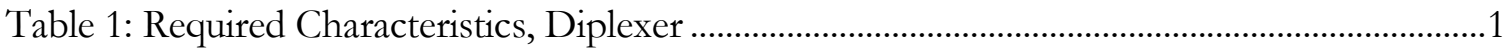

Table 2: Digital Elliptic Diplexer, Normalized Element Values and Designer Optimized

Values

Table 3: Digital Elliptic Diplexer Dimensions ................................................................................... 34

Table 4: Resonator Lengths, Before/After HFSS Tuning .......................................................... 37

Table 5: Diplexer Performance Results, Worst Case ........................................................................ 40 


\section{LIST OF FIGURES}

Number

Figure 1: Filter Block Diagram 3

Figure 2: Ideal Filter Response

Figure 3: $5^{\text {th }}$ Order Chebyshev Lowpass Filter Response..........................................................6

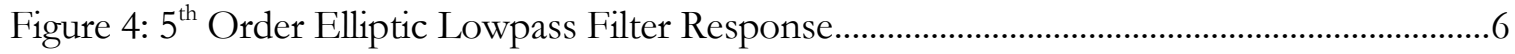

Figure 5: Normalized Lossless Two-Port Network......................................................................

Figure 6: Lowpass Filter Response …………............................................................................

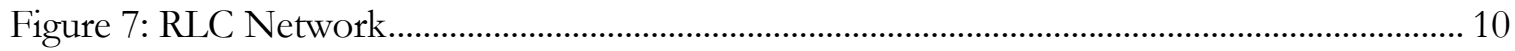

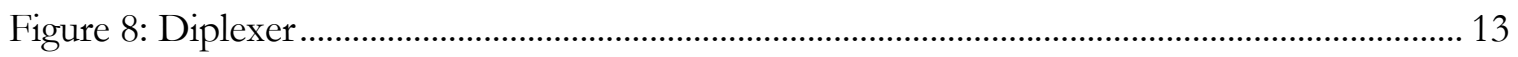

Figure 9a: Semi-Lumped Lowpass Filter Realization: Tubular, Cross-section .............................. 14

Figure 9b: Equivalent Lumped Element Circuit ............................................................................ 14

Figure 10a: Highpass Semi-Lumped Filter Section Realization, Cross-section ............................. 17

Figure 10b: Equivalent Lumped Element Circuit .................................................................... 17

Figure 11: Alternate Series Capacitor Configuration, Cross-section ............................................. 17

Figure 12: Semi-Lumped Diplexer Configuration, Cross-section.................................................... 18

Figure 13: Semi-Lumped Diplexer Equivalent Lumped Element Circuit ...................................... 18

Figure 14: Semi-Lumped Element Equivalent Circuit a)Passband Insertion Loss, b)Isolation 19

Figure 15: Semi-Lumped Element Equivalent Circuit Return Loss, Common Junction ........... 20

Figure 16: Semi-Lumped Diplexer Insertion Loss ............................................................................ 20

Figure 17: Semi-Lumped Diplexer a) Isolation, and b) Return Loss............................................. 21

Figure 18: Discontinuities modeled in HFSS, Lowpass/Highpass Filters .................................... 23 
Figure 19: Diplexer Optimization Results in Designer: a) Insertion Loss, b) Isolation..... 25

Figure 20: Diplexer Optimization Results in Designer: Return Loss ............................................ 26

Figure 21: HFSS Simulation, Designer-Optimized Diplexer, Insertion Loss .............................. 26

Figure 22: HFSS Simulation, Designer-Optimized Diplexer, Isolation .......................................... 27

Figure 23: HFSS Simulation, Designer-Optimized Diplexer, Return Loss................................... 27

Figure 24: Digital Elliptic Diplexer and L-C prototype ............................................................... 29

Figure 25: L-C Prototype Diplexer Frequency Response .................................................................. 30

Figure 26: Digital Elliptic Diplexer Frequency Response.............................................................. 31

Figure 27: Static Capacitance and Series Stub Impedance Values ................................................. 33

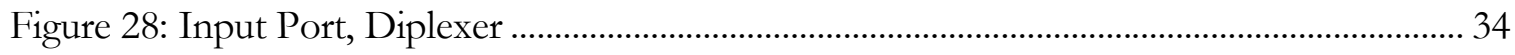

Figure 29: Diplexer Frequency Response in HFSS........................................................................ 35

Figure 30: Diplexer Isolation Between Lowpass and Highpass Filters......................................... 35

Figure 31: Return Loss at Diplexer Common Port ………............................................................ 36

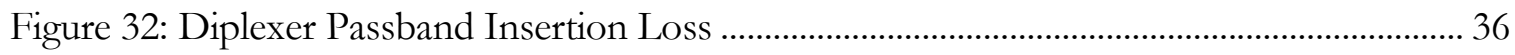

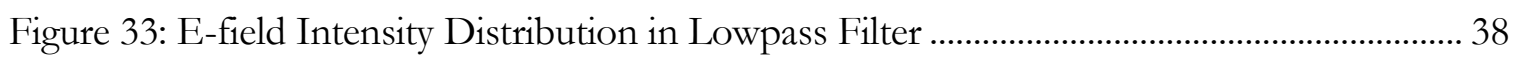

Figure 34: E-field Intensity Distribution in Highpass Filter ......................................................... 39

Figure 35: Overall Dimensions, Proposed Digital Elliptic Diplexer ............................................. 41

Figure A.1: Prototype Digital Elliptic Diplexer Response ........................................................... 48 


\section{Chapter 1}

\section{INTRODUCTION}

\subsection{Objective}

The primary objective of this project is to predict and optimize the RF performance of candidate diplexers for AEW applications to meet the specifications of Table 1 below. Ansoft's commercial circuit simulator software (Designer) combined with the 3D full-wave electromagnetic (EM) field simulator HFSS (High Frequency Structure Simulator) model the designs.

Table 1: Required Characteristics, Diplexer

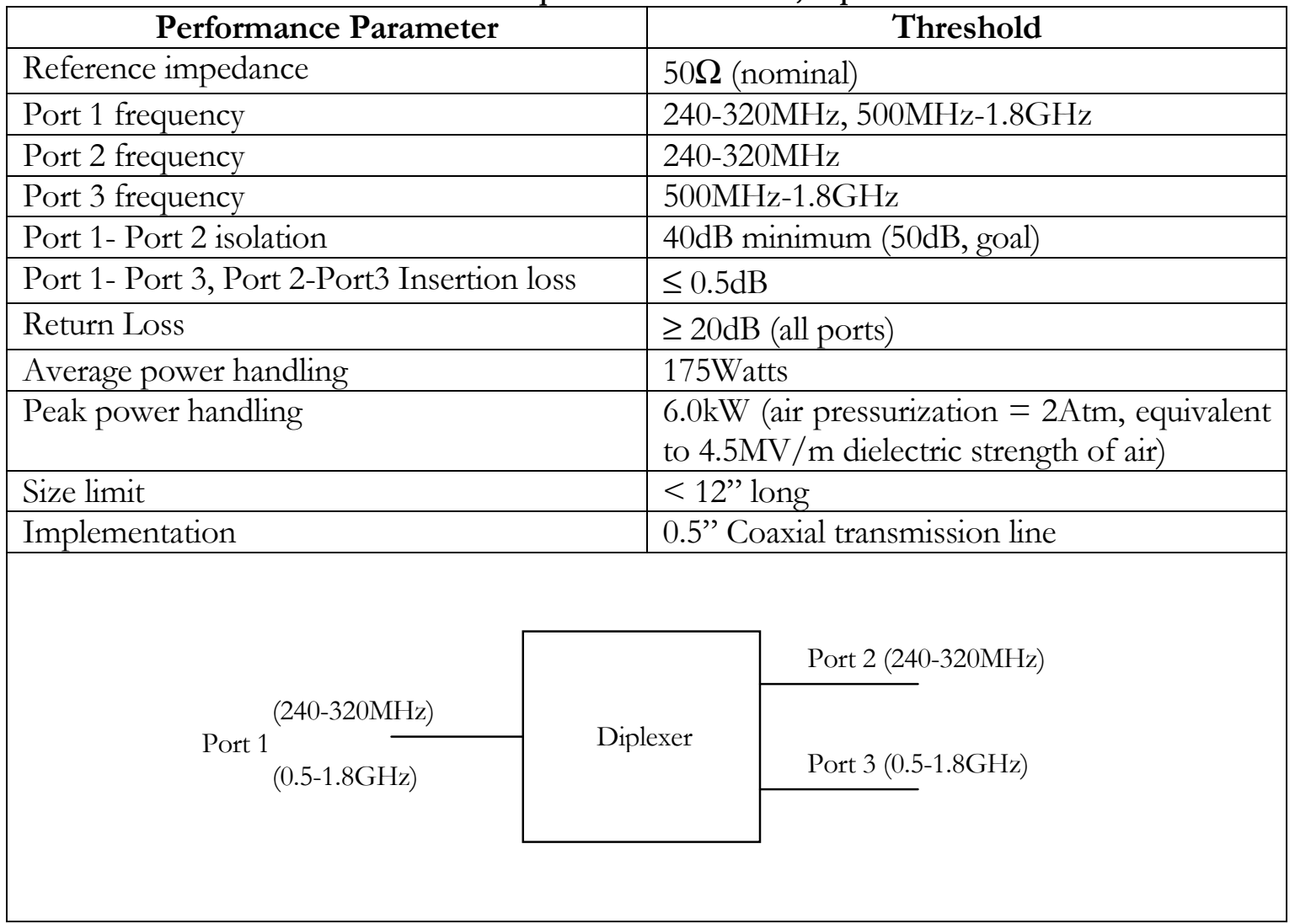


A pseudo-complementary ${ }^{1.1}$ shunt connected highpass and lowpass filter can best meet Table 1 specifications with a center frequency at the arithmetic mean of the cutoff frequencies. Since the lowpass and highpass filter cutoffs are at $320 \mathrm{MHz}$ and $500 \mathrm{MHz}$, respectively, the diplexer center frequency is set to $410 \mathrm{MHz}$.

\subsection{Chapter Organization}

Chapter 2 provides a brief review of electrical filter theory, while Chapter 3 presents an investigation of the semi-lumped diplexer. The author is unaware of the design and implementation of the semi-lumped diplexer (Chapter 3), either in literature or in industry and believes that with careful study, it might be of practical value. Chapter 4 presents the investigation of a 4.4:1 bandwidth digital elliptic diplexer topology that designers have traditionally employed in applications of up to 4.0:1 bandwidth. Finally, Chapter 5 presents a summary of results relative to design specifications, and recommended future work. 


\section{Chapter 2}

\section{LITERATURE REVIEW}

A filter is a network with a prescribed response for a given excitation [1, 2], as shown in Fig. 1, where $X(s)$ and $Y(s)$ are the Laplace transforms of continuous time functions $x(t)$ and $y(t)$. The filters appearing in this paper are based on lossless, time-invariant, reactive-component (inductors and capacitors) networks.

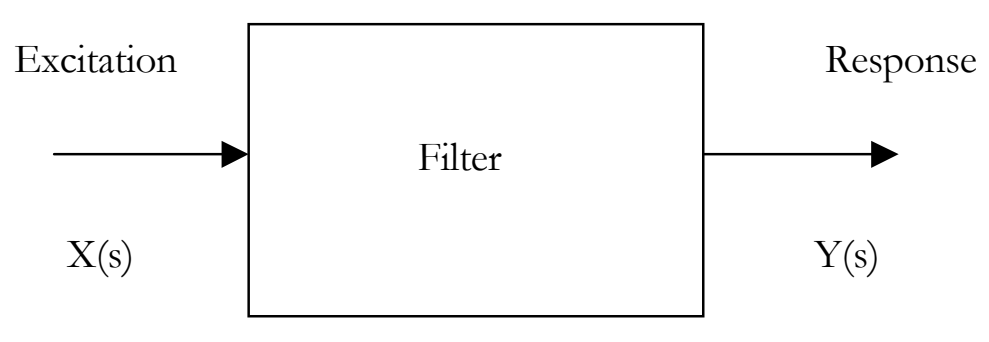

Figure 1: Filter Block Diagram

Filters are classified according to selectivity, approximation method, and implementation. Selectivity — the filter's insertion loss outside the desired band, typically specified in $\mathrm{dB}$ - quantifies the filter's ability to differentiate between signals of different frequencies, while the approximation method determines how well the filter's response matches the desired response. Implementation defines the filter's physical form and its suitability for a particular application. 


\subsection{Filter Approximation}

An ideal lowpass filter allows a band of frequencies, from zero to a specified cutoff frequency, to pass through the network unimpeded and rejects all other frequencies. Therefore, the filter has zero loss in the passband and infinite loss outside the band-the stopband-and no transition band. However, such a filter is physically unattainable, only an approximation is achievable. Fig. 2 shows the ideal lowpass filter and its time domain impulse response. [3]
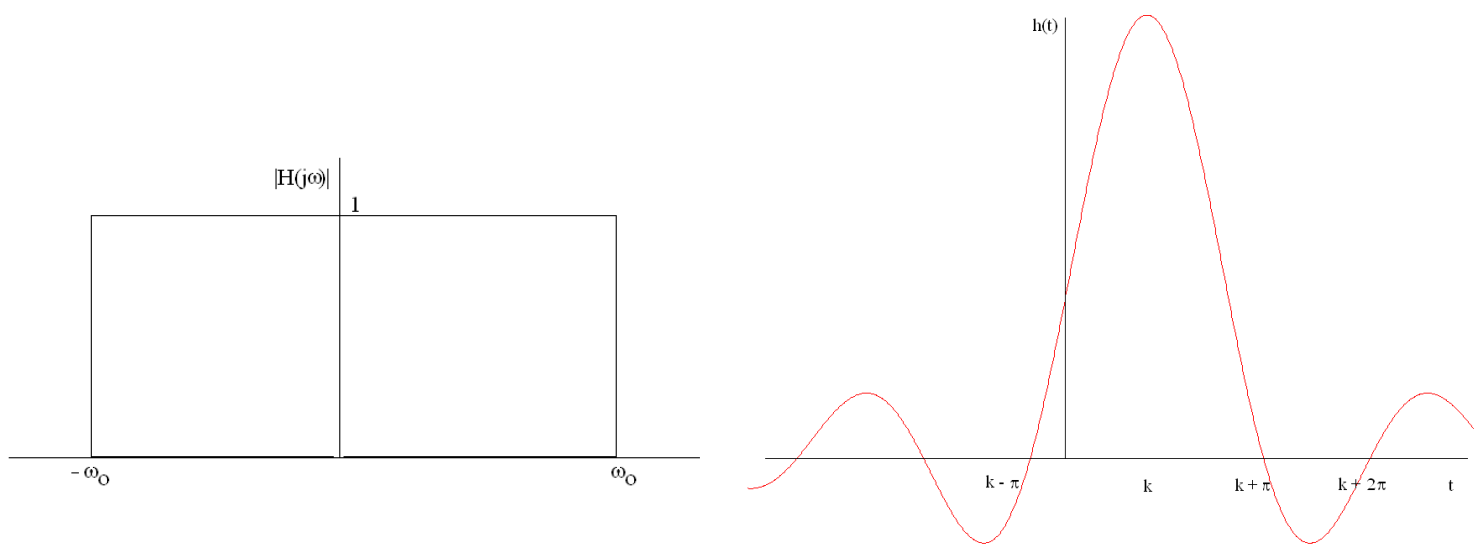

Figure 2: Ideal Filter Response

In the passband, an ideal filter has unity gain magnitude, linear phase, and constant group delay. Hence

$$
\begin{aligned}
& |H(j \omega)|=1\left\{\begin{array}{l}
|\omega|<\omega_{O} \\
|\omega|>\omega_{O}
\end{array}\right. \\
& \phi(\omega)=-k \omega \\
& t_{g}=\frac{-d \phi(\omega)}{d \omega}=k
\end{aligned}
$$


Setting $\omega_{0}=1 \mathrm{rad} / \mathrm{sec}$, the time domain response is the sinc function, which is noncausal, thus resulting in an unrealizable filter. If $t_{g}$ tends to infinity, the response would be causal, but the filter would still be unrealizable due to infinite group delay. Filter approximation is necessary to provide a compromise between filter selectivity and group delay.

Of the many available filter approximations [2, 4-7], this paper only discusses the Chebyshev and elliptic (or Cauer) since they provide the "optimum" gain approximation of any known filter type (for a proof see [3]). The Chebyshev filter is characterized by equiripple in the passband, while the elliptic filter is characterized by equiripple in both the passband and stopband. Of the two filter approximations, the elliptic provides the sharpest roll-off in the transition band, and the worst group delay variation in the passband; however, designers use these filters for their selectivity as opposed to group delay. Figs. 3 and 4 show magnitude responses of $5^{\text {th }}$ order Chebyshev and elliptic filter functions in blue along with their corresponding group delays (GD) in red. Note that the elliptic filter has a maximum passband group delay variation of $5.6 \mathrm{~ns}$, whereas the Chebyshev exhibits only $1.25 \mathrm{~ns}$.

Group delay variation across the filter passband is of interest to the designer, not its instantaneous value. Acceptable variation depends on the specific filter application. For instance, a $1 \mathrm{MHz}$ signal modulated on a $5 \mathrm{GHz}$ carrier passing through a $2-10 \mathrm{GHz}$ bandpass filter will, for all intents and purposes, experience approximately constant group delay since there is negligible variation over any $1 \mathrm{MHz}(<0.01 \%)$ portion of the passband. However, the same cannot be said if the $1 \mathrm{MHz}$ signal passes through a $1 \mathrm{MHz}$ bandwidth elliptic filter. These results are readily apparent in Figures 3 and 4, if the normalized frequencies are scaled appropriately. Yet in other instances, such as digital communications over a cable network, 
greater group delay variation is permissible than those in Figs. 3 and 4: DOCSIS (Data Over Cable Service Interface Specification) allows a maximum of $75 \mathrm{~ns}$ group delay variation across a 6MHz wide channel for QAM (Quadrature Amplitude Modulation).

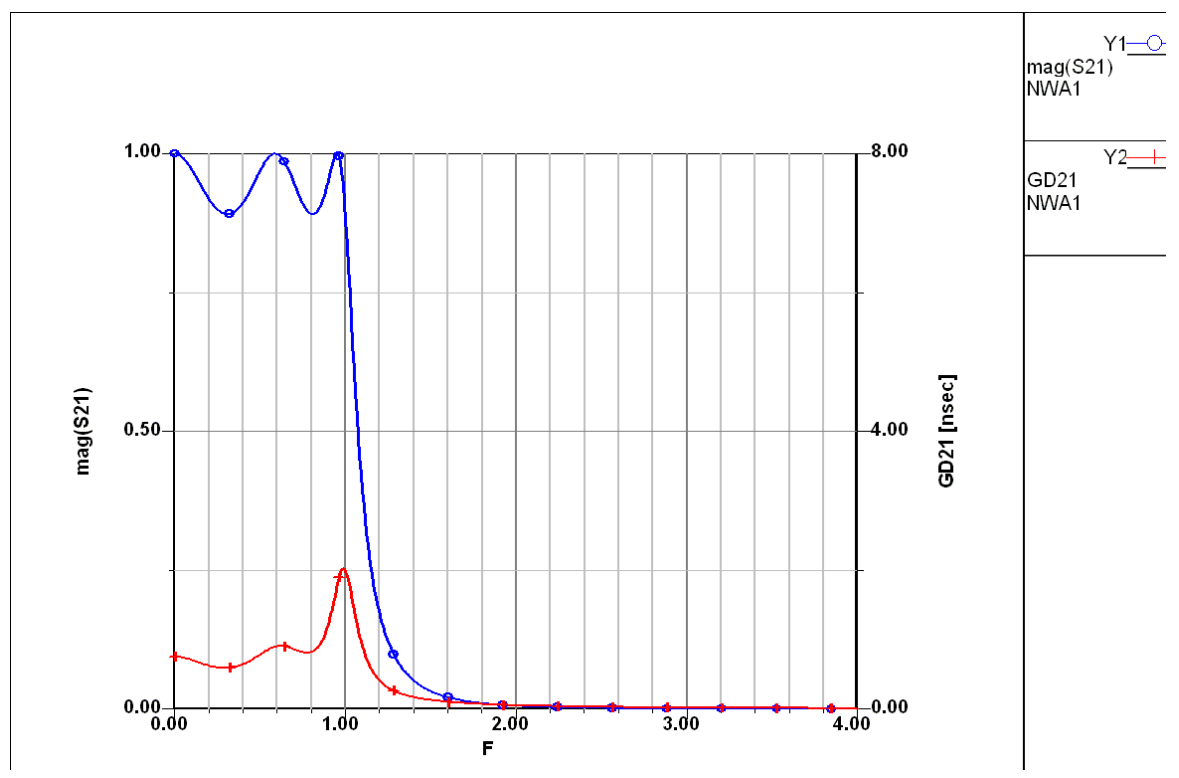

Figure 3: $5^{\text {th }}$ Order Chebyshev Lowpass Filter Response

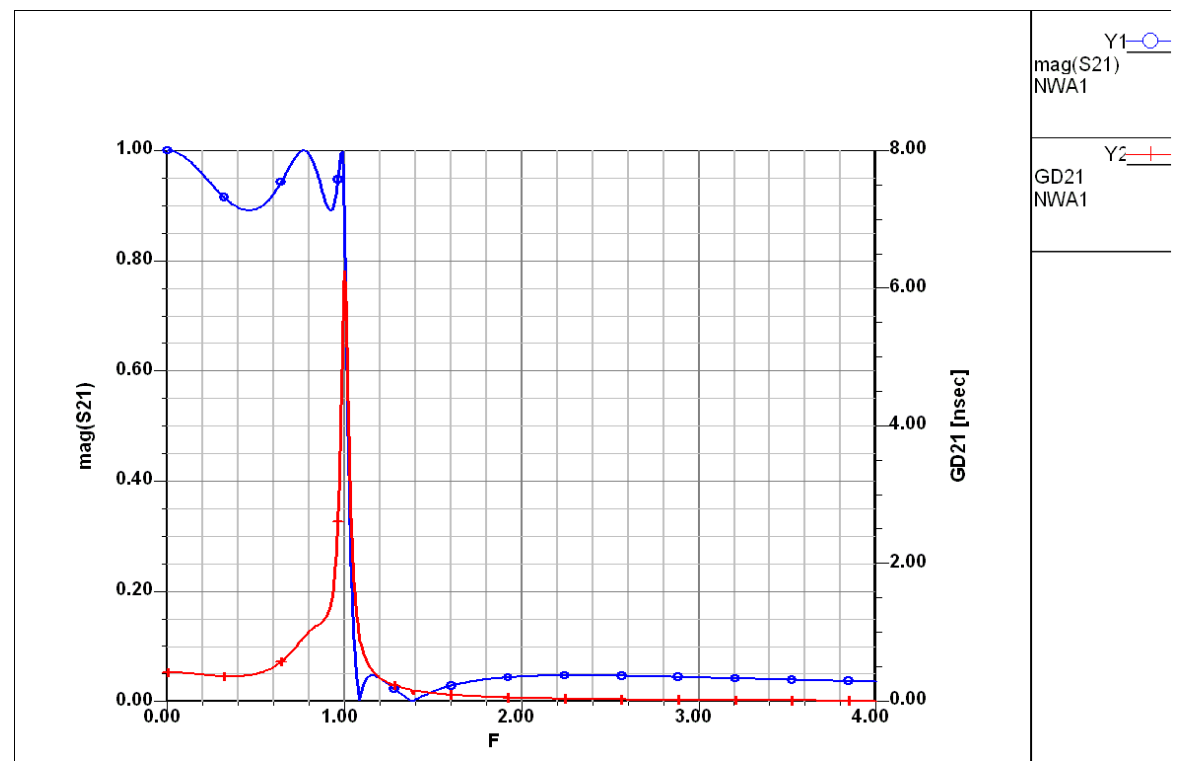

Figure 4: $5^{\text {th }}$ Order Elliptic Lowpass Filter Response 


\subsubsection{Lowpass Prototype}

Most filter designs begin with a lowpass prototype; a passive, reciprocal, lossless, twoport network operating between a unit impedance generator and a unit impedance load as shown in Figs. 5 and 6 [1-10].

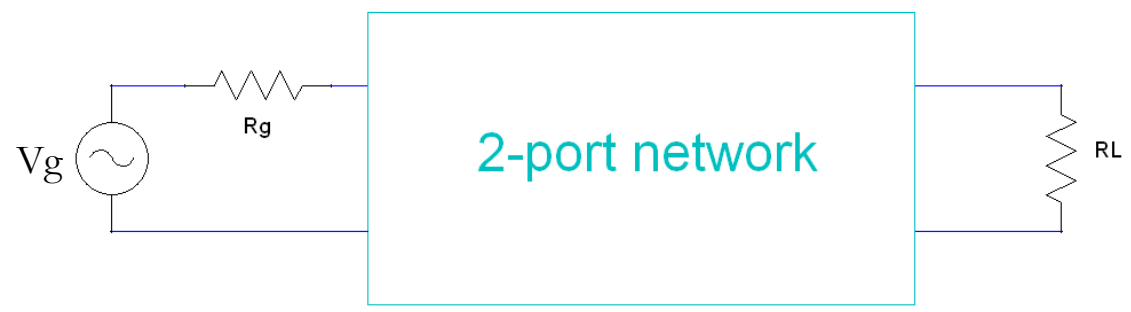

Figure 5: Normalized Lossless Two-Port Network. $\mathrm{Rg}=\mathrm{RL}=1$

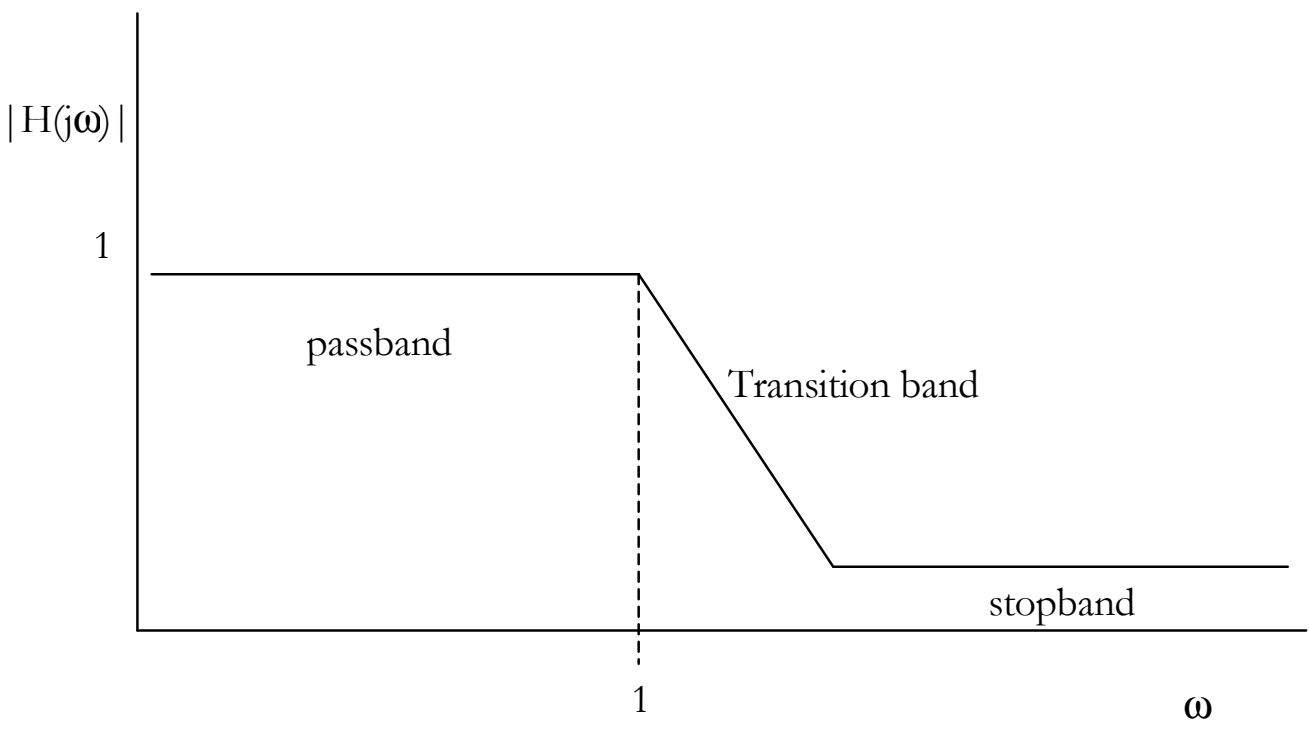

Figure 6: Lowpass Filter Response

The lowpass prototype allows the derivation of all other filter types such as highpass, bandpass, and others based on well known transformations $[2,8]$. Similarly, network element 
values (capacitor, inductors, and terminating impedances) are scaled for the desired frequency bands.

Most filters are based on lumped element LC network prototypes that approximate the response of ideal filters by a ratio of polynomials such as the Chebyshev. Specifically, the Chebyshev amplitude approximation is

$$
|H(j \omega)|^{2}=\left|S_{12}(j \omega)\right|^{2}=\frac{1}{1+\varepsilon^{2} C_{n}^{2}(\omega)}
$$

where, $C_{n}$ is the $n^{\text {th }}$-degree Chebyshev polynomial

$$
C_{n}(\omega)=\cosh \left[n \cdot \cosh ^{-1}(\omega)\right]
$$

resulting in

$$
\left|S_{12}(j \omega)\right|^{2}=\frac{1}{1+\varepsilon^{2} \cosh ^{2}\left[n \cdot \cosh ^{-1}(\omega)\right]} .
$$

Therefore, the passband insertion loss ripple is

$$
\mathrm{IL}=10 \cdot \log \left(1+\varepsilon^{2}\right),
$$

thus $\varepsilon$ is the ripple factor in equation 2.4. Outside the passband, the insertion loss increases monotonically with frequency. 
Similarly, the elliptic filter response is

$$
|H(j \omega)|^{2}=\left|S_{12}(j \omega)\right|^{2}=\frac{1}{1+\varepsilon^{2} R_{n}^{2}(\omega)},
$$

where $\varepsilon$ is the same as the Chebyshev response, but $\mathrm{R}_{\mathrm{n}}$ is the nth-order elliptic rational function (or Cauer or Chebyshev rational function) $[3,7]$. Unlike $C_{n}, R_{n}$ does not have a closed form representation and requires the use of elliptic integrals and Jacobian elliptic functions. $R_{n}$ is a rational function and thus produces ripple in the passband as well as in the stopband. Alternatively, some authors [3] utilize the highpass prototype response

$$
\left|S_{12}(j \omega)\right|^{2}=\frac{\varepsilon^{2} R_{n}^{2}(\omega)}{1+\varepsilon^{2} R_{n}^{2}(\omega)} .
$$

Since the prototype network is passive and lossless, the following holds [3]

$$
\left|S_{11}(j \omega)\right|^{2}+\left|S_{12}(j \omega)\right|^{2}=1 .
$$

Therefore, since $S_{11}$ is related to the input impedance $\mathrm{Z}$ by

$$
\begin{aligned}
& S_{11}(s)=\frac{Z(s)-1}{Z(s)+1} \\
& Z(s)=\frac{1+S_{11}(s)}{1-S_{11}(s)}
\end{aligned}
$$

the lumped element prototype values may be determined. 


\subsection{Filter Implementation}

There are a number of ways to synthesize element values for filter networks such as direct synthesis of element values from filter specifications, synthesis by numerical optimization schemes [12-13], by approximation, and even by genetic programming.

For most wideband filters, lumped elements are the preferred choice, except for frequency bands where lumped element components no longer exhibit desired responses and behave as distributed components $[6,8,14]$. This distinction depends on both the physical dimensions of the filter elements and the electrical wavelength in the propagating medium and vary based on the technology and materials employed. However, appropriately designed distributed filters, such as microstrip [16,17], can exhibit 15:1 stopbands.

An example involves replacing the lumped inductor in the RLC circuit of Fig. 7 with a shorted series transmission line of length $l$. This increases the circuit's Q-factor, thus reducing its bandwidth [16].

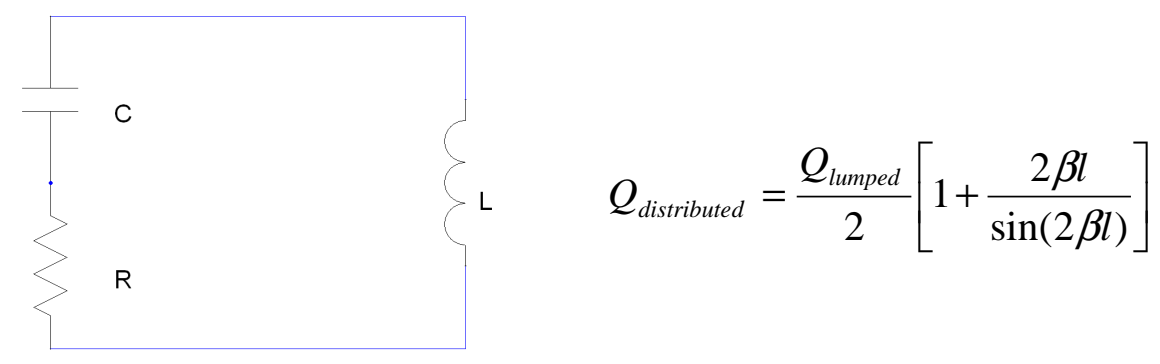

Figure 7: RLC Network 
A section of transmission line may approximate a lumped element over a frequency band if its electrical length is less than $\lambda / 4[3,8]$. Since the transmission matrix (ABCD matrix) of a lossless transmission line is

$$
[T]=\left[\begin{array}{cc}
\cos (\beta l) & j Z_{0} \sin (\beta l) \\
j \sin (\beta l) / Z_{0} & \cos (\beta l)
\end{array}\right]
$$

A short length $(<\lambda / 4)$ high impedance $\left(\mathrm{Z}_{0} \rightarrow \infty\right)$ line becomes [3]

$$
[T]=\left[\begin{array}{cc}
1 & j Z_{0} \beta l \\
0 & 1
\end{array}\right], \beta l=\frac{\omega l}{v},
$$

where $v$ is the phase velocity. Thus equation 2.15 represents a series inductor $\mathrm{L}=Z_{0} l / v$. Similarly, a short section of low impedance $\left(Z_{0} \rightarrow 0\right)$ transmission line represents a shunt capacitance of $\mathrm{C}=/ / Z_{0} v[8]$.

Distributed transmission lines may be treated as inductors and capacitors with the aid of Richards' transform [14]

$$
S=j \Omega=j \tan \left(\frac{\pi}{2} \frac{\omega}{\omega_{0}}\right)
$$

in which $\omega_{0}$ is defined as the frequency at which $l$ equals one-quarter wavelength. A series inductor may be represented by a short-circuit transmission line with impedance

$$
Z_{S C}=j Z_{0} \tan \left(\frac{\pi}{2} \frac{\omega}{\omega_{0}}\right)=j \Omega L^{\prime}
$$


and an open-circuit transmission line represents a shunt capacitor with admittance

$$
Y_{O C}=j \frac{1}{Z_{0}} \tan \left(\frac{\pi}{2} \frac{\omega}{\omega_{0}}\right)=j \Omega C^{\prime}
$$

Note that unlike a lumped element, the distributed element exhibits an odd harmonic (in terms of $\left.\omega_{0}\right)$ frequency response because of the tan function.

\subsubsection{Filter Technology and Topology}

Once the filter specifications are known, the designer can select microstrip, stripline, waveguide, coaxial, ceramic, lumped element, or a combination to meet requirements [18-24]. For high power $(\mathrm{kW}$ range $)$ and low dissipation loss $(<0.5 \mathrm{~dB})$, TEM mode structures such as coaxial, combline, and interdigital filters are well suited. Though waveguide filters provide low dissipation loss and high-power handling capability, they require excessive physical space.

TEM mode or quasi-TEM mode topologies such as combline and digital filters are based on parallel conductor transmission line theory [25-27] and are useful for low-loss, highpower filters with narrow bandwidth $(<1 \%)$ to broadband filters of $100 \%$ or more [28-32]. Appendix B shows example filter technologies and topologies. 


\subsection{Diplexers}

Diplexers are multi-channel filters_-typically two filters-connected in either series or parallel to divide a frequency band into two or more channels [31]. Diplexers may consist of highpass and lowpass, bandpass and bandpass, bandpass and bandstop, and other combinations $[8,14]$.

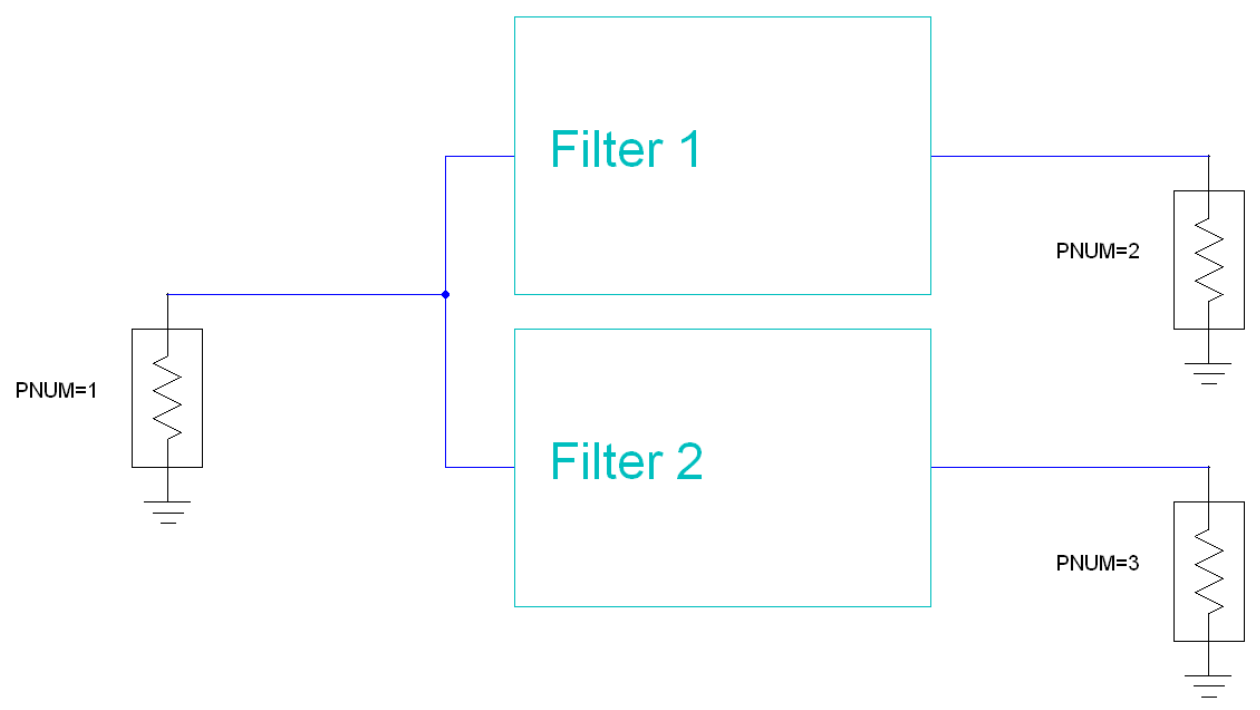

Figure 8: Diplexer

To transmit power from the source (port 1) to either load (ports 2 or 3), the input admittance must be matched $[14,19,33]$

$$
\mathrm{Y}_{\mathrm{IN}}=\mathrm{Y}_{\mathrm{IN} \_1}+\mathrm{Y}_{\mathrm{IN} \_2}=1 \text {. }
$$

Hence, the input admittance must be purely real. These filters are considered complementary (see Appendix A). Though Chebyshev and elliptic filters cannot be completely complementary (due to passband ripple), they exhibit more than $20 \mathrm{~dB}$ input return loss if $\left|\mathrm{Y}_{\mathrm{IN}}\right|$ in equation 2.19 remains $1 \pm 20 \%[33,34]$ in which case they are considered pseudo-complementary. 


\section{Chapter 3}

\section{THE SEMI-LUMPED COAXIAL DIPLEXER}

The semi-lumped diplexer is an attractive choice for wideband applications because of its lumped element behavior (see section 2.3), low-loss, ease of fabrication, and its high-power handling capability.

\subsection{The Lowpass Filter}

The lowpass filter consists of short sections $(<\lambda / 4)$ of high and low impedance transmission lines representing series inductors and shunt capacitors, respectively. Fig. 9 shows the tubular realization of such a filter and its equivalent lumped element circuit.

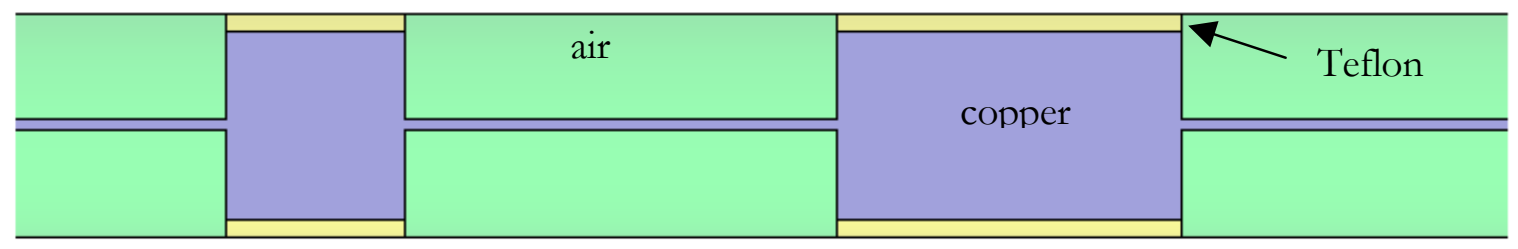

Figure 9a: Semi-Lumped Lowpass Filter Realization: Tubular, Cross-section

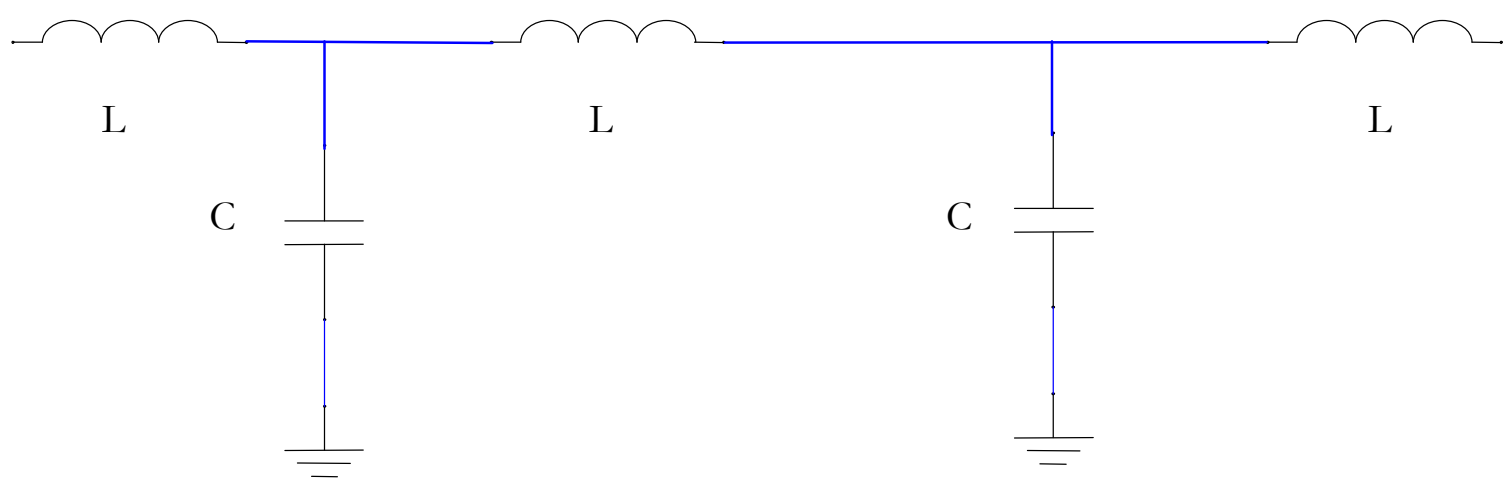

Figure 9b: Equivalent Lumped Element Circuit 
Teflon dielectric supports the low impedance sections of the transmission line and provides support for the entire structure. To achieve an overall filter length less than 12" (Table 1), the design should minimize high impedance line diameters, while minimizing low impedance line diameters; however, the filter should limit the overall diameter to prevent higher order mode $\left(\mathrm{TE}_{11}\right)$ propagation. High impedance values should be sufficient to minimize line section lengths (equation 2.15) while meeting bandwidth requirements. The lines must also withstand mechanical stresses and accommodate electrical current requirements. To meet general requirements without defined specifications, the author used the following reasoning to constrain the initial lowpass filter physical dimensions, subject to modifications after testing the physical prototype ${ }^{3.1}$ :

1. 1.25" outer diameter coaxial tubing for the lowpass filter provides an adequate compromise between the overall physical size, bandwidth and next higher order mode, and is readily available and commonly used in high power AEW applications.

2. The high impedance line diameter is set to a minimum of 0.062 ", equivalent to a $16 \mathrm{AWG}$ (American Wire Gauge) solid wire, rated for 20A of DC current. Since the maximum current in the lowpass filter at $6 \mathrm{~kW}$ peak $(50 \Omega$ system) is $11 \mathrm{~A}$, the 0.062 " diameter is a reasonable starting point. This diameter also places a maximum limit on impedance at $180 \Omega$ when employed in the 1.25 " coaxial tube, which in turn dictates line length based on equation 2.15. In a multisection filter, each line has a different length.

3. The low impedance line diameter is set to 1.06 ", which allows for a 0.080 " thick Teflon support ring that can handle $547 \mathrm{~V}$ peak voltage at $6 \mathrm{~kW}$ peak power since the dielectric 
strength of Teflon is $2.36 \mathrm{MV} /$ in. Furthermore, the line diameter sets the next higher order coax propagation mode $\left(\mathrm{TE}_{11}\right)$ to $2.2 \mathrm{GHz}$, well outside the $1.8 \mathrm{GHz}$ diplexer requirement (see Table 1). Again, equation 2.15 specifies the length of each low impedance section.

\subsection{The Highpass Filter}

The highpass filter consists of series Teflon-separated disks and shunt high impedance tubular transmission line sections. Fig. 10 shows the realization and equivalent circuit of such a filter. The mechanical and electrical considerations mentioned for the lowpass filter apply here as well. Furthermore, the disk capacitor should utilize a relatively thick dielectric $(>0.001 ")$ to improve peak power capacity, and the plate area should minimize fringing capacitance. An empirical method is used to determine an acceptable level of fringing capacitance. Similar to the lowpass filter, the author used the following dimensions ${ }^{3.2}$ :

1. The outer conductor's outer diameter is set to 0.5 " with a wall thickness of 0.030 " (readily available tube size). Since this is less than the 1.25 " diameter of the lowpass filter, whose next higher order propagation mode is greater than $2.2 \mathrm{GHz}$, higher order mode propagation is eliminated.

2. The disk capacitor diameter is set to 0.270 " and the capacitor equation,

$$
\mathrm{C}=\varepsilon_{\text {dielectric }} \text { Area/thickness } \text { dielectric }_{\text {the }}
$$

with Teflon dielectric $\left(\varepsilon_{\mathrm{r}}=2.1\right)$, determines the dielectric thickness. The metal plate thickness is initially set to 0.030 ". The 0.270 " diameter and the 0.030 " disk thickness contribute less than $140 \mathrm{fF}$ of fringing capacitance and is assumed negligible. 


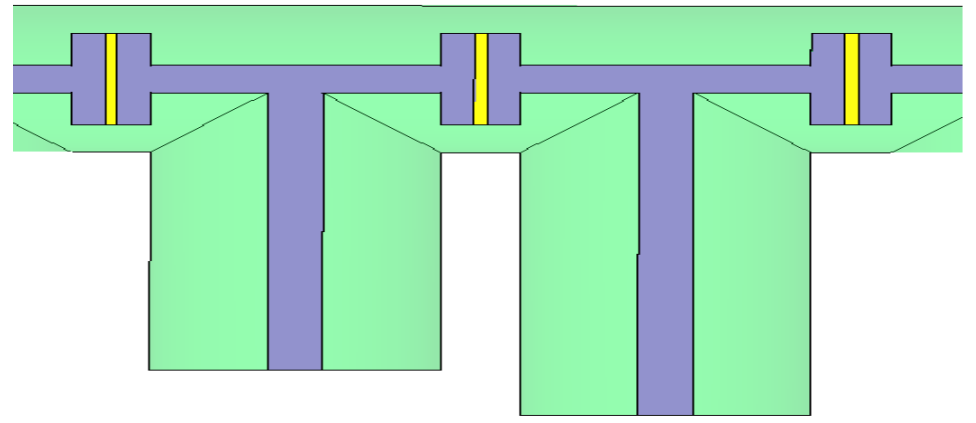

Figure 10a: Highpass Semi-Lumped Filter Section Realization, Cross-section

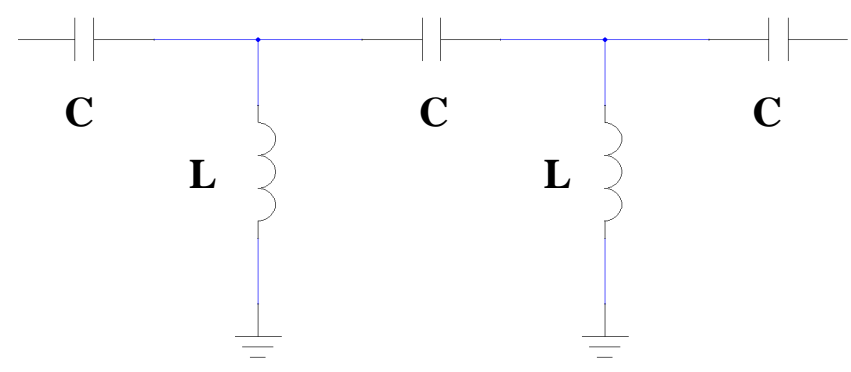

Figure 10b: Equivalent Lumped Element Circuit of Fig.-10a

An alternate realization for the series capacitors of Fig. 10 consists of a Teflon spacer on the coax inner conductor as depicted in Fig. 11. This represents an open-circuit stub, which is advantageous in bandpass filter designs requiring quarter wavelength open-circuit stubs, similar to that in Chapter 4.

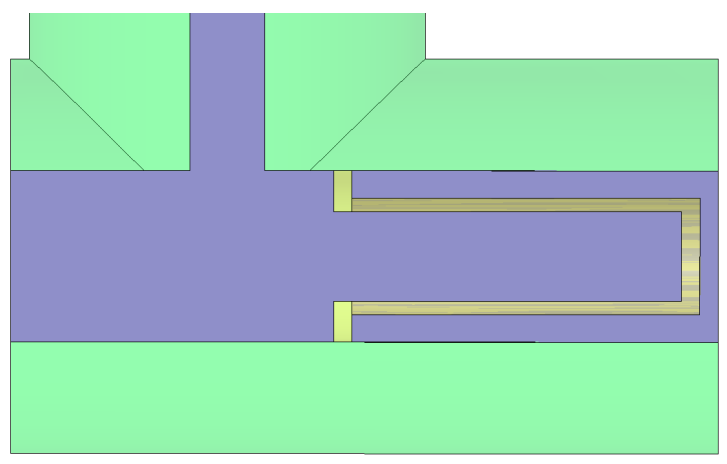

Figure 11: Alternate Series Capacitor Configuration, Cross-section 


\subsection{The Diplexer}

Figs. 12 and 13 show the semi-lumped diplexer configuration and its equivalent circuit. The initial filter circuit element values yield a cutoff frequency equal to the mean of the highpass and lowpass cutoff frequencies, resulting in a pseudo-complementary diplexer with $40 \mathrm{~dB}$ isolation and equiripple passbands (Chebyshev design). Ansoft Designer's filter design utility provided element values for singly terminated lowpass and highpass filters. The individual filters were connected together and simulated for the frequency band of interest. Figs. 14 and 15 display the lumped circuit response, while Figs. 16 and 17 display the response of the semi-lumped diplexer modeled in Ansoft HFSS. Observe that the HFSS model results do not meet Table 1 requirements, thus requiring an optimization procedure.

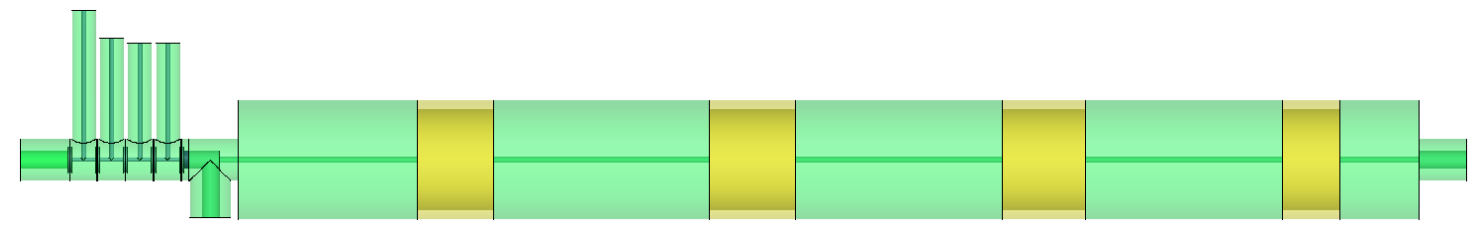

Figure 12: Semi-Lumped Diplexer Configuration, Cross-section

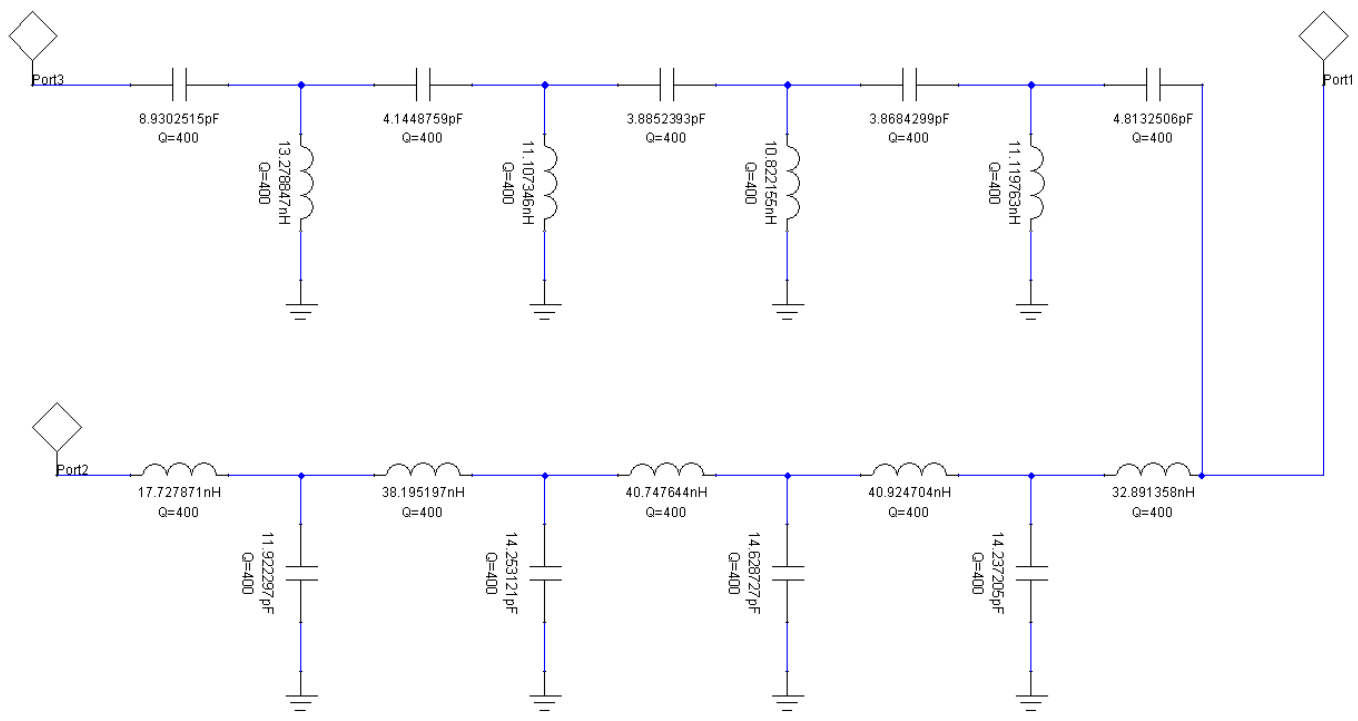

Figure 13: Semi-Lumped Diplexer Equivalent Lumped Element Circuit 

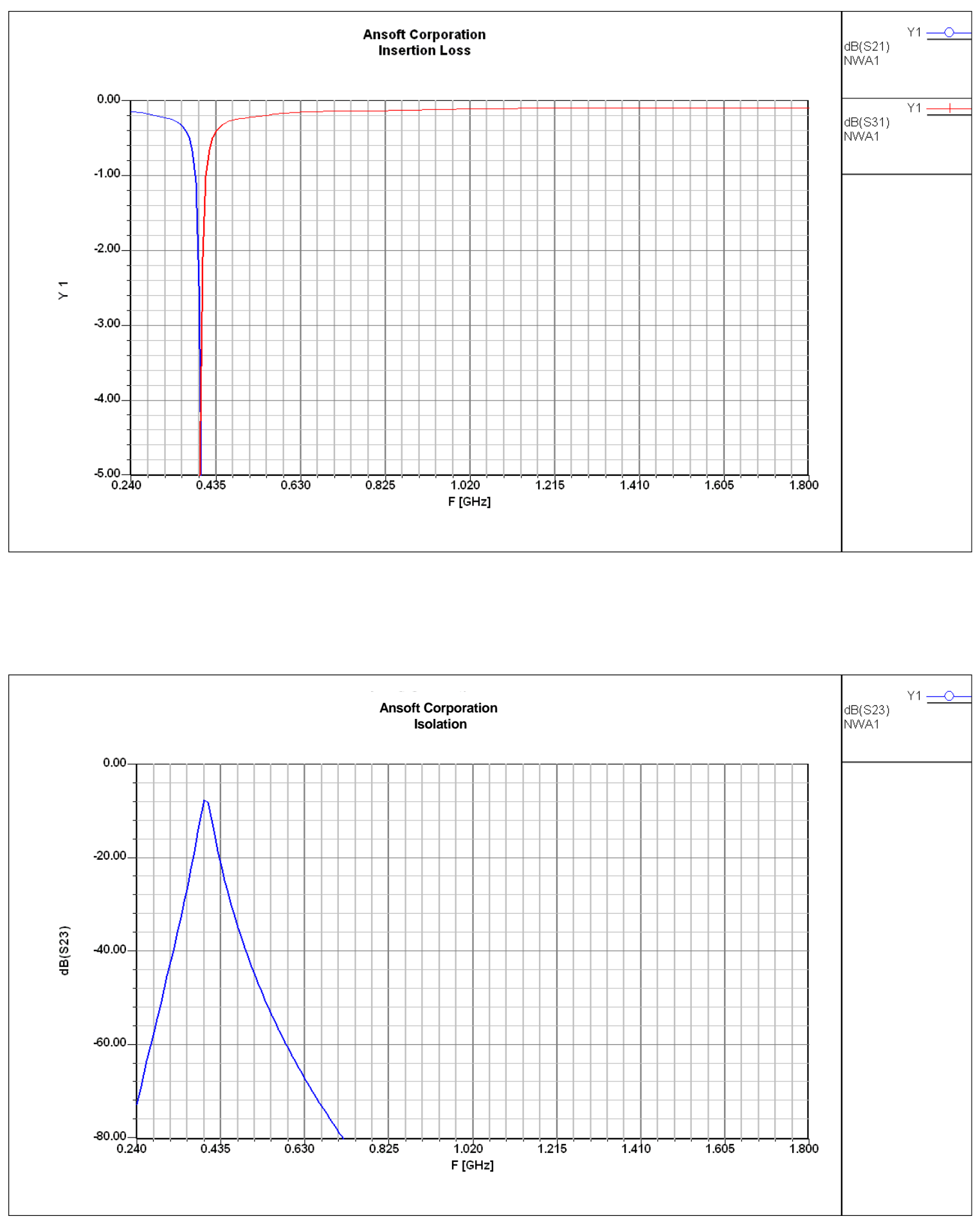

Figure 14: Semi-Lumped Element Equivalent Circuit a) Passband Insertion Loss (dB), b) Isolation (dB) 


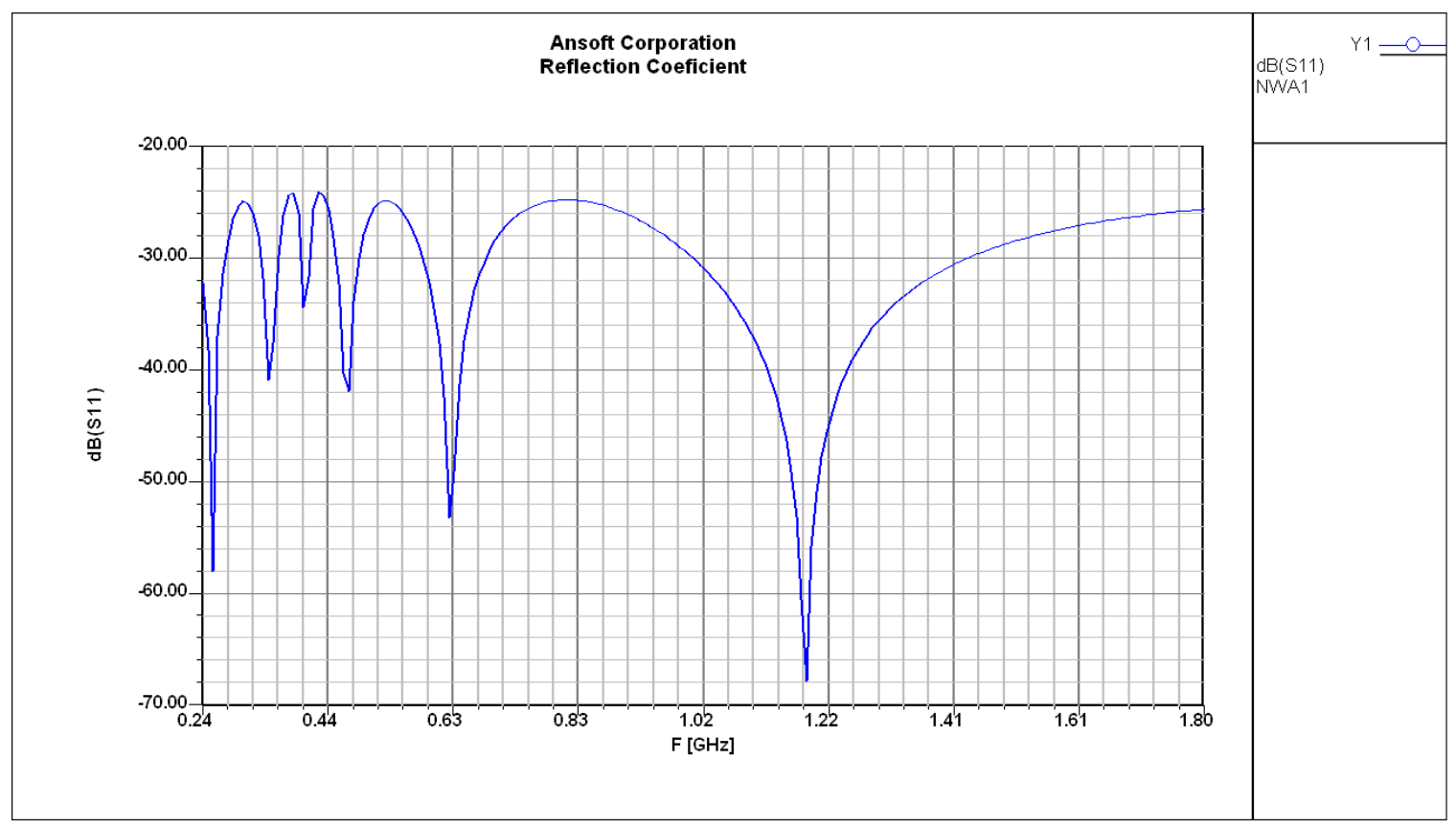

Figure 15: Semi-Lumped Element Equivalent Circuit Return Loss (dB), Common Junction (port1)

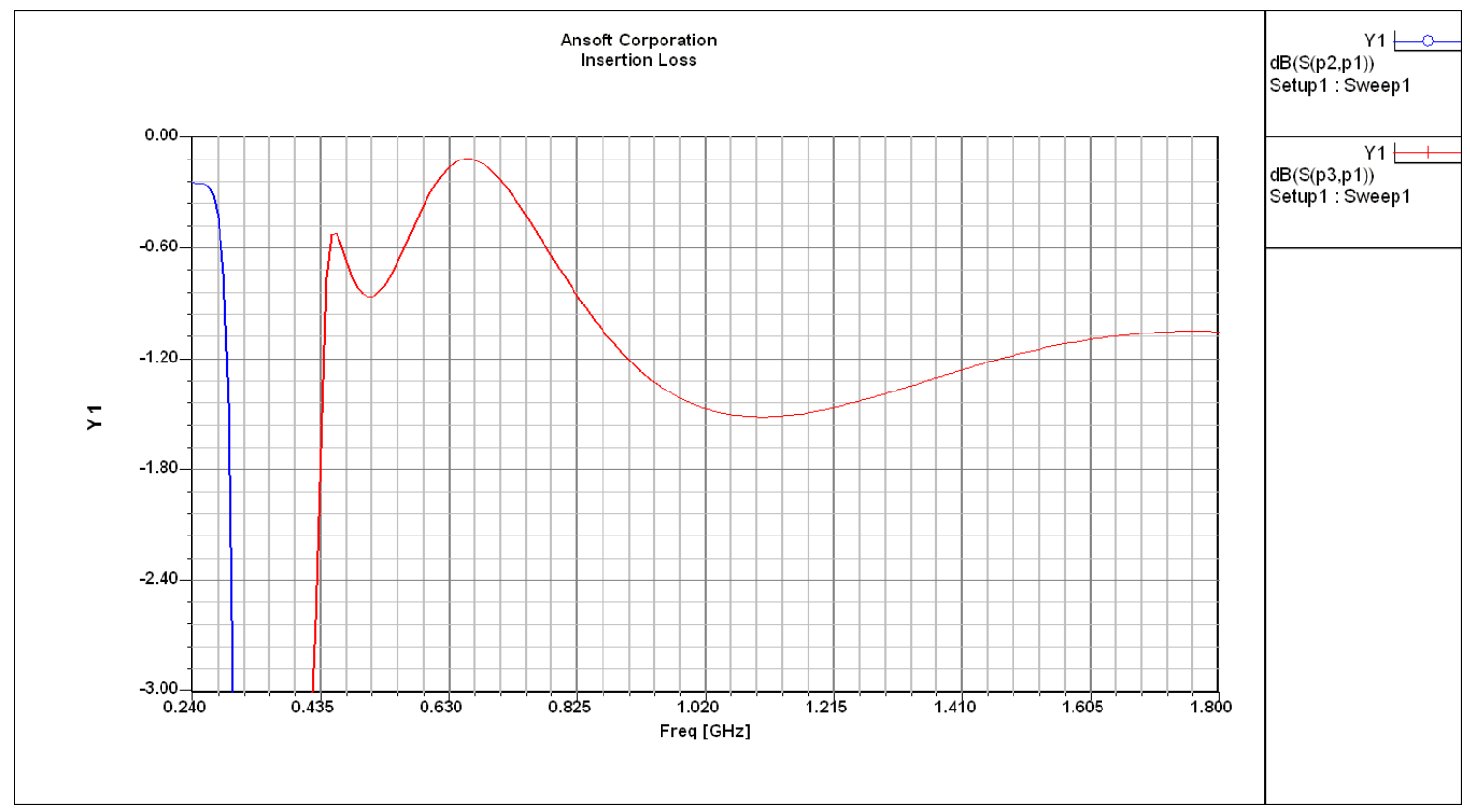

Figure 16: Semi-Lumped Diplexer Insertion Loss (dB) 

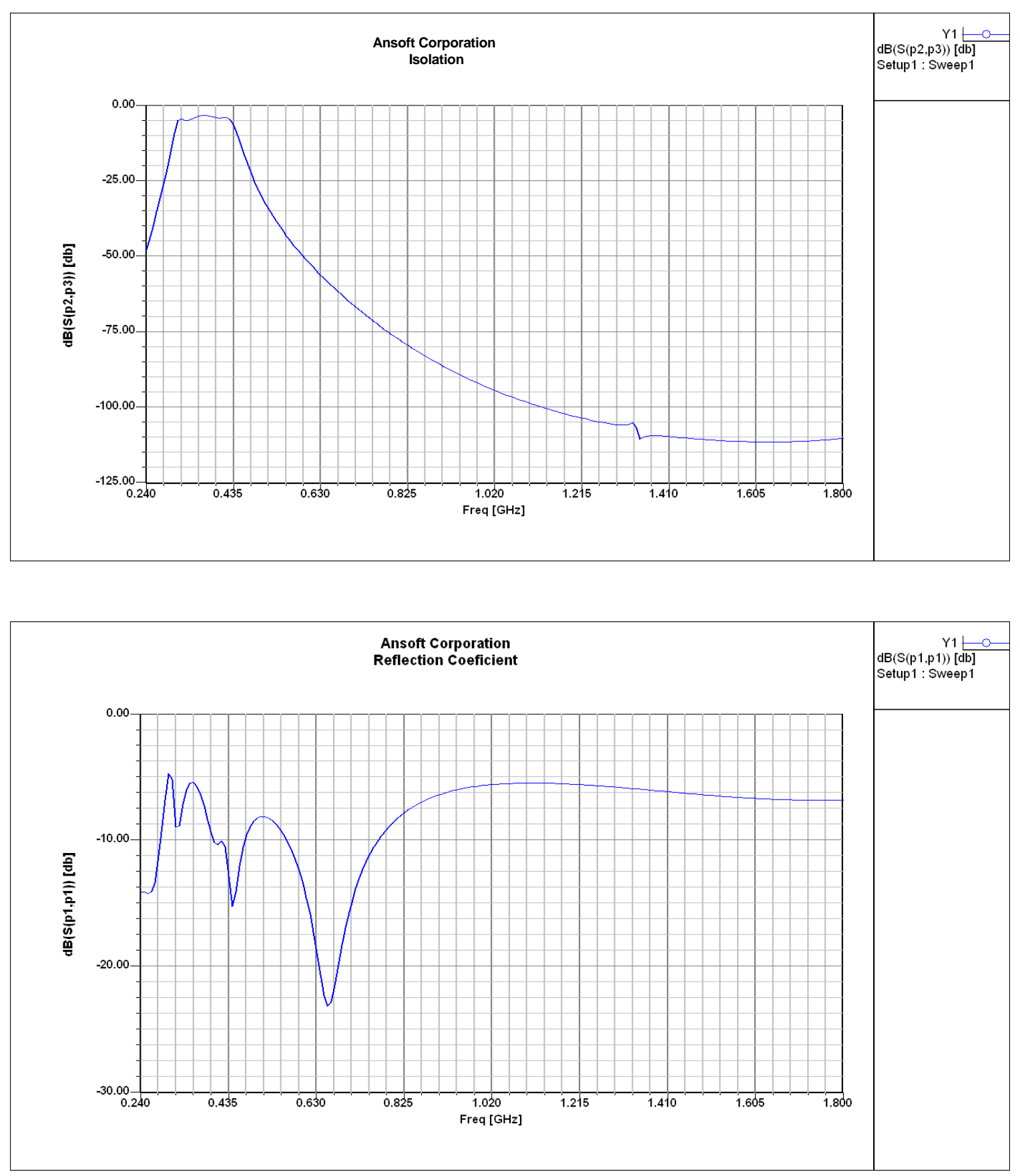

Figure 17: Semi-Lumped Diplexer a) Isolation (dB), and b) Return Loss (dB) 


\subsection{Optimization}

The full-wave simulation results above demonstrate that the lumped equivalent circuit does not take into account the various discontinuities in the lowpass and highpass filters' transition sections, the input and output ports, and the common junction of the two filters. Therefore, a four step process was used to optimize the diplexer:

1. HFSS — simulation of transitions and other discontinuities in the filters.

2. Designer-optimize the lowpass filter for return loss.

3. Designer-optimize the highpass filter for return loss.

4. Designer — optimize both the highpass and lowpass filter simultaneously for return loss.

Steps 2 and 3 are not necessary, but the author wanted to observe the performance of each filter independently. Finally, the Designer-optimized values were incorporated into HFSS and simulated. The four step process minimizes simulation and optimization times over full-wave HFSS model optimization. Even with the combination of a $3.2 \mathrm{GHz}$ Pentium 4 computer, 3GB of RAM, and division of the diplexer model along the plane of symmetry, HFSS optimization times can be extensive ( $>24$ hours), whereas Designer optimizations require less than a few minutes.

The above procedures were carried out for both series capacitance realizations for the highpass filter (Figs. 10 and 11). 


\subsubsection{Simulation in HFSS and Designer}

The lowpass filter was divided into high and low impedance transmission lines, output port, and common junction sections for simulation in HFSS and Designer (steps 1 to 3 of the optimization process). See Fig. 18 below.

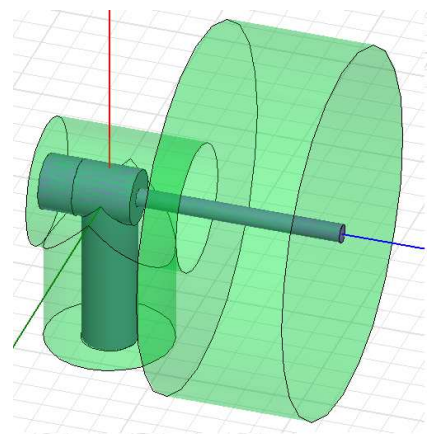

Common Junction

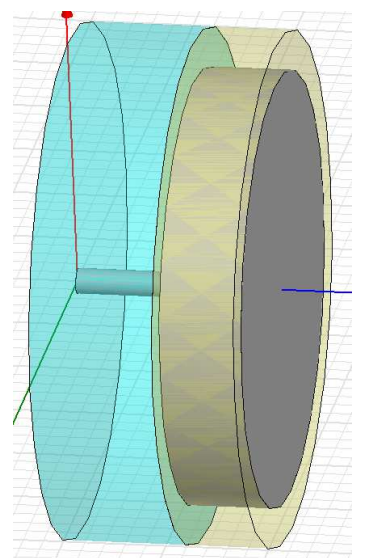

High/Low Impedance Transition

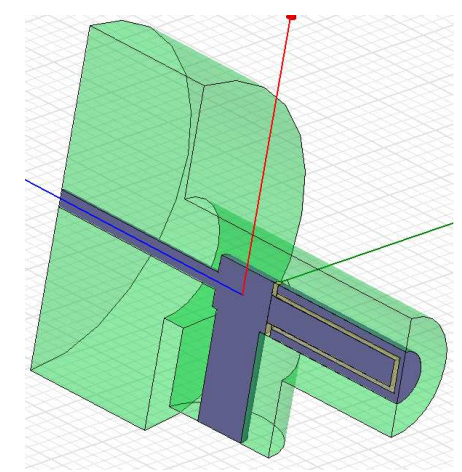

Common Junction with Alternate Series Capacitor Configuration

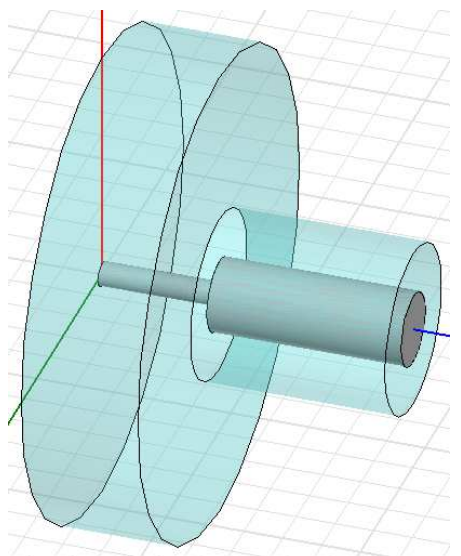

Lowpass Output Port

Figure 18: Discontinuities modeled in HFSS, Lowpass/Highpass Filters

Similarly, the highpass filter was divided into sections and simulated in HFSS, then

optimized in Designer. Appendix C, page 58, shows the typical HFSS models used in the Designer schematic for optimization. 
All components are S-parameter models imported from HFSS except for the short-circuit transmission lines in the highpass filter.

\subsubsection{Results}

The optimized diplexer response from Designer is shown in Figs. 19 and 20. The figures show that passband insertion loss is less than $0.13 \mathrm{~dB}$, and isolation and return loss are greater than $40 \mathrm{~dB}$ and $19 \mathrm{~dB}$, respectively. The diplexer response applied to the entire HFSS model is shown in Figs. 21-23; passband insertion loss is less than $0.36 \mathrm{~dB}$, isolation is a minimum of $38 \mathrm{~dB}$, and the return loss is greater than $12.2 \mathrm{~dB}$. Clearly, the two responses do not match. However, the optimization goal is to obtain a diplexer that meets Table 1 specifications as predicted by HFSS, a 3D full-wave EM simulator that accounts for all EM interactions and is not limited to electrical circuit model accuracy (i.e. Designer). Inspection of Fig. 23 reveals that the return loss, minimum of $12.2 \mathrm{~dB}$ at $1.7 \mathrm{GHz}$, exceeds specification, otherwise the diplexer performance is acceptable.

Discrepancies between Designer and HFSS models arise because the series capacitors and shunt inductors in the highpass filter are not modeled as discrete sections in HFSS prior to optimization in Designer (see Appendix C, page 58). Hence, the Designer model does not fully represent the HFSS model. Modeling all components in HFSS for use in subsequent Designer optimization did not improve the HFSS response.

There is a definite need to study and understand the discrepancies between the complete and sectional models, but it was decided that even if the discrepancies were resolved, the proposed diplexer's 20" overall length exceeds the 12" size limit (see Table 1) for this 
particular application. However, if overall length is not a factor, this type of diplexer may prove practical.
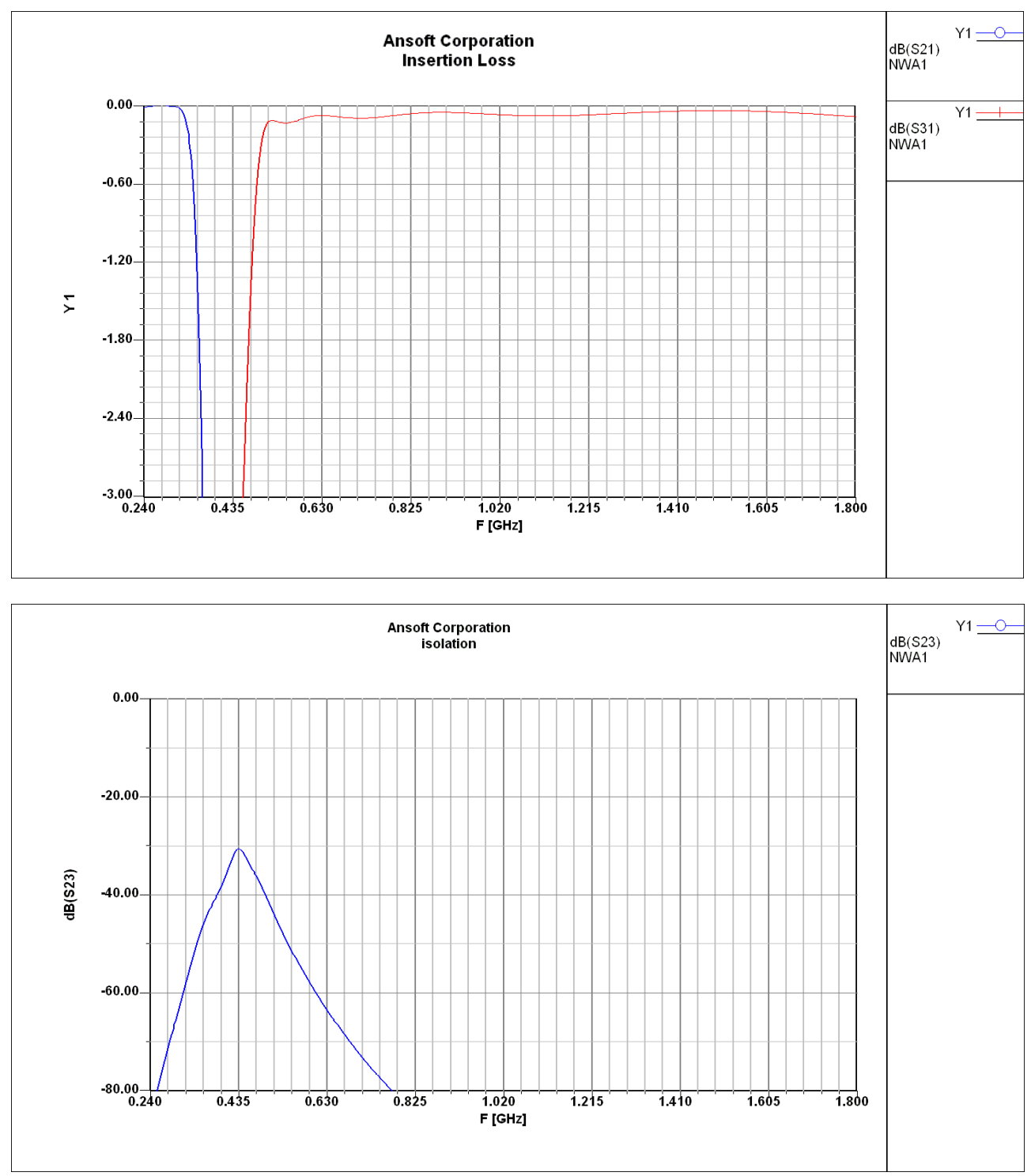

Figure 19: Diplexer Optimization Results in Designer: a) Insertion Loss (dB), b) Isolation (dB) 


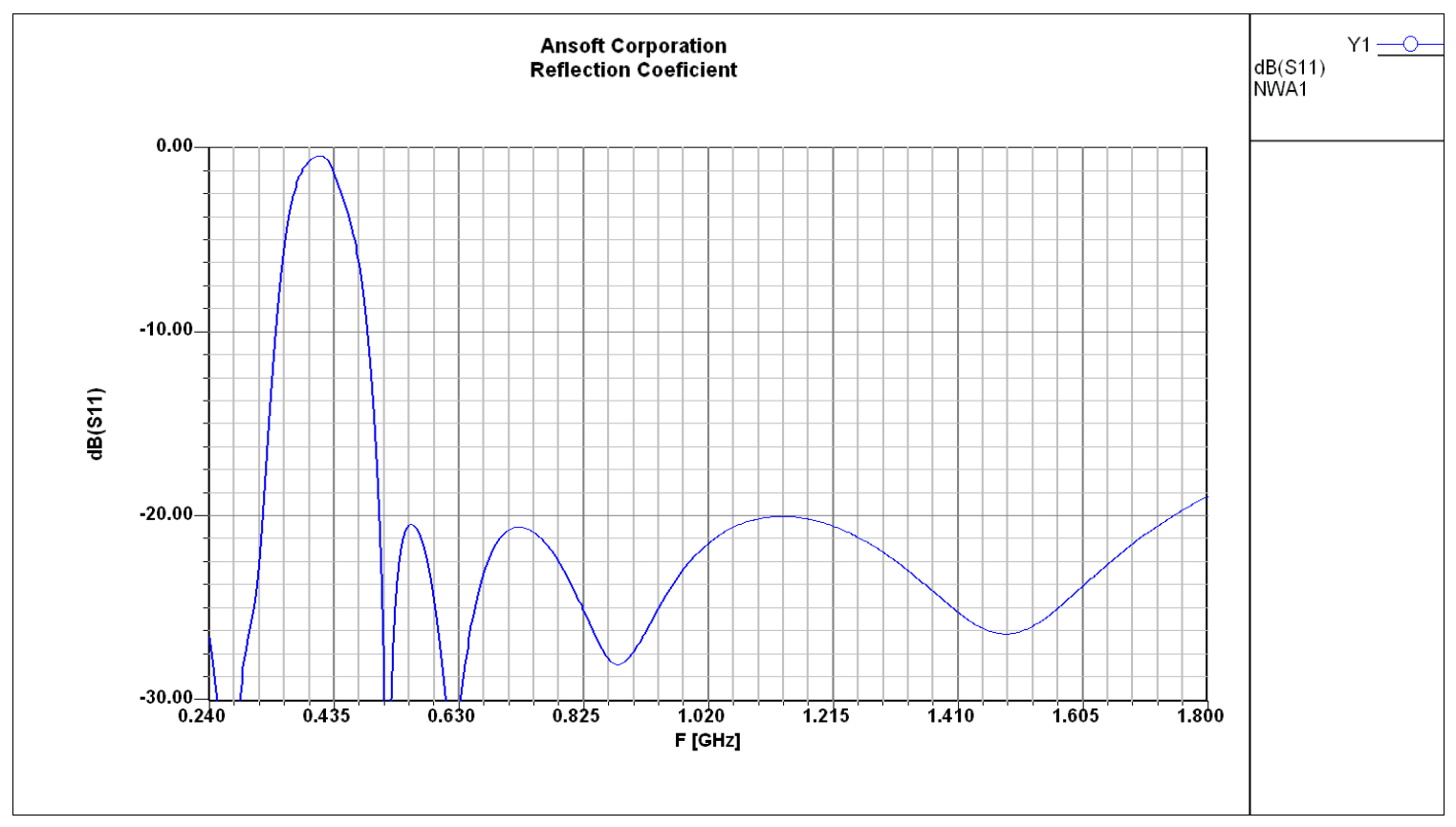

Figure 20: Diplexer Optimization Results in Designer: Return Loss (dB)

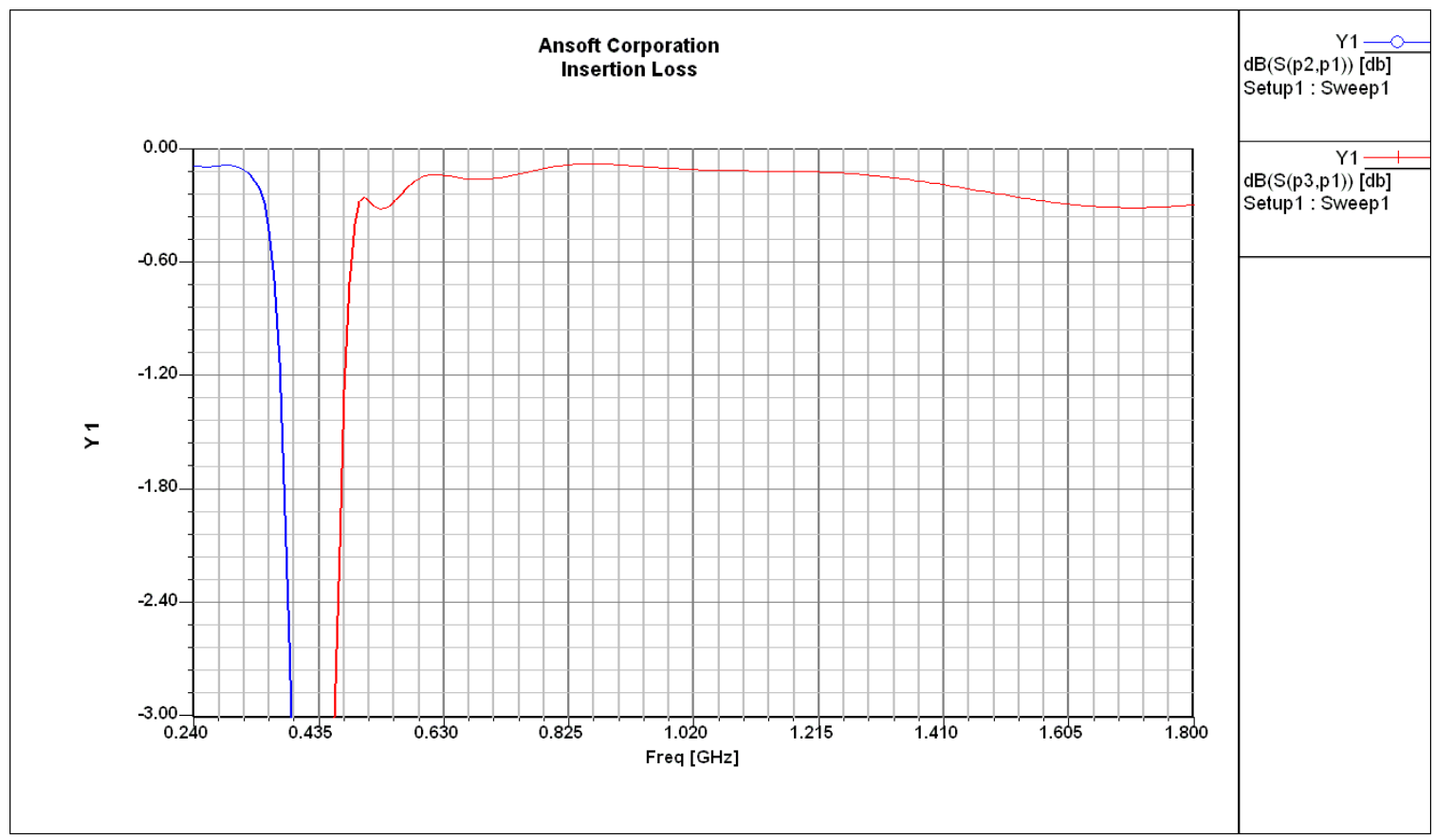

Figure 21: HFSS Simulation, Designer-Optimized Diplexer, Insertion Loss (dB) 


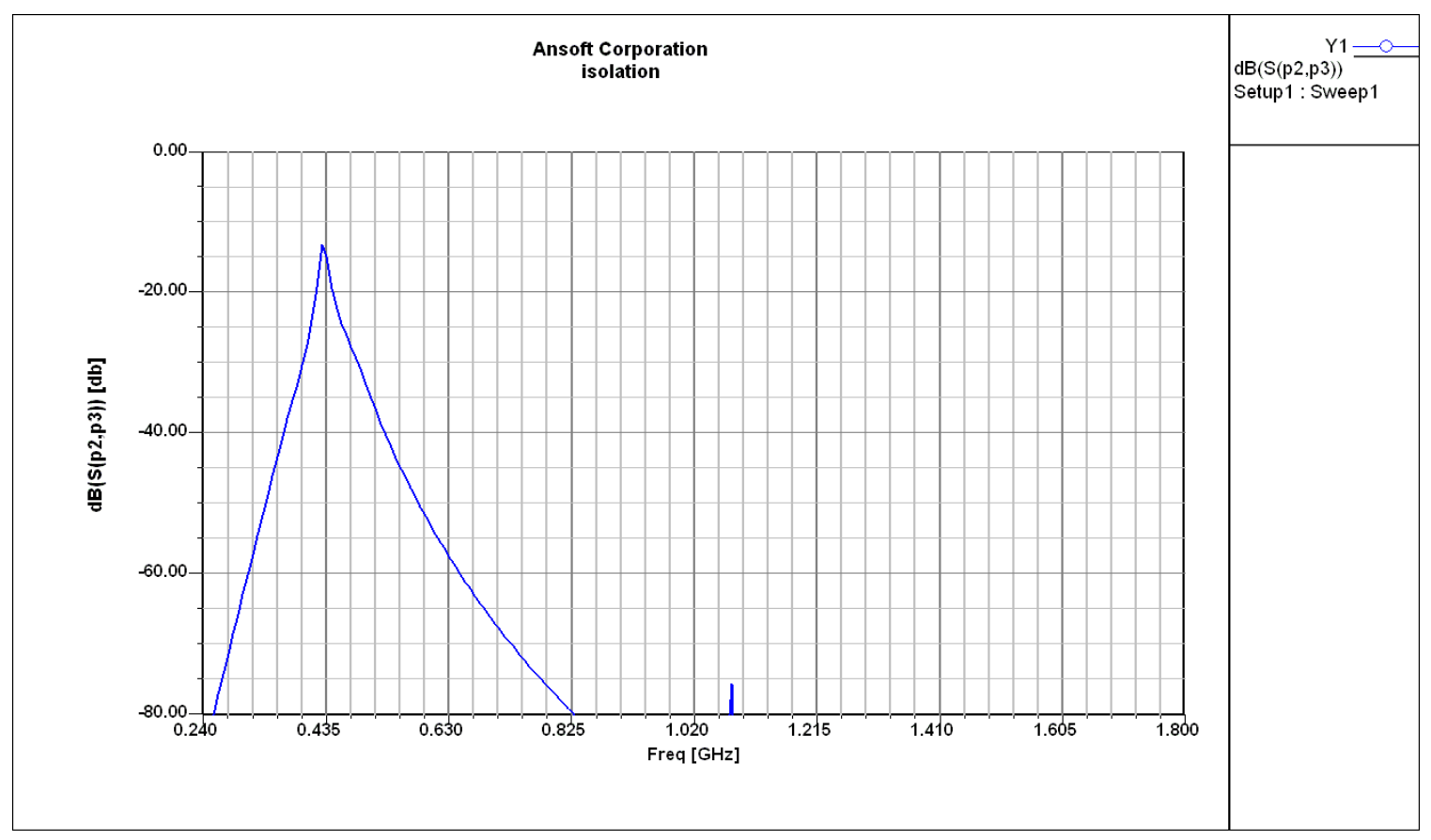

Figure 22: HFSS Simulation, Designer-Optimized Diplexer, Isolation (dB)

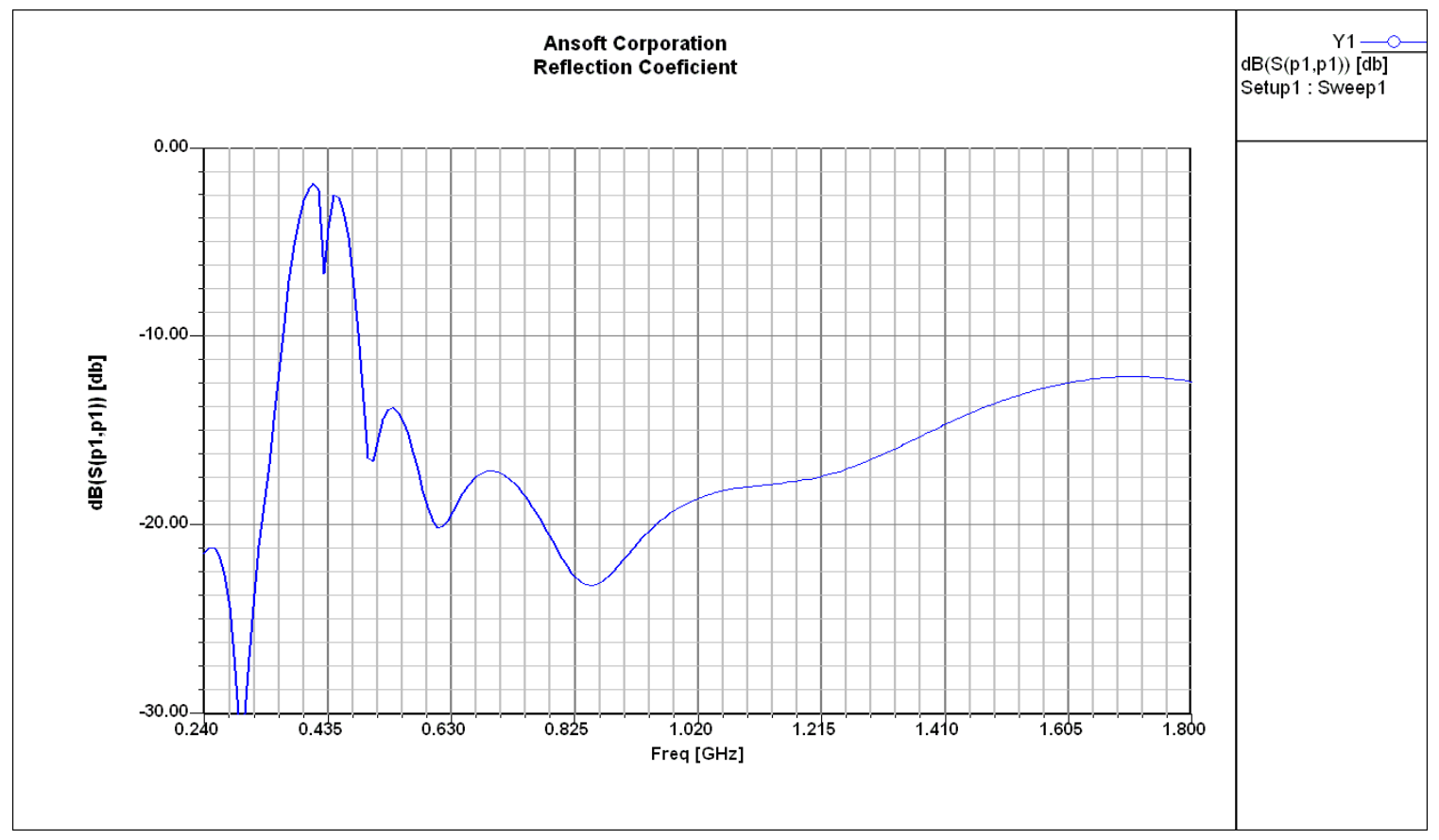

Figure 23: HFSS Simulation, Designer-Optimized Diplexer, Return Loss (dB) 


\section{Chapter 4}

\section{THE DIGITAL ELLIPTIC DIPLEXER}

A topology that can meet the wide bandwidth requirements of Table 1 while maintaining relatively small size and high-power handling capability is the digital elliptic filter proposed by Wenzel [33]. The semi-lumped coax design produces a diplexer with an estimated 20" length (excluding connectors), whereas the digital elliptic diplexer is less than 5 " in length (excluding connectors). However, the literature $[14,33]$ suggests that this type of filter operates over a maximum 4.0:1 bandwidth, which is less than the 4.4:1 bandwidth required for the AEW diplexer requirements. Nonetheless, it may be possible to achieve this bandwidth specification along with realizable diplexer element values by simulation and optimization in a full-wave simulator such as HFSS. 


\subsection{The Digital Elliptic Diplexer}

The digital elliptic diplexer consists of coupled rectangular bars between parallel plates with internal series stubs to realize a non-redundant (i.e., all components contribute to the filter response) and inherently wideband (>30\%) pseudo-complementary diplexer [33]. Fig. 24 shows the diplexer's L-C prototype circuit and corresponding physical structure. To satisfy equation 2.19, the highpass prototype obtains its elements values from the lowpass prototype by direct inversion.
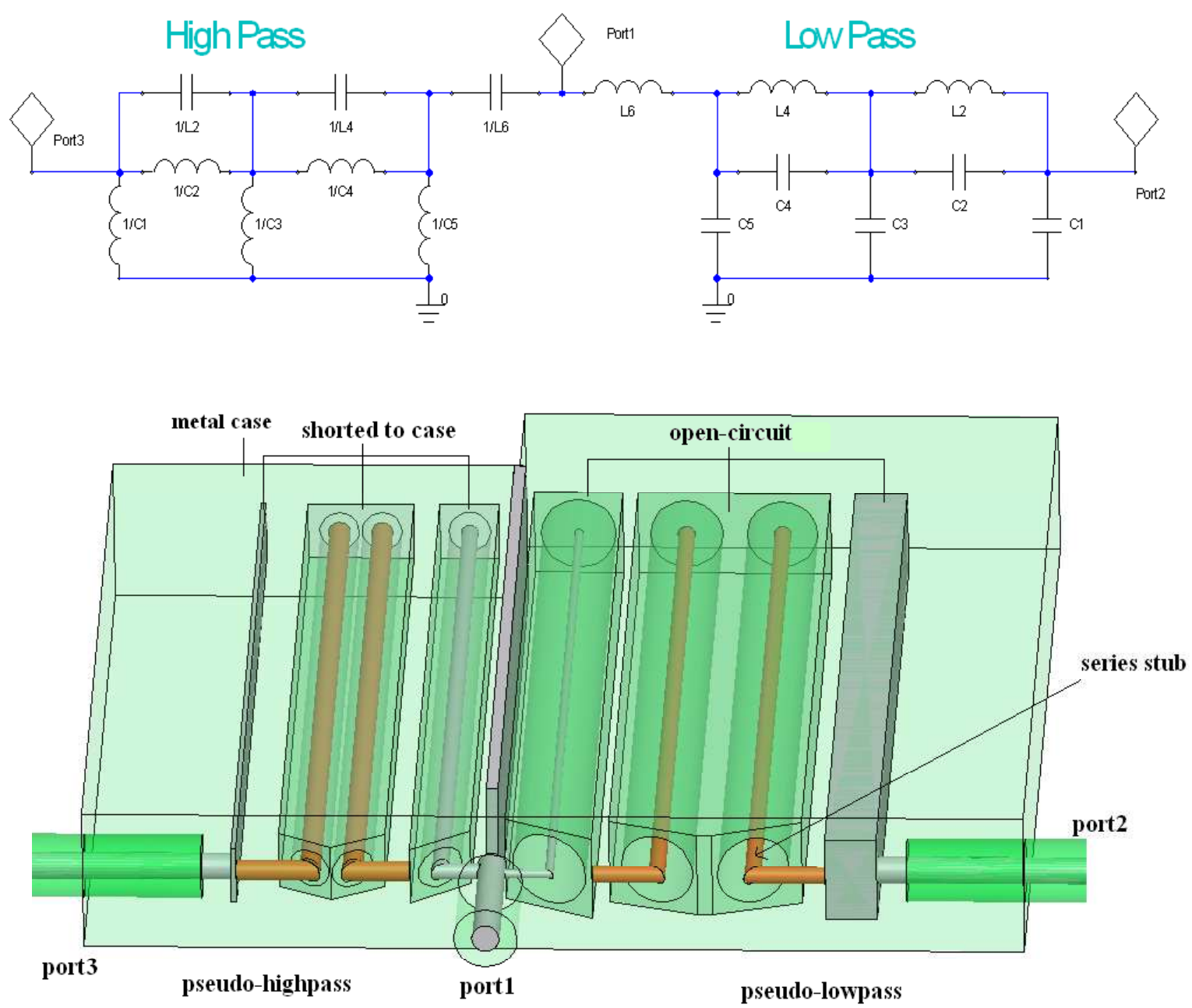

Figure 24: Digital Elliptic Diplexer and L-C prototype 
The open-circuit bars in the lowpass filter represent capacitive elements in the L-C prototype's lowpass filter, while the short-circuit bars in the highpass filter serve as inductors. Short-circuit coaxial transmission lines in the lowpass filter serve as series inductors while open-circuit transmission lines serve as series capacitors in the highpass filter. Filter component lengths are one-quarter wavelength at the $1.15 \mathrm{GHz}$ midband (resonant) filter frequency. Since the lowpass bars are open-circuit, they require dielectric material (not shown, $\left.\varepsilon_{\mathrm{r}}=2.1\right)$ for support, as do the open-circuit coaxial stubs in the highpass filter. Thin width $(1 / 32$ ') sections of fiberglass/Teflon provide adequate support for the lowpass bars while meeting performance specifications defined in Table 1.

Figs. 25 and 26 show the frequency responses of the L-C and distributed prototypes, respectively. As discussed in Chapter 2, the distributed prototype's frequency response is periodic.

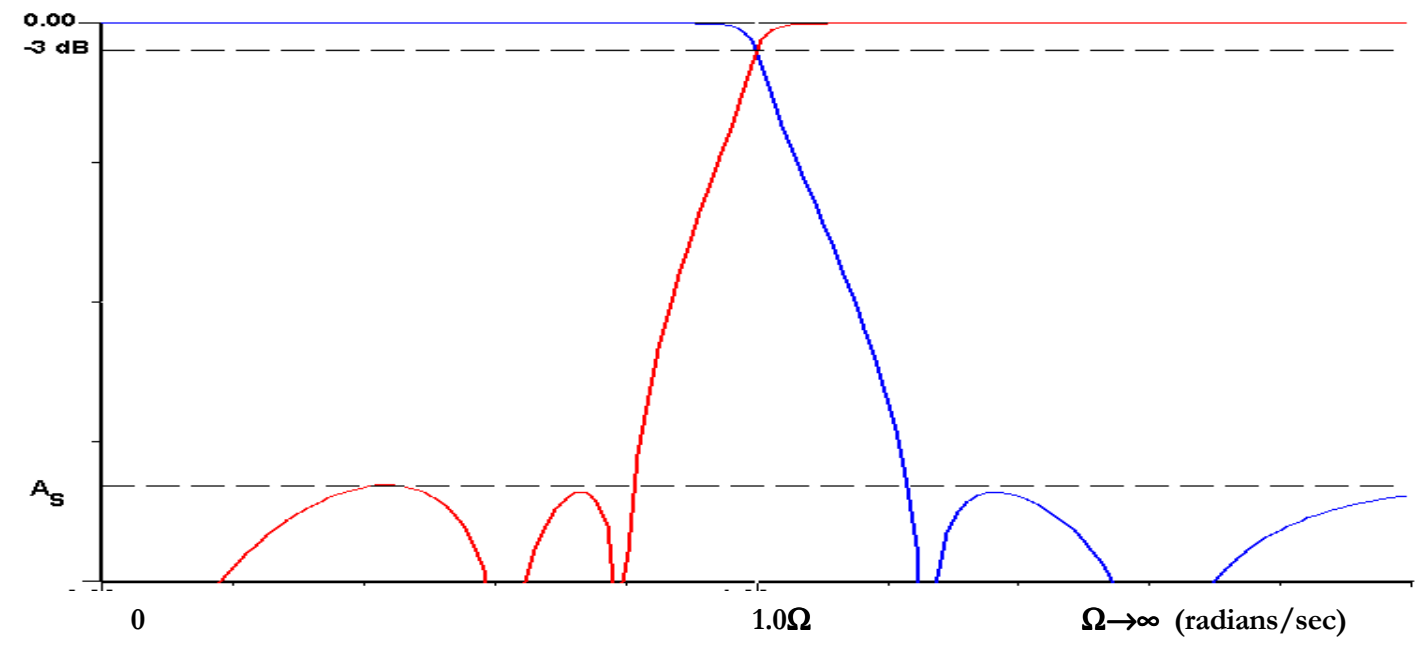

Figure 25: L-C Prototype Diplexer Frequency Response (see Appendix A for definitions) 


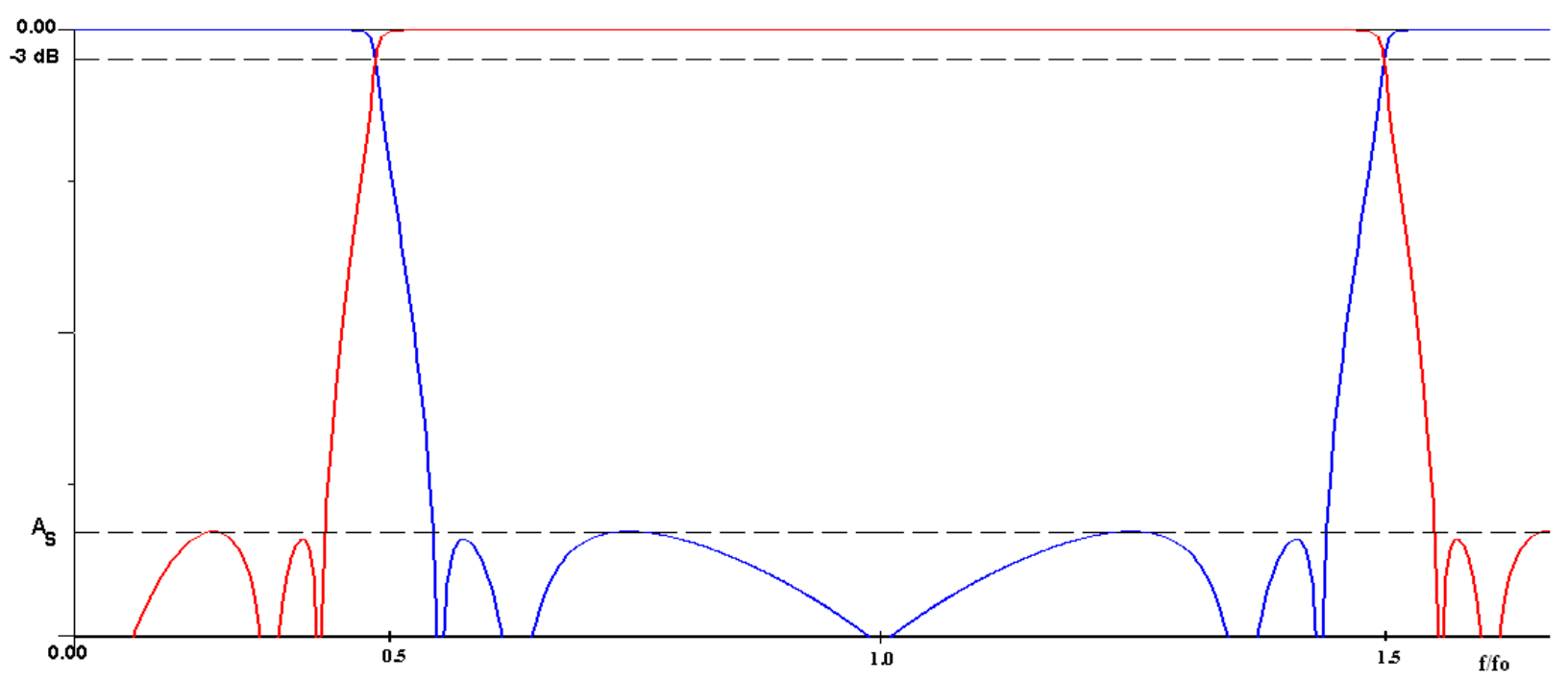

Figure 26: Digital Elliptic Diplexer Frequency Response

\subsection{Synthesis and simulation}

Diplexer synthesis follows directly from the procedure outlined in [33]. From the diplexer specifications in Table 1 and design equations in reference [33] (see Appendix A for definition of terms):

$f_{C 1}{ }^{\prime}=0.410 \mathrm{GHz}$ (center of the transition band), $f_{C 2}{ }^{\prime}=1.85 \mathrm{GHz}$ (allows $40 \mathrm{~dB}$ attenuation at $1.8 \mathrm{GHz}), f_{A_{S}}{ }^{\prime \prime}=0.32 \mathrm{GHz}$, and $f_{A_{S}}{ }^{\prime}=0.5 \mathrm{GHz}$.

$$
\begin{aligned}
& f_{0}=\frac{f_{C 1}{ }^{\prime}+f_{C 2}{ }^{\prime}}{2}=1.13 \mathrm{GHz} \\
& \Omega_{C}{ }^{\prime}=\tan \frac{\pi f_{C 1}{ }^{\prime}}{2 f_{0}}=0.641 \\
& \Omega_{A_{S}}{ }^{\prime}=\tan \frac{\pi f_{A_{S}}{ }^{\prime}}{2 f_{0}}=0.834 \\
& k \geq k_{L}=\frac{\Omega_{C}{ }^{\prime}}{\Omega_{A_{S}}{ }^{\prime}}=0.77
\end{aligned}
$$


A $6^{\text {th }}$ order filter $(\mathrm{N}=6)$ with $\mathrm{k}=0.8, \mathrm{~A}_{\mathrm{S}}=51 \mathrm{~dB}$ at $\Omega_{A_{S}}=1.2318(0.69 \mathrm{GHz})$ meets requirements [33]. The normalized element values presented in Table II [33] provide a maximum VSWR of 1.2702 (Return Loss $(\mathrm{RL})=18.48 \mathrm{~dB}$ ) at the common port of the diplexer, yet Table 1 requires an $\mathrm{RL} \geq 20 \mathrm{~dB}$ at all ports of the diplexer. This requires normalized element values adjustment. References $[1-2,7,12,32]$ outline procedures for synthesizing element values, but they are non-trivial and tedious, requiring Jacobi-elliptic integrals. An alternate approach is to use the optimization feature of Ansoft Designer to determine element values that meet the $20 \mathrm{~dB}$ RL requirement with initial element values given by Wenzel [33]. In addition, Designer constrains element values to yield practical physical dimensions while meeting electrical requirements. Table 2 shows the normalized element values from the original prototype [33] and the optimized values from Designer (optimized for $21 \mathrm{~dB}$ return loss).

Table 2: Digital Elliptic Diplexer, Normalized Element Values and Designer Optimized Values

\begin{tabular}{|c|c|c|c|c|}
\hline $\mathbf{i}$ & $\mathbf{C}_{\mathbf{i}}$ prototype & $\mathbf{C}_{\mathbf{i}}$ optimized & $\mathbf{L}_{\mathbf{i}}$ prototype & $\mathbf{L}_{\mathbf{i}}$ optimized \\
\hline 1 & 0.5871 & 0.5808 & - & - \\
\hline 2 & 0.3304 & 0.3276 & 1.1586 & 1.1552 \\
\hline 3 & 1.2000 & 1.2048 & - & 1.1588 \\
\hline 4 & 0.5403 & 0.5451 & 1.1653 & - \\
\hline 5 & 1.3581 & 1.4155 & - & 1.6260 \\
\hline 6 & - & - & 1.7153 & \\
\hline
\end{tabular}


Substituting the normalized values of Table 2 into equations T-5 through T-8 of Wenzel [33] yields static capacitance ${ }^{4.1}$ values and series stub impedances for the diplexer shown in Fig. 27. The lowpass series stubs and all coupled bars employ an air dielectric, whereas the highpass series stubs employ Teflon $\left(\boldsymbol{\varepsilon}_{\mathrm{r}}=2.1\right)$ to provide support for the center conductor of the open circuit stubs.

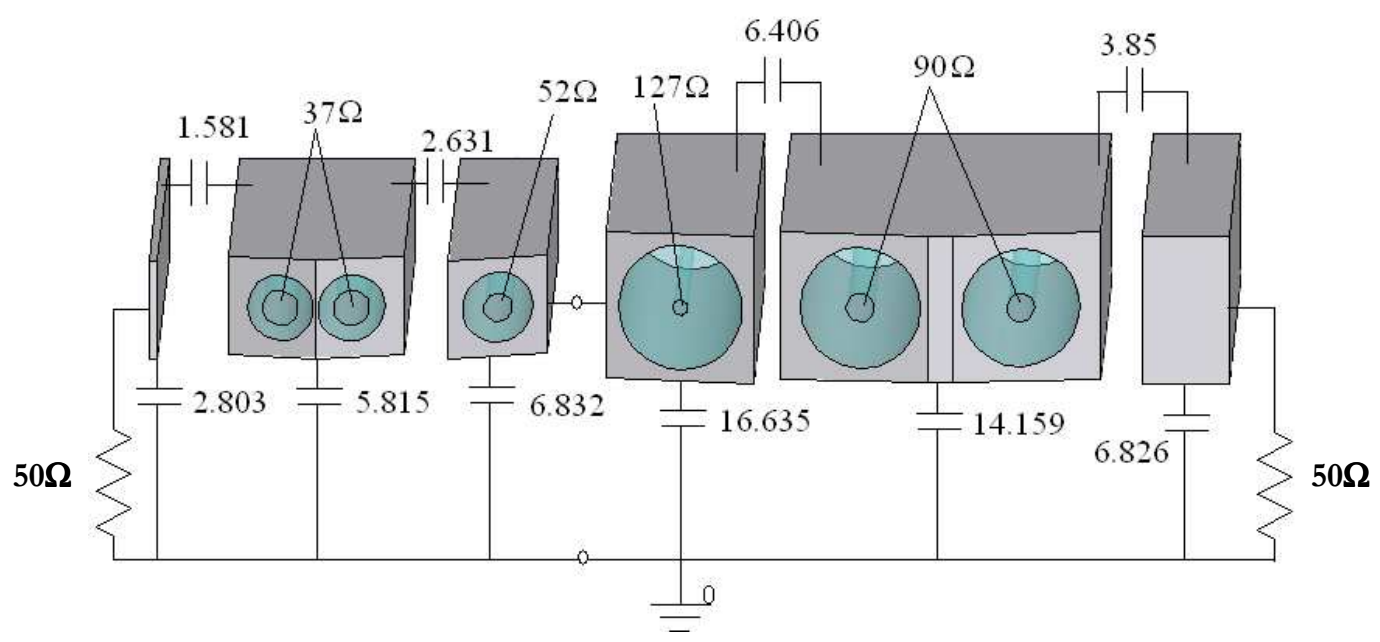

Figure 27: Static Capacitance and Series Stub Impedance Values

Set $\mathrm{t} / \mathrm{b}=0.6$ (see Fig. 28) for the lowpass filter and $\mathrm{t} / \mathrm{b}=0.4$ for the highpass filter. A t/b ratio of 0.6 for the highpass filter leads to negative dimensions for the coupled bars. Setting the component minimum dimensions to 30mil, the same as the wall thickness of Randtron's 0.5" coaxial lines, seems an acceptable arbitrary starting point. Table 3 shows diplexer coupled bar section dimensions as determined from Getsinger data [25] and the coaxial line impedance equation:

$$
Z=\frac{\mu_{0} c}{2 \pi \sqrt{\varepsilon_{r}}} \ln \frac{D}{d} .
$$


Table 3: Digital Elliptic Diplexer Dimensions (inches), $\mathrm{b}=0.750 \mathrm{in}$

\begin{tabular}{|c|c|c|c|c|c|c|c|c|c|c|}
\hline & \multicolumn{5}{|c|}{ lowpass: t/b = 0.6 } & \multicolumn{5}{c|}{ highpass: t/b = 0.4 } \\
\hline $\mathbf{i}$ & $\mathbf{w}_{\mathbf{i}}$ & $\mathbf{s}_{\mathrm{i}, \mathrm{i}+2}$ & $\mathbf{s}_{\mathrm{i}, \text { wall }}$ & $\mathbf{D}$ & $\mathbf{d}$ & $\mathbf{w}_{\mathrm{i}}$ & $\mathbf{s}_{\mathrm{i}, \mathrm{i}+2}$ & $\mathbf{s}_{\mathrm{i}, \text { wall }}$ & $\mathbf{D}$ & $\mathbf{d}$ \\
\hline 1 & 0.264 & 0.125 & 0.051 & - & - & 0.041 & 0.218 & 0.126 & - & - \\
\hline 2 & - & - & - & 0.371 & 0.083 & - & - & - & 0.185 & 0.075 \\
\hline 3 & 0.97 & 0.075 & - & - & - & 0.516 & 0.140 & - & - & - \\
\hline 4 & - & - & & 0.374 & 0.083 & - & - & & 0.185 & 0.075 \\
\hline 5 & 0.450 & - & 0.525 & - & - & 0.300 & - & 0.313 & - & - \\
\hline 6 & - & - & - & 0.374 & 0.045 & - & - & - & 0.212 & 0.060 \\
\hline
\end{tabular}

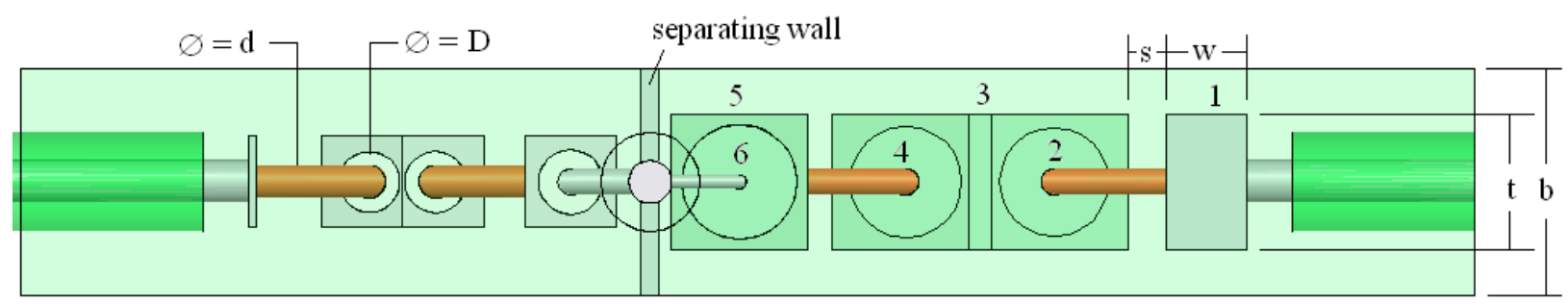

Figure 28: Input Port, Diplexer

\subsection{Tuning in HFSS 4.2}

Ideally, the coupled bars and series stubs are one-quarter wavelength at the resonant frequency $\left(f_{0}\right)$, but their exact lengths are difficult to determine [33] analytically and require electrical measurement or simulation. Ansoft HFSS provides the capability to tune all resonator lengths. Fig. 29 shows the diplexer response after tuning. 


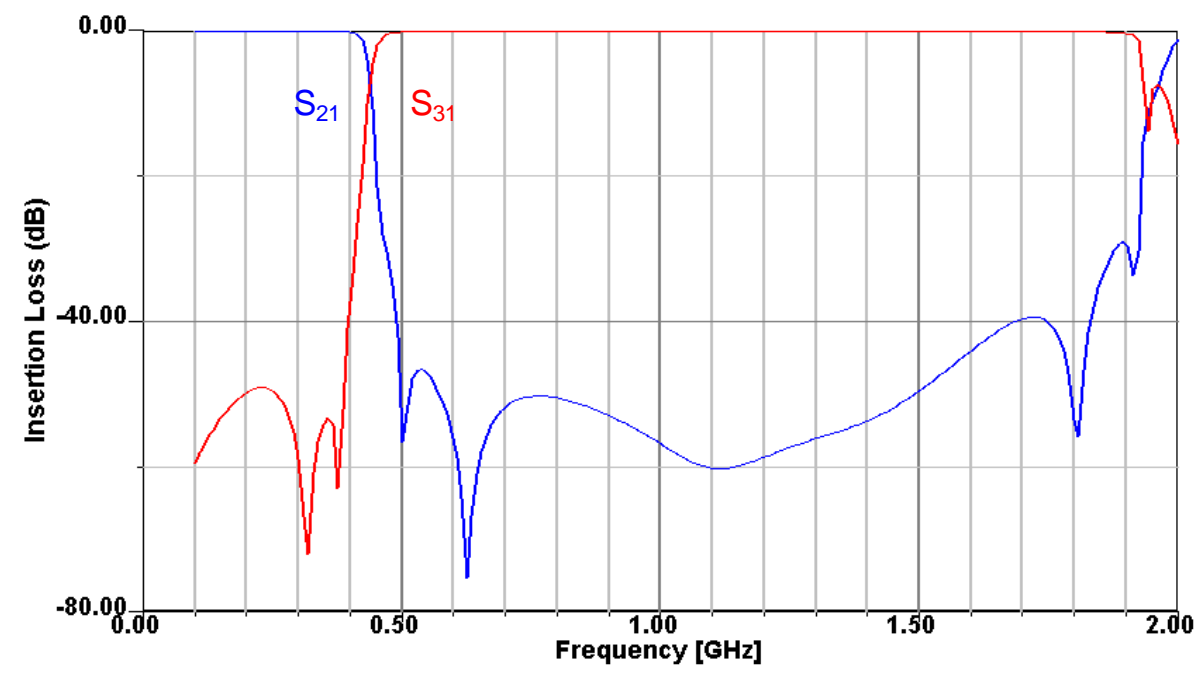

Figure 29: Diplexer Frequency Response in HFSS

Fig. 30 shows isolation $\left(\mathrm{S}_{23}\right)$ in the frequency bands of interest (see Table 1). Fig. 31 shows the RL at the common port of the diplexer (port 1) and Fig. 32 is a zoomed-in view of insertion loss in the passbands from Fig. 29. Finally, Table 4 displays the tuned resonator lengths.

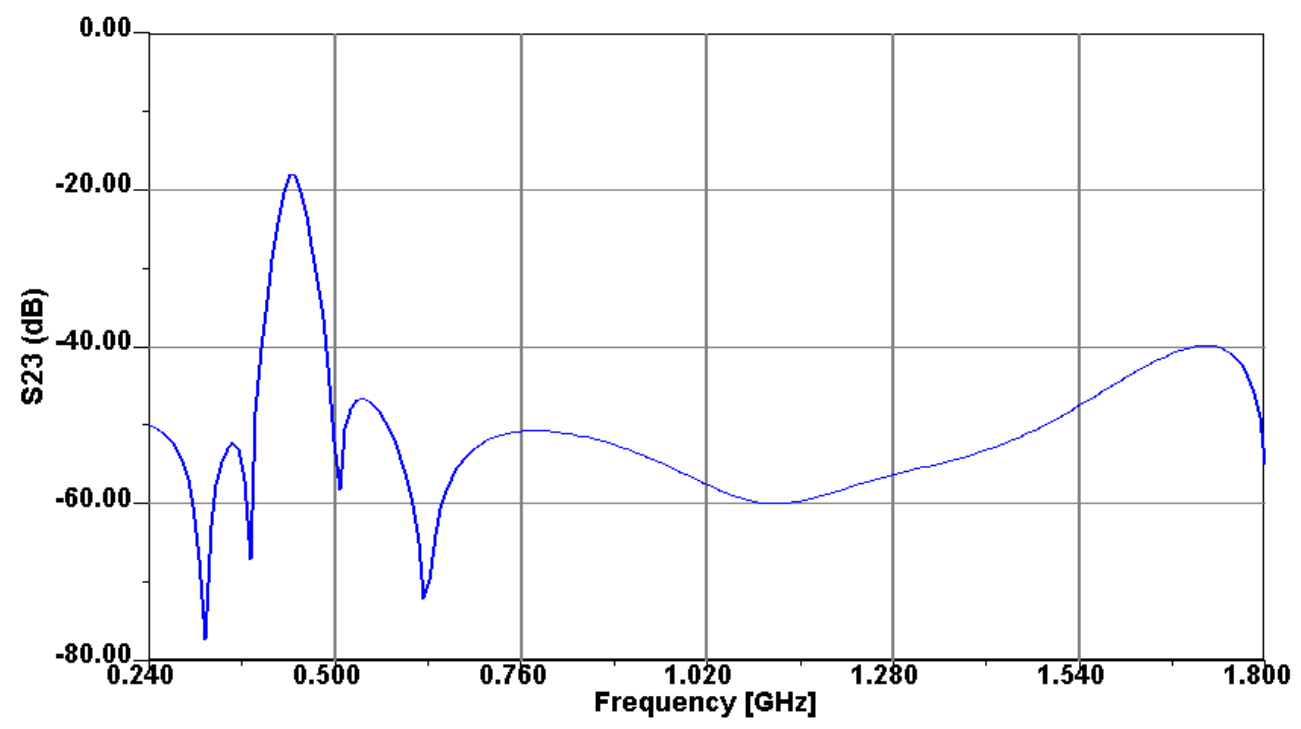

Figure 30: Diplexer Isolation Between Lowpass and Highpass Filters 


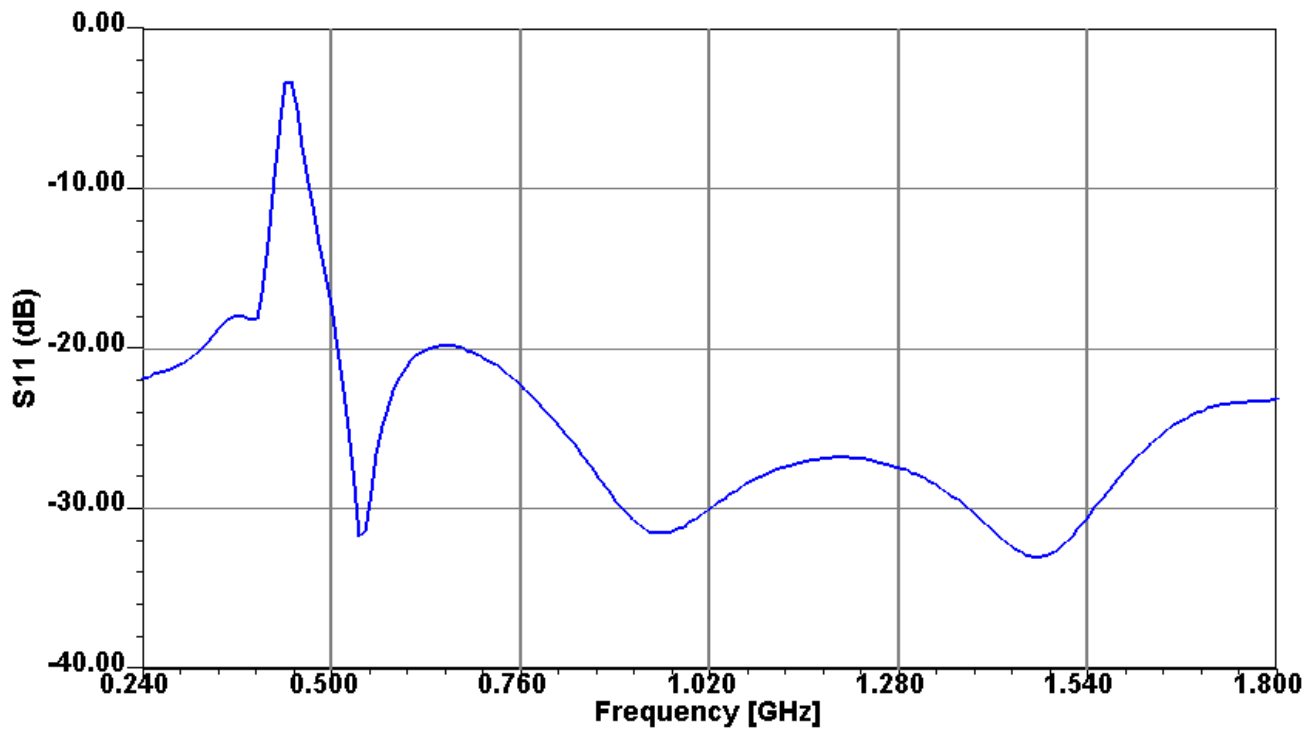

Figure 31: Return Loss at Diplexer Common Port

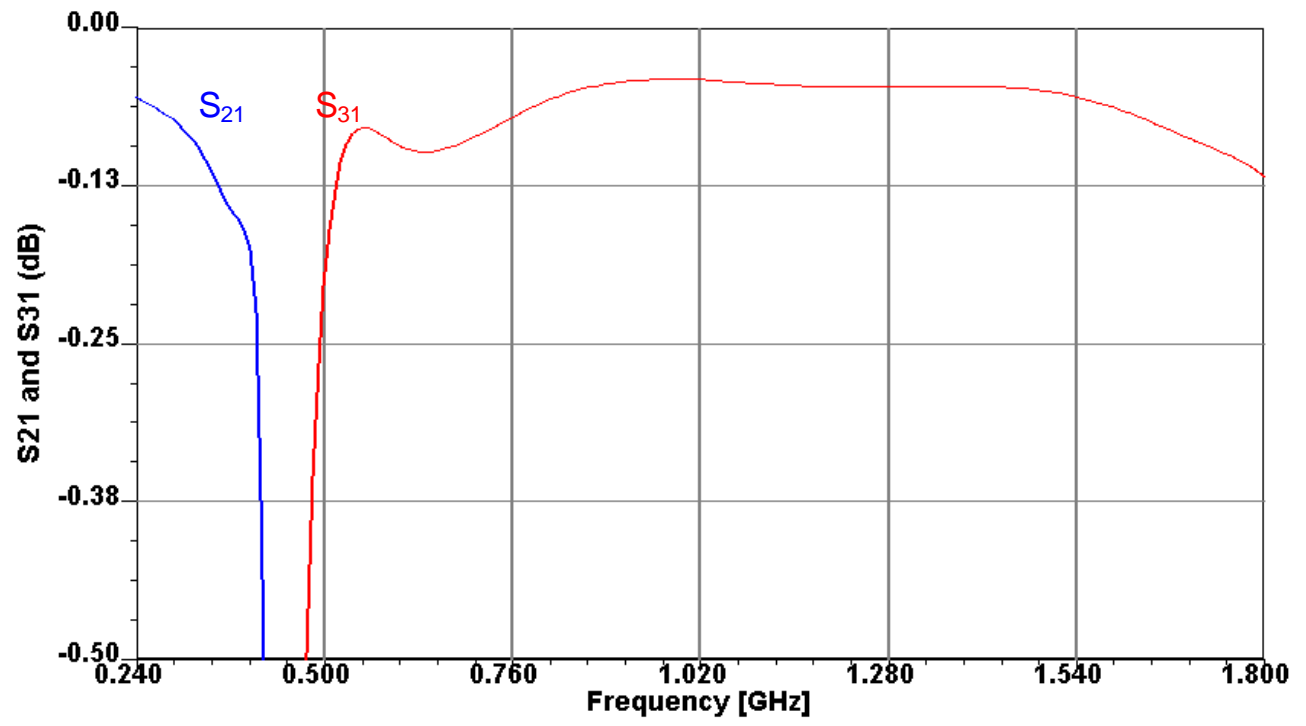

Figure 32: Diplexer Passband Insertion Loss 
Table 4: Resonator Lengths, Before/After HFSS Tuning, (inches)

\begin{tabular}{|c|c|c|c|c|c|c|c|c|}
\hline & \multirow[t]{2}{*}{ lowpass bars } & \multicolumn{3}{|c|}{ lowpass stubs $\left(\varepsilon_{\mathrm{r}}=1\right)$} & \multirow[t]{2}{*}{ highpass bars } & \multicolumn{3}{|c|}{ highpass stubs $\left(\varepsilon_{\mathrm{r}}=2.1\right)$} \\
\hline & & 2 & 4 & 6 & & 2 & 4 & 6 \\
\hline initial & 2.61 & \multicolumn{3}{|c|}{2.61} & 2.61 & 1.802 & 1.802 & 1.802 \\
\hline final & 2.30 & \multicolumn{3}{|c|}{2.294} & 2.48 & 1.353 & 1.488 & 1.594 \\
\hline
\end{tabular}

\subsection{Peak Power Handling Capability}

Figs. 33 and 34 show the regions of maximum electric field intensity in the lowpass and highpass filters, respectively, with 6.0kW input power at frequencies of $0.320 \mathrm{GHz}$ (Fig. 33) and $0.653 \mathrm{GHz}$ (Fig. 34). At 2.0Atm, the dielectric strength ${ }^{4.3}$ of air is $50 \%$ greater than at standard [9]; therefore, the maximum allowable field strength is $4.5 \mathrm{MV} / \mathrm{m}$. Using a safety factor of 2 limits the filter's maximum field to $2.25 \mathrm{MV} / \mathrm{m}$. As Figs. 33 and 34 indicate, maximum field strengths of $1.34 \mathrm{MV} / \mathrm{m}$ and $2.17 \mathrm{MV} / \mathrm{m}$ occur in the diplexer's lowpass and highpass filters, respectively. 

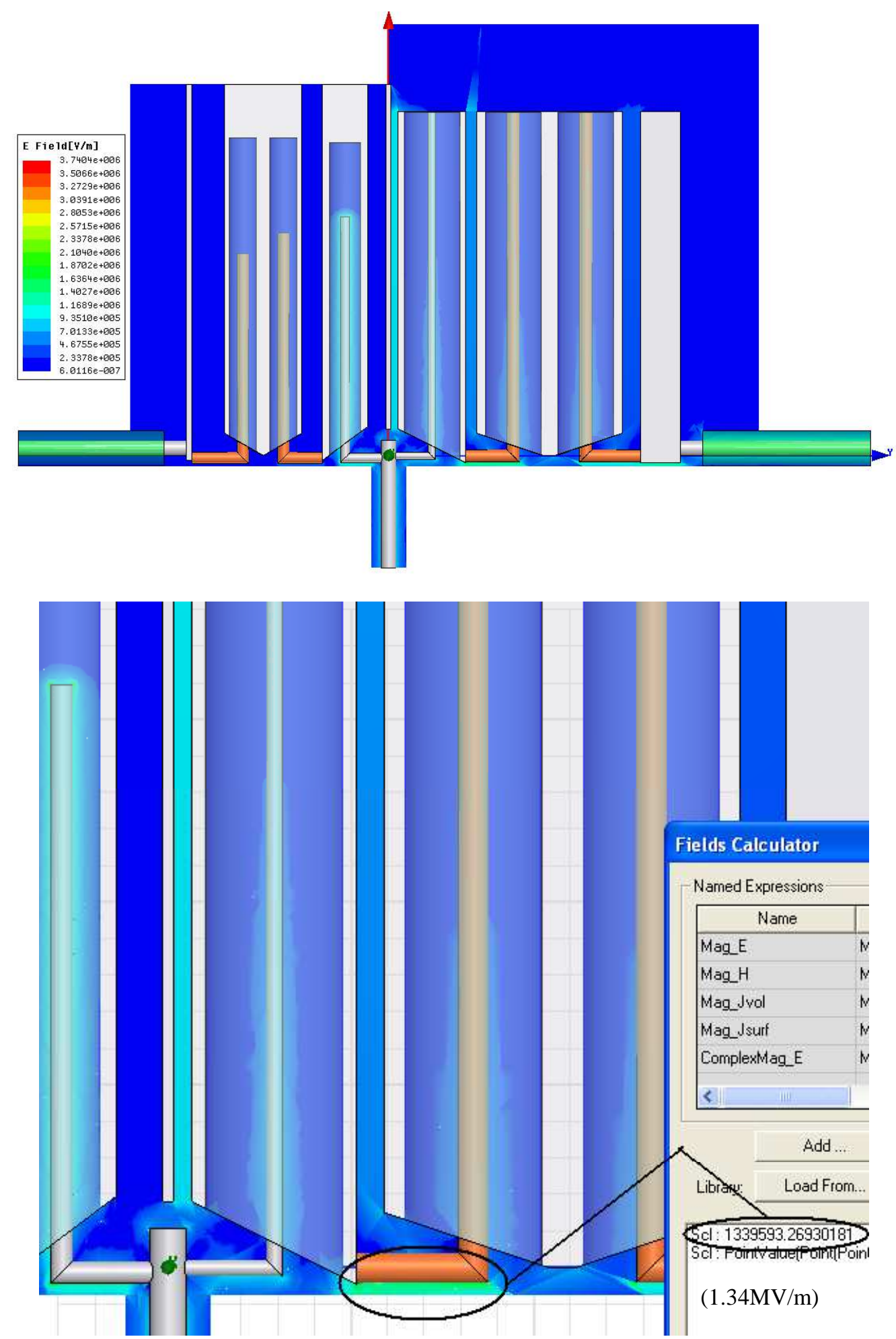

Figure 33: E-field Intensity Distribution in Lowpass Filter 


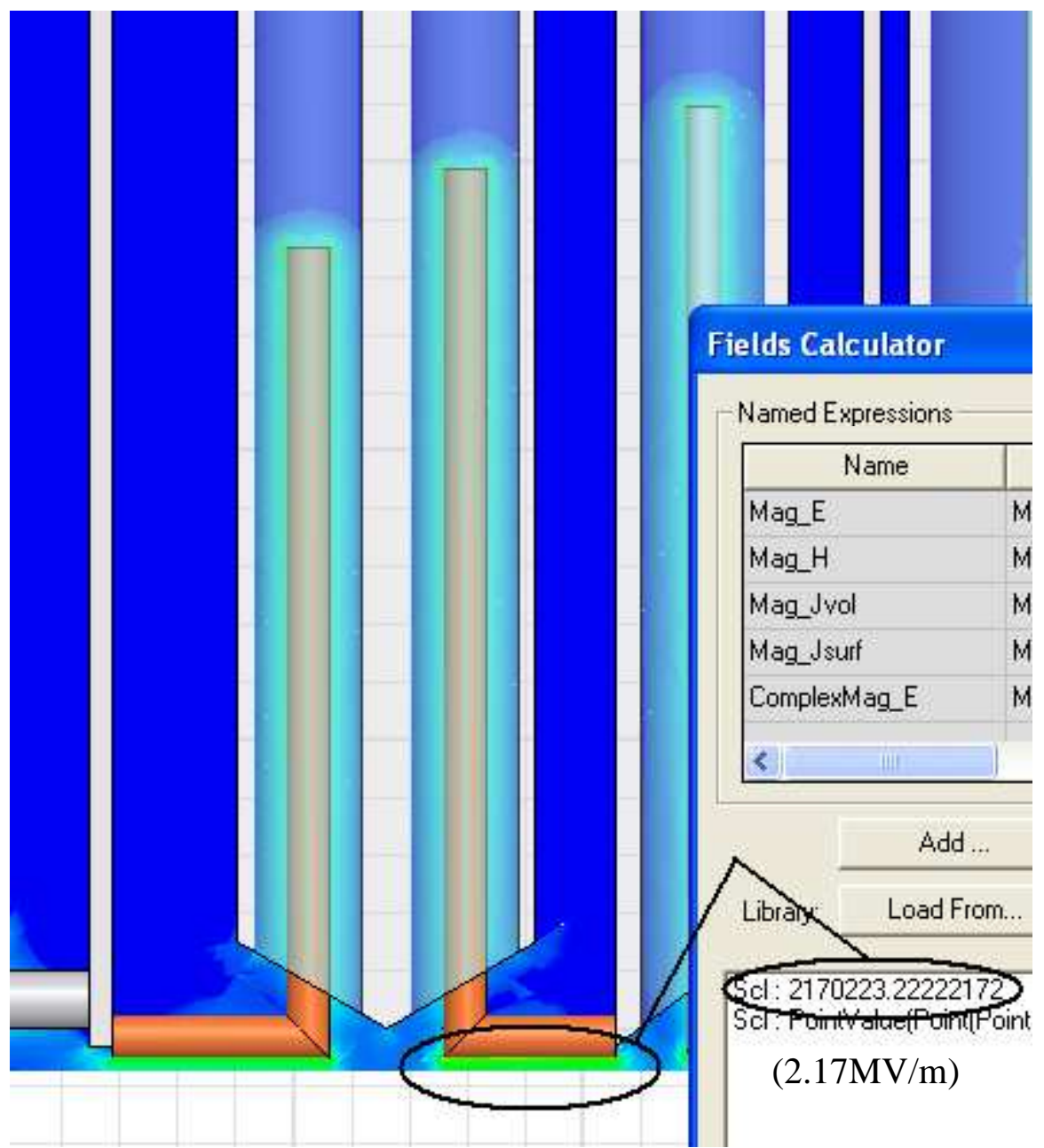

Figure 34: E-field Intensity Distribution in Highpass Filter 


\subsection{Summary}

The diplexer design meets the performance requirements specified in Table 1 . Table 5 displays the results and Fig. 35 shows the overall filter dimensions. The input and output connections are generic 0.25 " $4.4,50 \Omega$ connectors, which interface with 0.5 " 4.4 connectors.

A mechanical dimension sensitivity analysis is recommended prior to fabrication of the proposed diplexer design. This analysis can be carried out in HFSS.

Table 5: Diplexer Performance Results, Worst Case

\begin{tabular}{|l|c|c|c|c|}
\hline & Isolation & Reflection & Insertion Loss & Peak Power \\
& $(\mathbf{d B})$ & $\mathbf{( d B )}$ & $\mathbf{( d B )}$ & $\mathbf{( k W )}$ \\
\hline Specification & $\geq 40$ & $\geq 20$ & $\leq 0.5$ & 6.0 \\
\hline Simulation & 39.8 & 19.8 & 0.2 & 6.45 \\
\hline
\end{tabular}




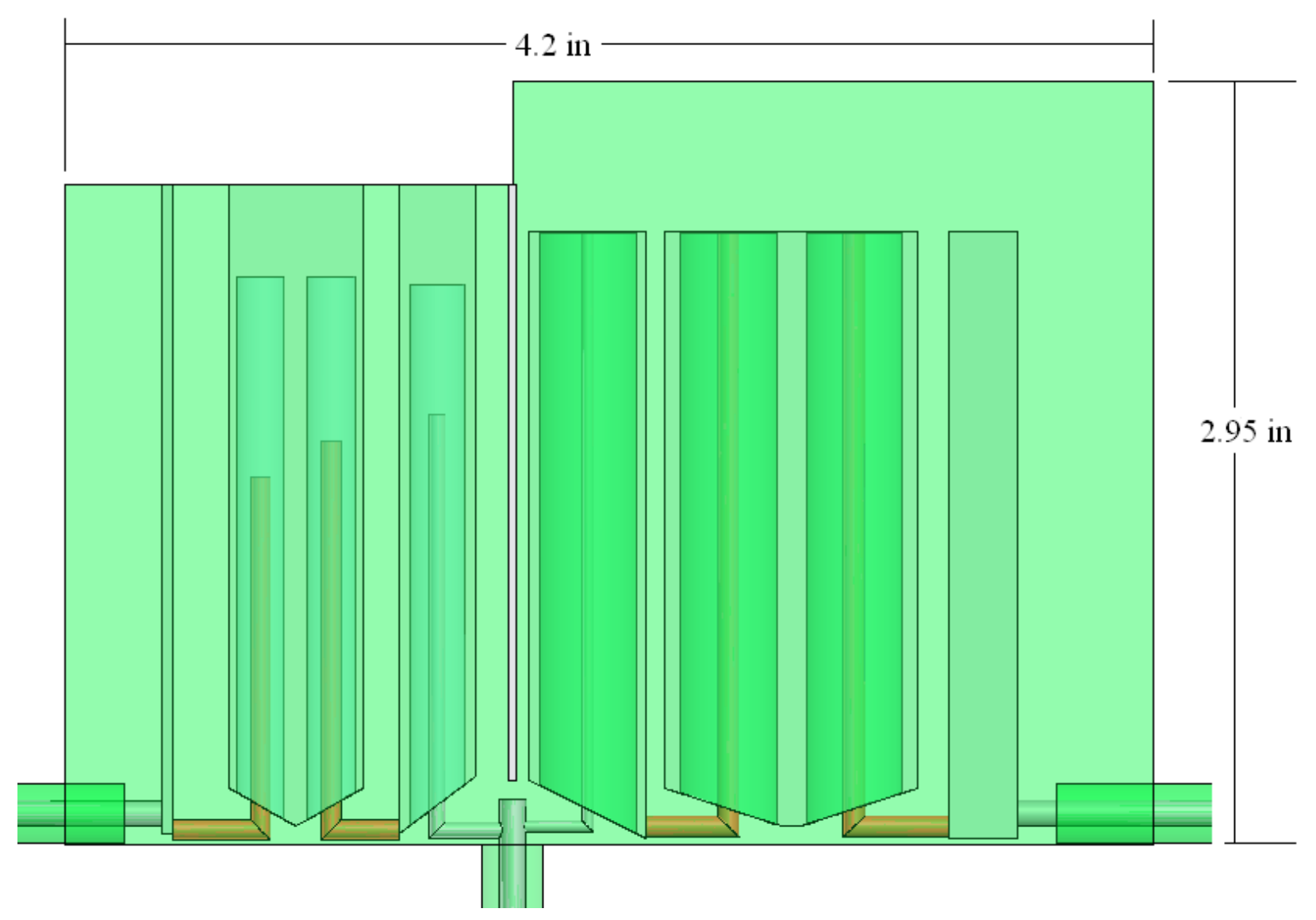

Figure 35: Overall Dimensions, Proposed Digital Elliptic Diplexer 


\section{Chapter 5}

\section{CONCLUSION}

This project involves the investigation of two wideband high power handling diplexer candidates for AEW application: semi-lumped coaxial and digital elliptic topologies. Each has its own advantages and disadvantages.

The semi-lumped coaxial diplexer has the advantages of straightforward design and manufacturability, but also involves unresolved complexities that prevent software performance design optimization. Furthermore, physical prototype tuning requires the ability to adjust lowpass element lengths, for example, which requires disassembly, remanufacturing, reassembly, and retest until the filter attains desired performance. The required level of effort is not practical.

The digital elliptic diplexer, which also exhibits semi-lumped behavior, is not as mechanically simple as the coaxial design, but has the advantages of smaller packaging, and simplified physical prototype tuning. For instance, the resonator lengths are adjustable through "tuning slugs" as outlined in [33].

Although the second diplexer has been implemented since the 1960s, the author is not aware of operating bandwidths greater than the 4.0:1. It is rewarding to know that the Wenzel wideband diplexer [33] can indeed operate over the wider bandwidth of 4.4:1. The author is

also not aware of any coaxial semi-lumped diplexers presented in Chapter 3, which can be 
implemented in other applications. In any case, both diplexers offer low loss $(<0.3 \mathrm{~dB}$ and $<0.2 \mathrm{~dB}$ for semi-lumped and digital elliptic, respectively), which is particularly attractive.

Randtron had plans to build digital elliptic diplexer prototypes to verify simulation results, but project goals have changed and the diplexer is no longer required.

HFSS is a useful three-dimensional full-wave EM simulator, but it has severe limitations on curved objects; simulations will either not converge or require days to complete. A more capable 3-D modeling suite might reduce simulation time. 


\section{BIBLIOGRAPHY}

[1] Temes, Gabor C. and Mitra, Sanjit K., Modern Filter Theory and Design. John Wiley \& Sons., NY, 1973.

[2] Zverev, Anatol I., Handbook of Filter Synthesis. John Wiley \& Sons, Inc., NY, 1967.

[3] Hunter, Ian C., Theory And Design Of Microwave Filters. IEE, UK, 2001.

[4] Chen, Wai-Kai, Passive And Active Filters: Theory And Implementations. John Wiley \& Sons, Inc., NY, 1986.

[5] Christian, Erich, LC Filters: Design, Testing, And Manufacturing. John Wiley \& Sons., NY, 1983.

[6] Rhodes, J. D., Theory Of Electrical Filters. John Wiley \& Sons., NY, 1976.

[7] Valkenburg, M. E. Van, Analog Filter Design. Holt, Rinehart and Winston, 1982.

[8] Mathaei, G., Young, L. and Jones, E.M.T., Microwave Filters, Impedance-Matching Networks, And Coupling Structures. Artech House Inc., Norwood MA, 1980.

[9] Rizzi, Peter A., Microwave Engineering Passive Circuits. Prentice-Hall, Inc., Englewood Cliffs NJ, 1988.

[10] Chen, Wai-Kai, Passive And Active Filters: Theory And Implementations. John Wiley \& Sons, Inc., NY, 1986.

[11] Saad, Theodore S., Microwave Engineers' Handbook Volume I. Artech House, Inc., Dedham MA, 1971.

[12] Szentirmai, George, Computer-Aided Filter Design. IEEE Press, 1973.

[13] Budimir, Djuradj, Generalized Filter Design by Computer Optimization. Artech House, Inc., 1998.

[14] Malherbe, J. A. G., Microwave Transmission Line Filters. Artech House, Inc., 1979.

[15] Chen, Han-Jan et al., "A Novel Cross-Shaped DGS Applied to Design Ultra-Wide Stopband Low-Pass Filters." IEEE Microwave and Wireless Components Letters, Vol. 16. No. 5, May 2006, pp. 252-254. 
[16] Combes, Paul F., Microwave Component Devices and Active Circuits. John Wiley \& Sons, Inc., NY, 1987.

[17] Nguyen, C., "Development Of New Miniaturized Bandpass Filter Having Ultrawide Bandwidth," Electronic Letters, Vol. 30 No. 10, May 1994, pp. 767-768.

[18] Wadell, Brian C., Transmission Line Design Handbook. Artech House, Inc., Norwood MA, 1991.

[19] Cristal, E. G. and Matthaei, G. L., "A Technique for the Design of Multiplexers Having Contiguous Channels," IEEE Transactions on Microwave Theory and Techniques, Vol. 12, No. 1, January 1964, pp. 88-93.

[20] Levy, Ralph and Rozzi, Tullio E., "Precise Design of Coaxial Low-Pass Filters," IEEE Transactions on Microwave Theory and Techniques, Vol. MTT-16, No. 3, March 1968, pp. 142-147.

[21] Mansour, Raafat R., "RF Filters and Diplexers for Wireless System Applications: Stateof-the-Art and Trends," Radio and Wireless Conference '03 Proceedings, August 2003, pp. 373-376.

[22] Coon, Allan, "Capabilities and Applications of SAW Coupled-Resonator Filters," RF Monolithics, Inc., AN 23, December 1990.

[23] Levy, Ralph and Anderson, Konrad J., “An Optimal Low Loss HF Diplexer Using Helical Resonators," IEEE Transactions MTT-S International Microwave Symposium Digest, Vol. 3, June 1992, pp. 1187-1190.

[24] Henryk, Gruchala, "Microwave Diplexer with Direct Coupled Filters," $12^{\text {th }}$ International Conference on Microwave, Radar and Wireless Communications, Vol. 2, May 1998, pp. 620-623.

[25] Getsinger, William J., "Coupled Rectangular Bars Between Parallel Plate,” IRE Transactions on Microwave Theory and Techniques, Vol. 10, No. 1, Jan 1962, pp. 65-72.

[26] Horton, M. C. and Wenzel, R. J., "General Theory and Design of Optimum QuarterWave TEM Filters," IEEE Transactions on Microwave Theory and Techniques, Vol. 13, No. 3, May 1965, pp. 316-327.

[27] Wenzel, R. J., "Exact Theory of Interdigital Band-Pass Filters and Related Coupled Structures," IEEE Transactions on Microwave Theory and Techniques, Vol. MTT-13, No. 5, September 1965, pp. 559-575.

[28] Young, Leo, "Direct-Coupled Cavity Filters for Wide and Narrow Bandwidths," IEEE Transactions on Microwave Theory and Techniques, Vol. 11, No. 3, May 1963, pp. 162178. 
[29] Matthaei, George L., "Design of Wide-Band (and Narrow-Band) Band-Pass Microwave Filters on the Insertion Loss Basis," IEEE Transactions on Microwave Theory and Techniques, Vol. 8, No. 6, November 1960, pp. 580-593.

[30] Matthaei, G. L. and Schiffman, B. M., "Exact Design of Band-Stop Microwave Filters," IEEE Transactions on Microwave Theory and Techniques, Vol. 12, No. 1, January 1964, pp. 6-15.

[31] Erich, Christian and Eisenmann, Egon, Filter Design Tables and Graphs. John Wiley \& Sons., NY, 1966.

[32] Levy R. and Whiteley I., "Synthesis of Distributed Elliptic-Function Filters From Lumped-Constant Prototypes," IEEE Transactions on Microwave Theory and Techniques, Vol. 14, No. 11, November 1966, pp. 506-517.

[33] Horton, M. C. and Wenzel, R. J., "The Digital Elliptic Filter-A Compact SharpCutoff Design for Wide Bandstop or Bandpass Requirements," IEEE Transactions on Microwave Theory and Techniques, Vol. MTT-15, No. 5, May 1967, pp. 307-314.

[34] Wenzel, R. J., "Small Elliptic-Function Lowpass Filters," IEEE Transactions on Microwave Theory and Techniques, Vol. 18, No. 12, December 1970, pp. 1150-1158.

Suggested Additional References

[35] Hunter, Ian C. et al., "Microwave Filters-Applications and Technology," IEEE Transactions on Microwave Theory and Techniques, Vol. 50, No. 3, March 2002, pp. 794-805.

[36] Levy, Ralph and Cohn, Seymour B., "A History of Microwave Filter Research, Design, and Development," IEEE Transactions on Microwave Theory and Techniques, Vol. MTT-32, No. 9, September 1984, pp. 1055-1067.

[37] Cameron, Richard J. et al., "Direct-Coupled Realization for Microwave Bandstop Filters," IEEE MTT-S International Microwave Symposium Digest, June 2005, pp. 32883297.

[38] Cohn, Seymour B., "Parallel-Coupled Transmission-Line-Resonator Filters," IEEE Transactions on Microwave Theory and Techniques, Vol. 6, No. 2, April 1958, pp. 223-231.

[39] Anselmo, A. J. and Hinte, A. F., "Practical Realization of Broadband Microwave Diplexer," MTT-S International Microwave Symposium Digest, Vol. 76, No. 1, 1976, pp. 119-121.

[40] Zverev, A. I. and Blinchikoff, H. J., "Realization of a Filter with Helical Components," IRE Transactions on Component Parts, Vol. 8, No. 3, September 1961, pp. 99-110. 
[41] Antoniuk, Jaroslaw et al., "Resonant Frequencies of Helical Resonators," $15^{\text {th }}$ International Conference on Microwave, Radar and Wireless Communications, Vol. 3, May 2004, pp. 1044-1047.

[42] Omar, Amjad A. et al., "Design and Synthesis of Microwave Coupled Resonator Diplexers," IEEE Antennas and Propagation Society International Symposium, Vol. 1, June 2002, pp. 376-379.

[43] Pozar, David M., Microwave Engineering Second Edition. John Wiley \& Sons., NY, 1998.

[44] Levy, Ralph et al., "Design of Microwave Filters," IEEE Transactions on Microwave Theory and Techniques, Vol. 50, No. 3, March 2002, 783-793.

[45] Wenzel, R. J., "Application of Exact Synthesis Methods to Multichannel Filter Design," IEEE Transactions on Microwave Theory and Techniques, Vol. 13, No. 1, January 1965 , pp. 5-15.

[46] Yu, Ming and Dokas, Van, "High Performance Helical Resonator Filters," $34^{\text {th }}$ European Microwave Conference, Vol. 2, October 2004, pp. 989-992.

[47] Cristal, Edward G., "Coupled Circular Cylindrical Rods Between Parallel Ground Planes," IEEE Transactions on Microwave Theory and Techniques, Vol. 12, No. 4, July 1964, pp. 428-439.

[48] Wenzel, R. J., "Wideband, High Selectivity Diplexers utilizing Digital-Elliptic Filters," IEEE Transactions on Microwave Theory and Techniques, Vol. MTT-15, No. 12, December 1967, pp. 669-680.

[49] Horton, M. C. and Wenzel, R. J., "Optimum Multipole Quarter-Wave TEM Filters," G-MTT Symposium Digest, Vol. 65, No. 1, May 1965, pp. 55-60.

[50] Wenzel, R. J., "Compact Multiplexing Networks For L-Band Through $\mathrm{K}_{\mathrm{U}}$-Band," GMTT International Microwave Symposium Digest, Vol. 70, No. 1, May 1970, pp. 85-89.

[51] Wenzel, Robert J., "Synthesis of Combline and Capacitively Loaded Interdigital Bandpass Filters of Arbitrary Bandwidth," IEEE Transactions on Microwave Theory and Techniques, Vol. MT'T-19, No. 8, August 1971, pp. 678-686.

[52] Wenzel, R. J., "Exact Design of TEM Microwave Networks Using Quarter-Wave Lines," IEEE Transactions on Microwave Theory and Techniques, Vol. 12, No. 1, January 1964, pp. 94-111. 


\section{APPENDIX A: DEFINITIONS OF SELECTED TERMS}

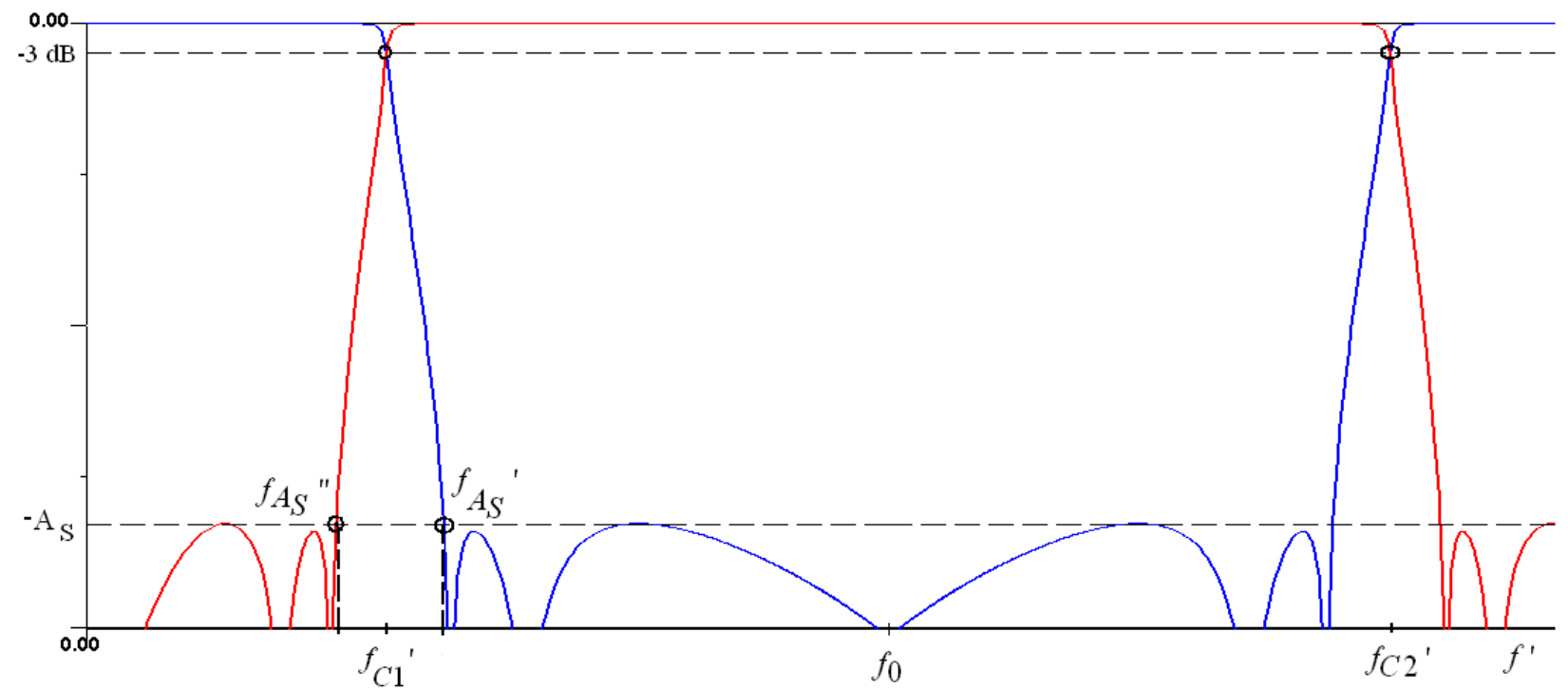

Figure A.1: Prototype Digital Elliptic Diplexer Response

$\mathbf{A}_{\mathbf{s}}$ : Minimum stopband attenuation in $\mathrm{dB}$.

$f_{0}$ : Resonant, or midband, frequency at which the lines are $\lambda / 4$ in length.

$f_{C 1}{ }^{\prime}:$ Lower $3 \mathrm{~dB}$ crossover frequency.

$f_{C 2}{ }^{\prime}:$ Upper $3 \mathrm{~dB}$ crossover frequency.

$f_{A_{S}}{ }^{\prime}$ : Lowpass filter frequency at which the attenuation is $A_{S} \mathrm{~dB}$.

$f_{A_{S}}$ ": Highpass filter frequency at which the attenuation is $A_{S} \mathrm{~dB}$.

$k$ : See skirt selectivity factor.

Bandwidth: The bandwidth may be defined in two ways. The first is $\mathrm{BW}=\frac{f_{C 2}{ }^{\prime}}{f_{C 1}{ }^{\prime}}$ (a ratio), and the second is $\mathrm{BW}=\frac{f_{C 2}{ }^{\prime}-f_{C 1}{ }^{\prime}}{f_{0}}$ (fractional). 
Combline filter: A filter topology with parallel coupled rectangular or circular bars that resemble a hair comb.

Complementary filters: Parallel connected filters that satisfy the following two equations [18]: $\operatorname{Re}\left[Y_{i n_{H P}}\right]+\operatorname{Re}\left[Y_{i n_{L P}}\right]=1$ and $\operatorname{Im}\left[Y_{i n_{H P}}\right]+\operatorname{Im}\left[Y_{i n_{L P}}\right]=0$. Series connected filters have an analogous definition that replaces admittances with impedances.

Dielectric strength $\left(\mathbf{E}_{\mathrm{d}}\right)$ : Intrinsic property of an insulator-the maximum electric field $(\mathrm{V} / \mathrm{m})$ the insulator can withstand prior to breakdown (i. e. before loss of its dielectric properties). The standard value of $\mathrm{E}_{\mathrm{d}}$ for air at room temperature and $1 \mathrm{Atm}$ is approximately $3 \mathrm{MV} / \mathrm{m}$.

Digital filter: A filter topology with parallel coupled rectangular or circular bars that resemble the digits of a hand.

Elliptic filter: A filter with equal ripple in the passband and stopband requiring Jacobi-elliptic functions for synthesis. It is also known as a Cauer or rational Chebyshev filter [17].

Filter: A network with a prescribed response for a given excitation. [15]

Non-redundant synthesis: Filter realization without unit elements, or filter realization where the unit elements contribute to the magnitude response of the filter.

Pseudo-complementary filters: Parallel connected filters when $Y_{i n_{H P}}+Y_{i n_{L P}} \approx 1$ (within 20\%) $[5]$.

Redundant synthesis: Use of extra (redundant) unit elements to realize filter networks. The unit elements do not affect the magnitude response of the filter.

Rotary coupler (RC): A rotary coupler consists of many two-port rotating joints that maintain electrical continuity while allowing $360^{\circ}$ rotation between the ports.

Selectivity: A filter's insertion loss outside the desired band, and typically specified in $\mathrm{dB}$ quantifies the filter's ability to differentiate between signals of different frequencies (or frequency bands).

Skirt selectivity factor (k): The ratio of the cutoff frequency to the frequency at which the filter attenuation reaches $A_{S}(d B)$.

Static capacitance: As used in Chapter 4, a unitless quantity that is the ratio of capacitance between conductors per unit length to the dielectric constant of the medium [25, 33].

Unit element (U): A transmission line of length $\lambda / 4$ and characteristic impedance $Z_{0}$. 
APPENDIX B: SOME FILTER TECHNOLOGIES/TOPOLOGIES
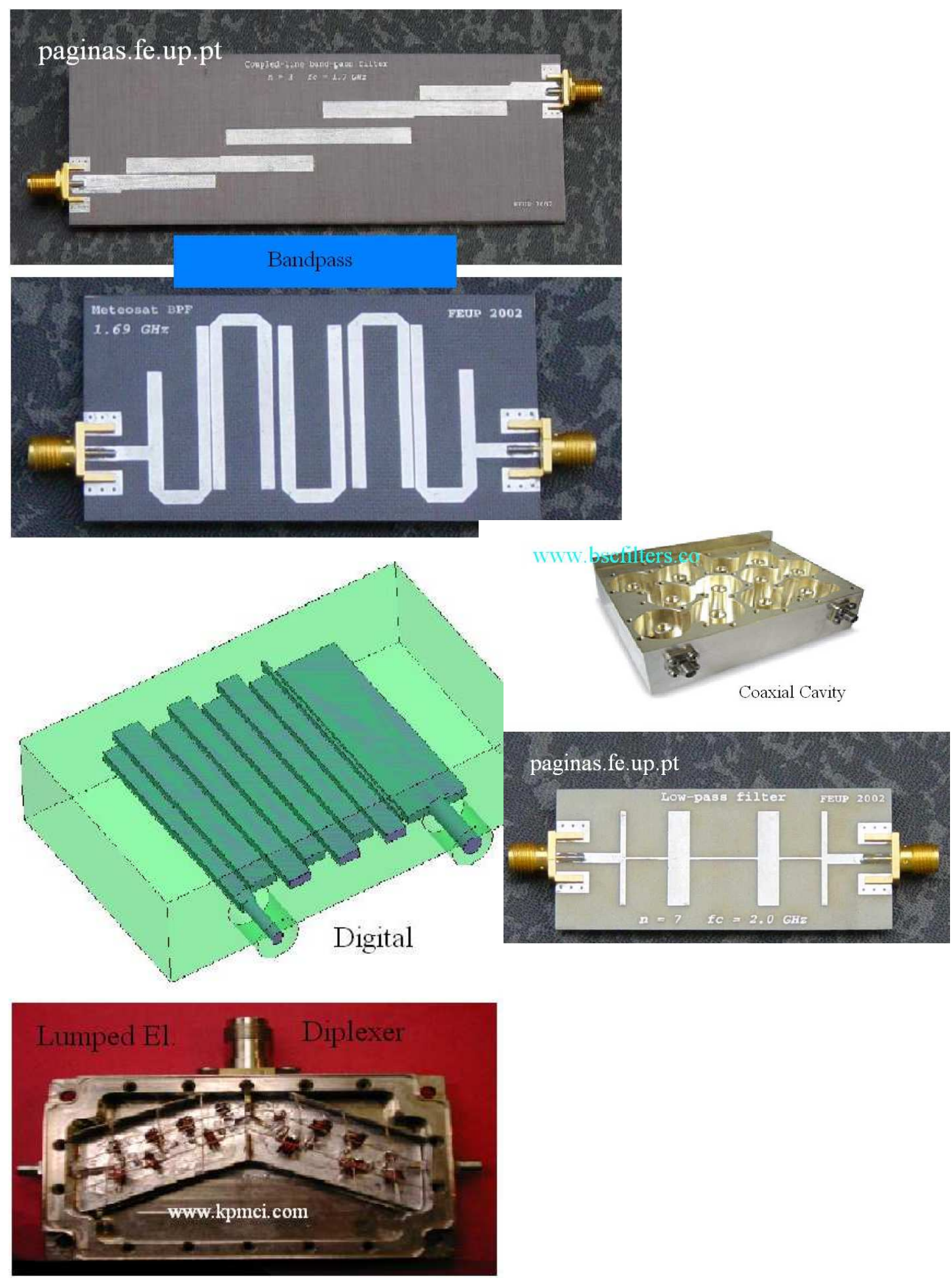


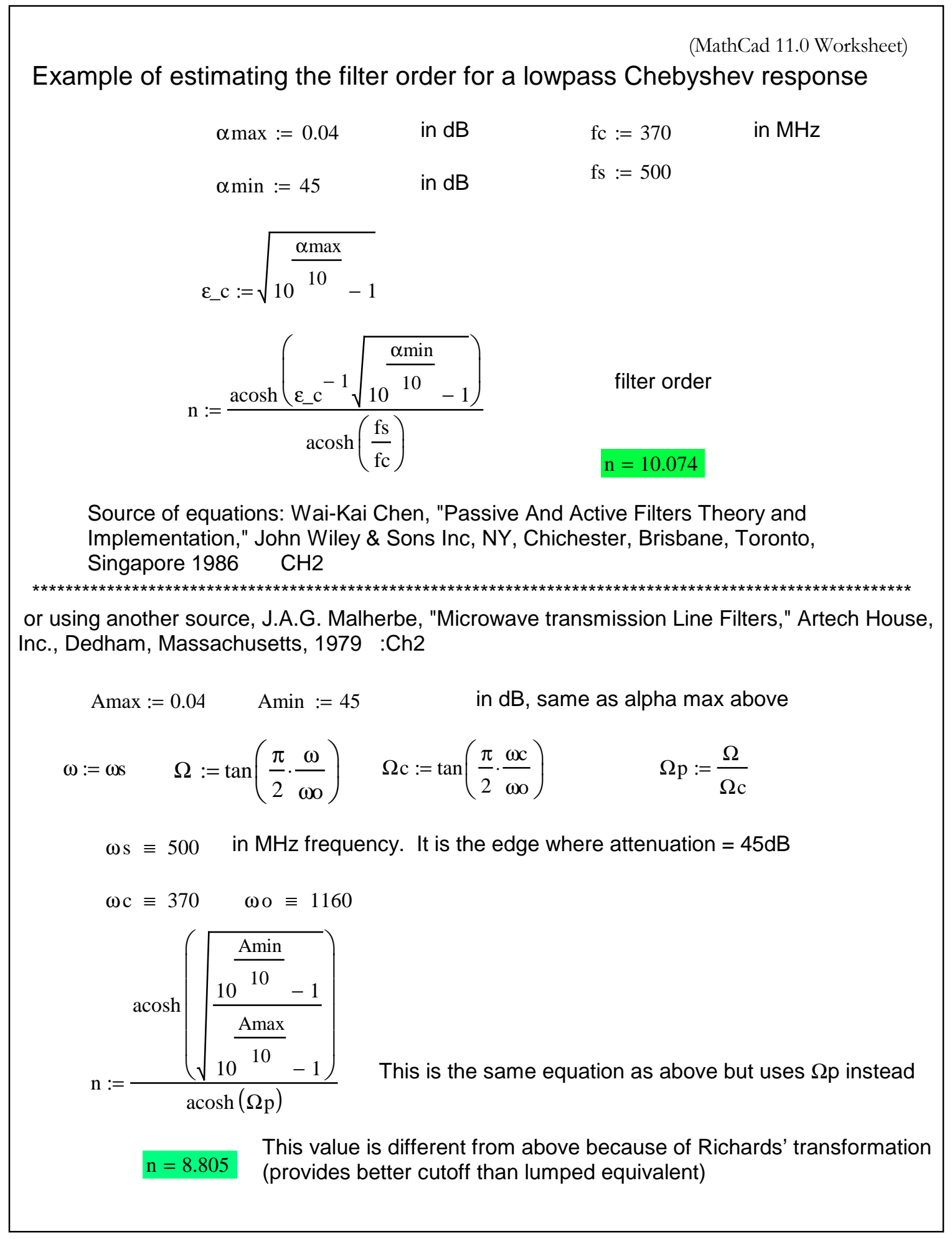




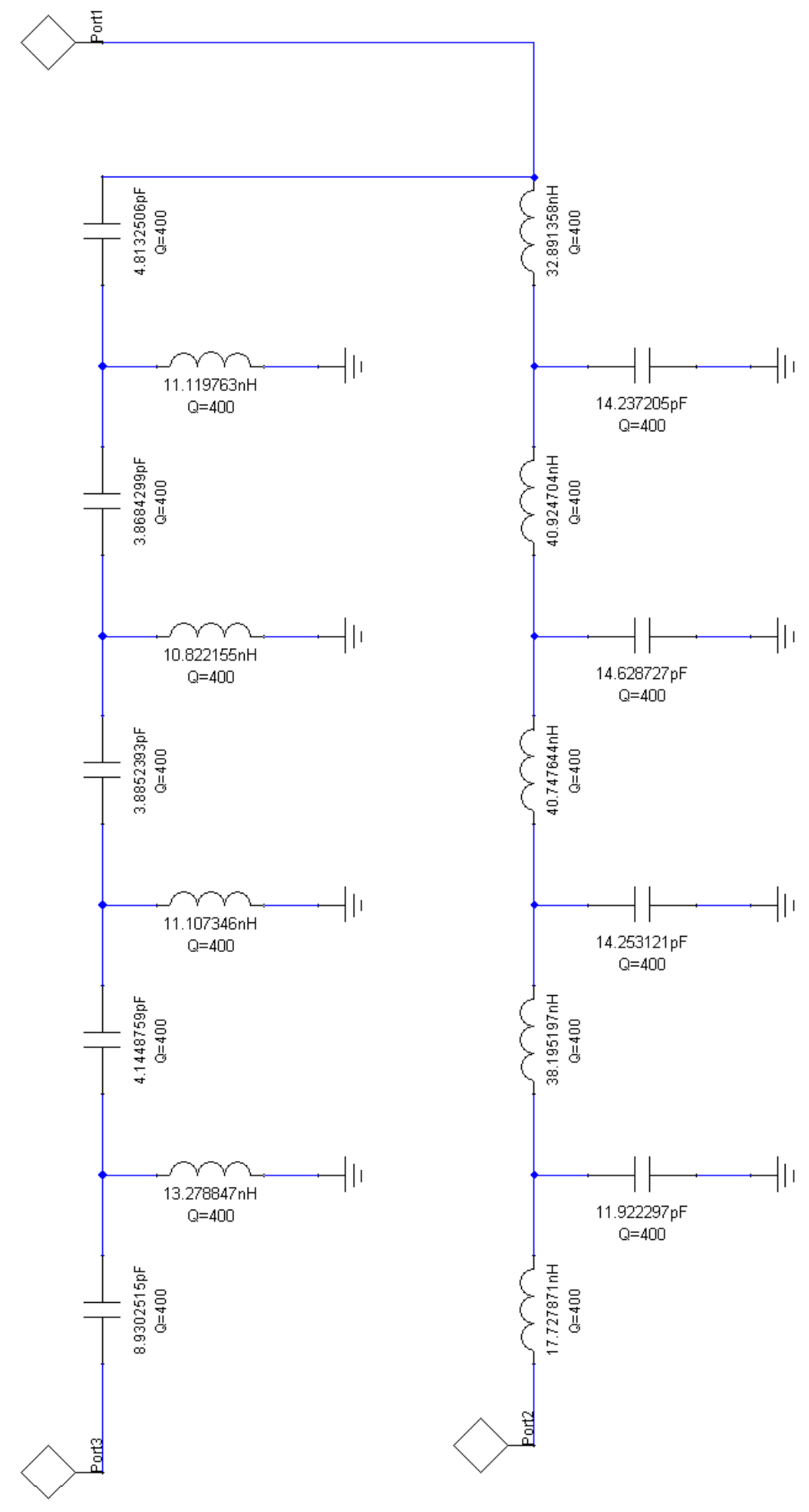

Semi-Lumped Diplexer: Initial circuit 


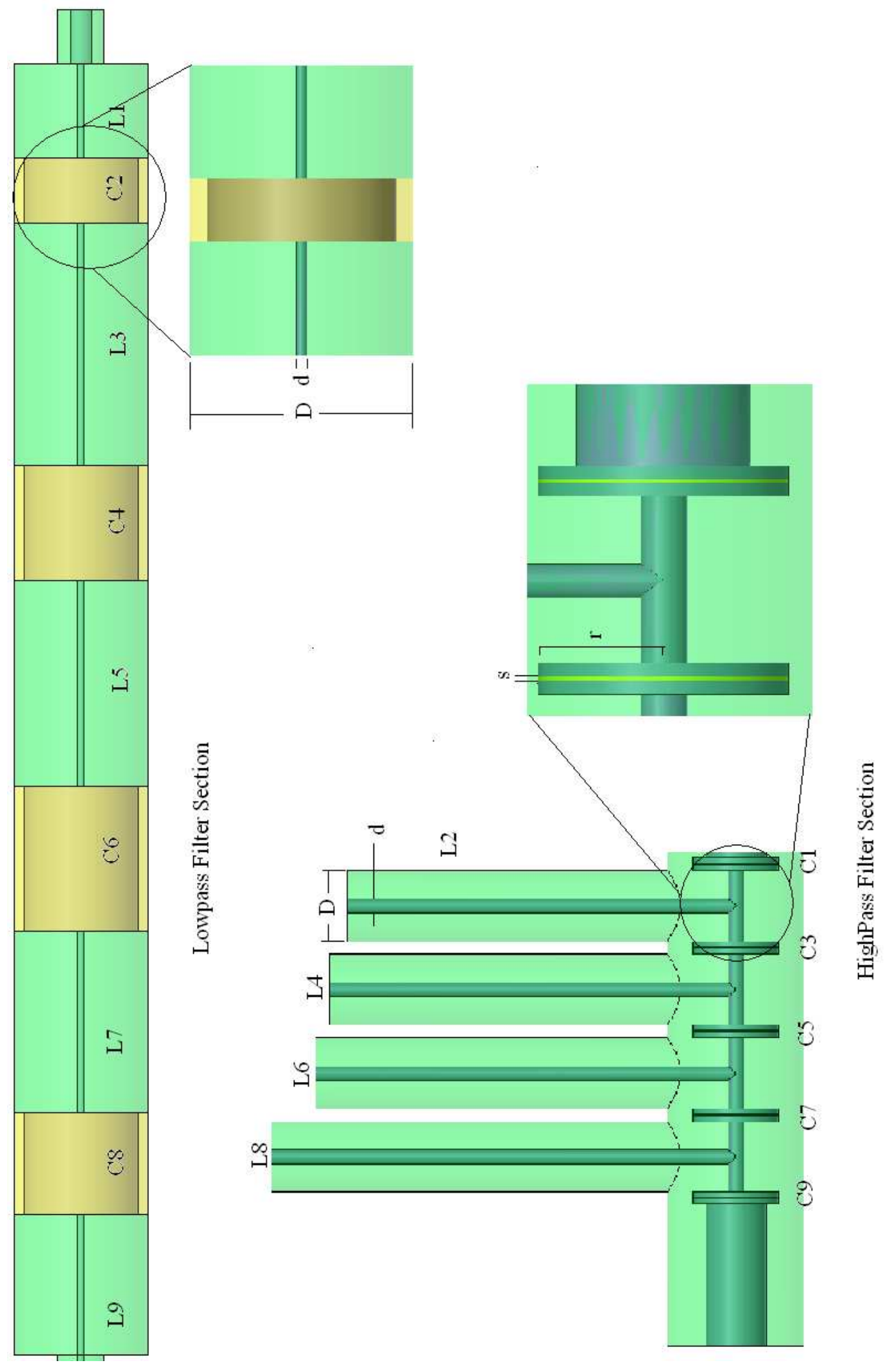




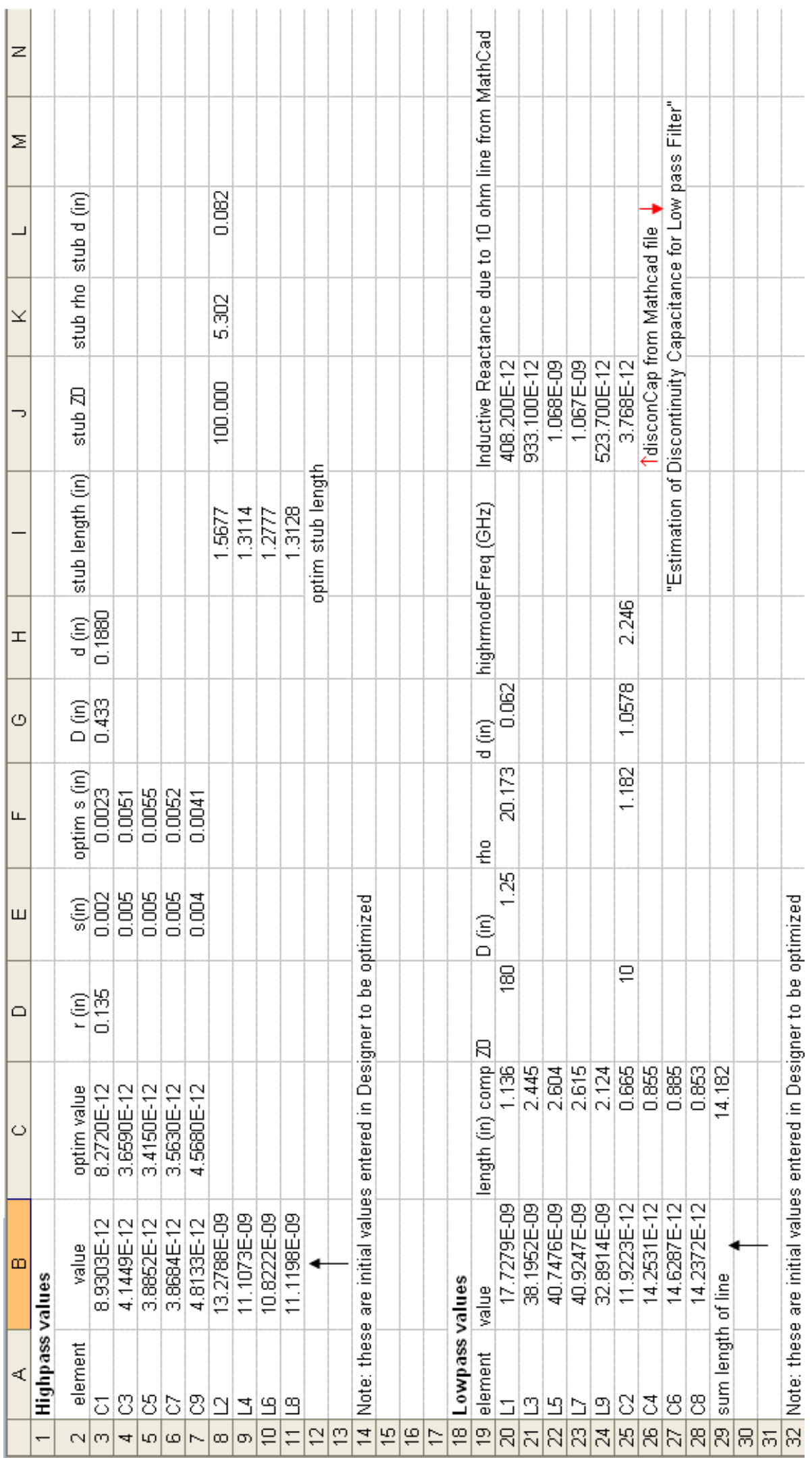




\section{Estimation of Discontinuity Capacitance for Lowpass Filter}

Wadell, Brian C., Transmission Line Design Handbook. Artech House, Inc., Norwood MA, 1991.

$$
\begin{aligned}
& c \equiv 2.9979245810^{8} \\
& \text { era } \equiv 1.000649 \\
& \text { ert } \equiv 2.1 \\
& \mathrm{f}:=0.410 \cdot 10^{-9} \\
& \mathrm{Zh}:=180 \\
& \omega:=2 \cdot \pi \cdot \mathrm{f} \\
& \mathrm{Zl}:=10 \\
& \text { vh }:=\frac{\mathrm{c}}{\sqrt{\mathrm{era}}} \\
& \text { Ind }:=14.237 \cdot 10^{-9} \\
& 1:=\frac{\mathrm{vh}}{\omega} \cdot \operatorname{asin}\left(\frac{\omega \cdot \mathrm{Ind}}{\mathrm{Zh}}\right) \cdot \frac{1}{0.0254} \\
& \mathrm{vl}:=\frac{\mathrm{c}}{\sqrt{\mathrm{ert}}} \cdot \frac{1}{0.0254} \\
& 1=0.933 \\
& \text { index }:=1 . .3 \\
& \tau:=\frac{\mathrm{r}_{3}}{\mathrm{r}_{1}} \\
& \alpha:=\frac{\mathrm{r}_{3}-\mathrm{r}_{2}}{\mathrm{r}_{3}-\mathrm{r}_{1}} \\
& \mathrm{r}_{\text {index }}:= \\
& \begin{array}{|c|}
\hline \frac{0.062}{2} \\
\hline \frac{1.0578}{2} \\
\hline \frac{1.25}{2} \\
\hline
\end{array} \\
& \operatorname{Cdp}:=\left[\frac{8.854183 \cdot 10^{-12} \cdot \operatorname{ert}}{100 \cdot \pi}\left(\frac{\alpha^{2}+1}{\alpha} \cdot \ln \left(\frac{1+\alpha}{1-\alpha}\right)-2 \cdot \ln \left(\frac{4 \alpha}{1-\alpha^{2}}\right)\right)+1.11 \cdot 10^{-15}(1-\alpha) \cdot(\tau-1)\right] \cdot 2.54 \\
& \mathrm{Cd}:=2 \pi \cdot \mathrm{r}_{3} \cdot \mathrm{era} \cdot \mathrm{Cdp} \\
& \mathrm{Cd}=1.884 \times 10^{-12}
\end{aligned}
$$

(continued on next page) 


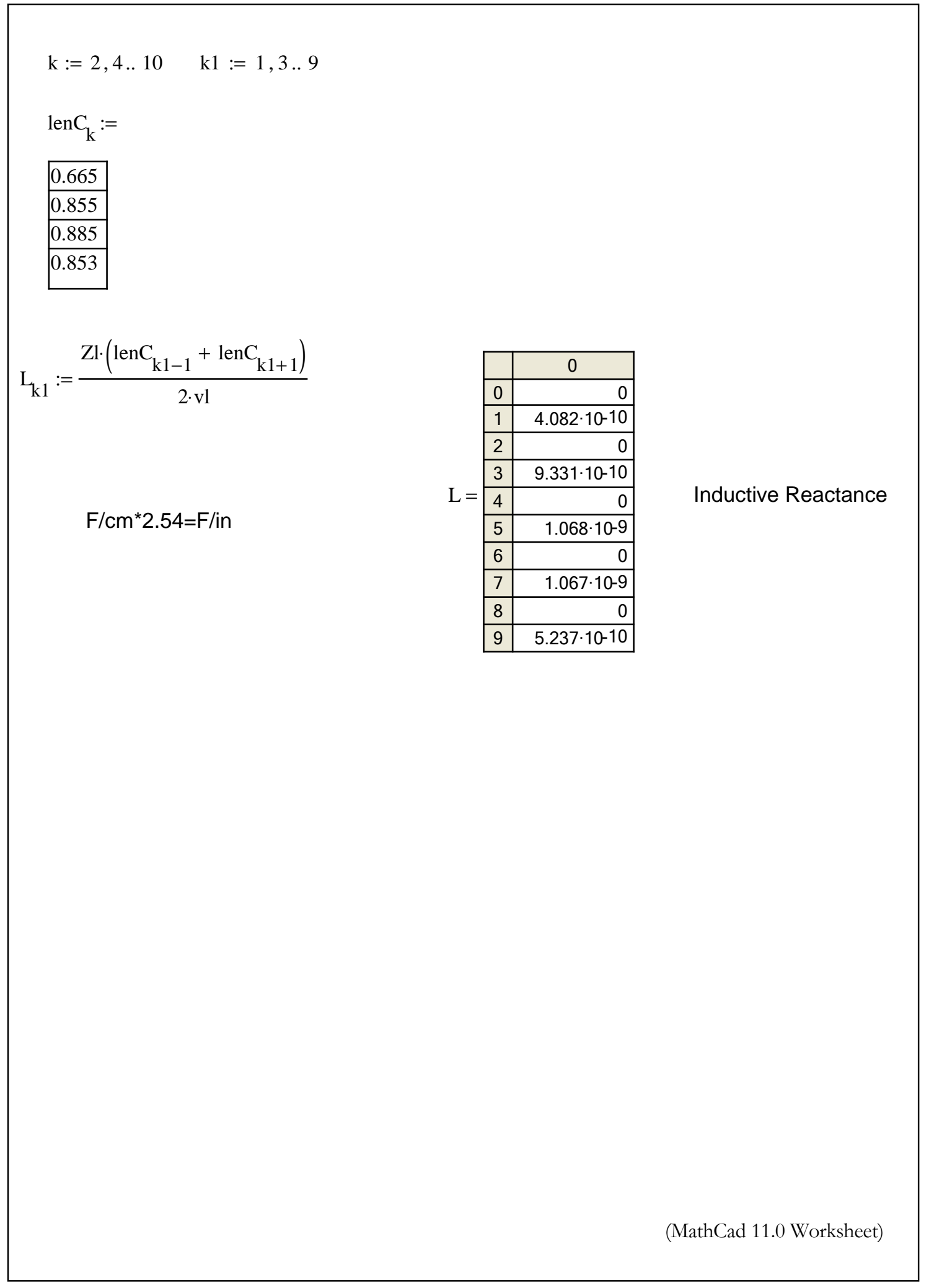




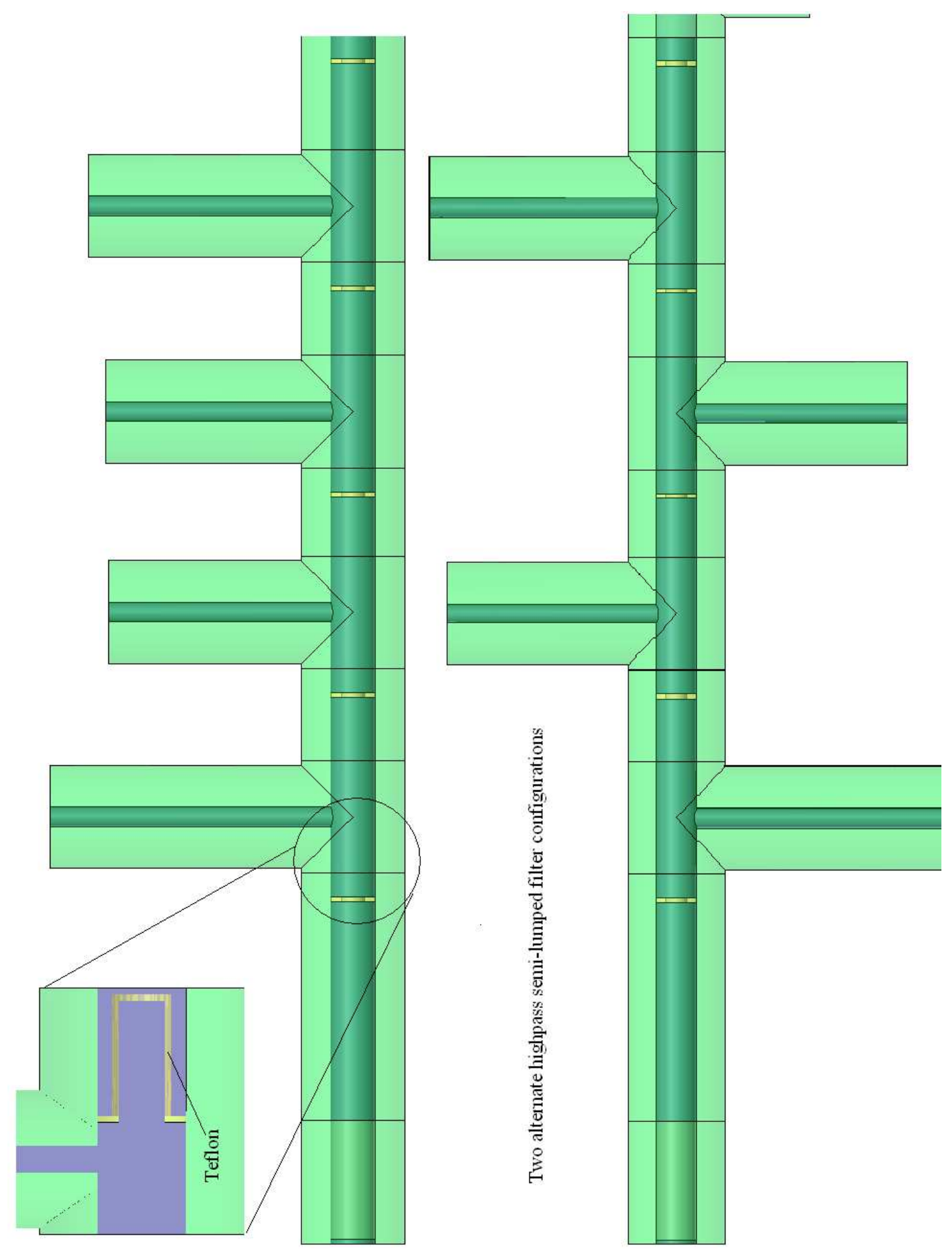




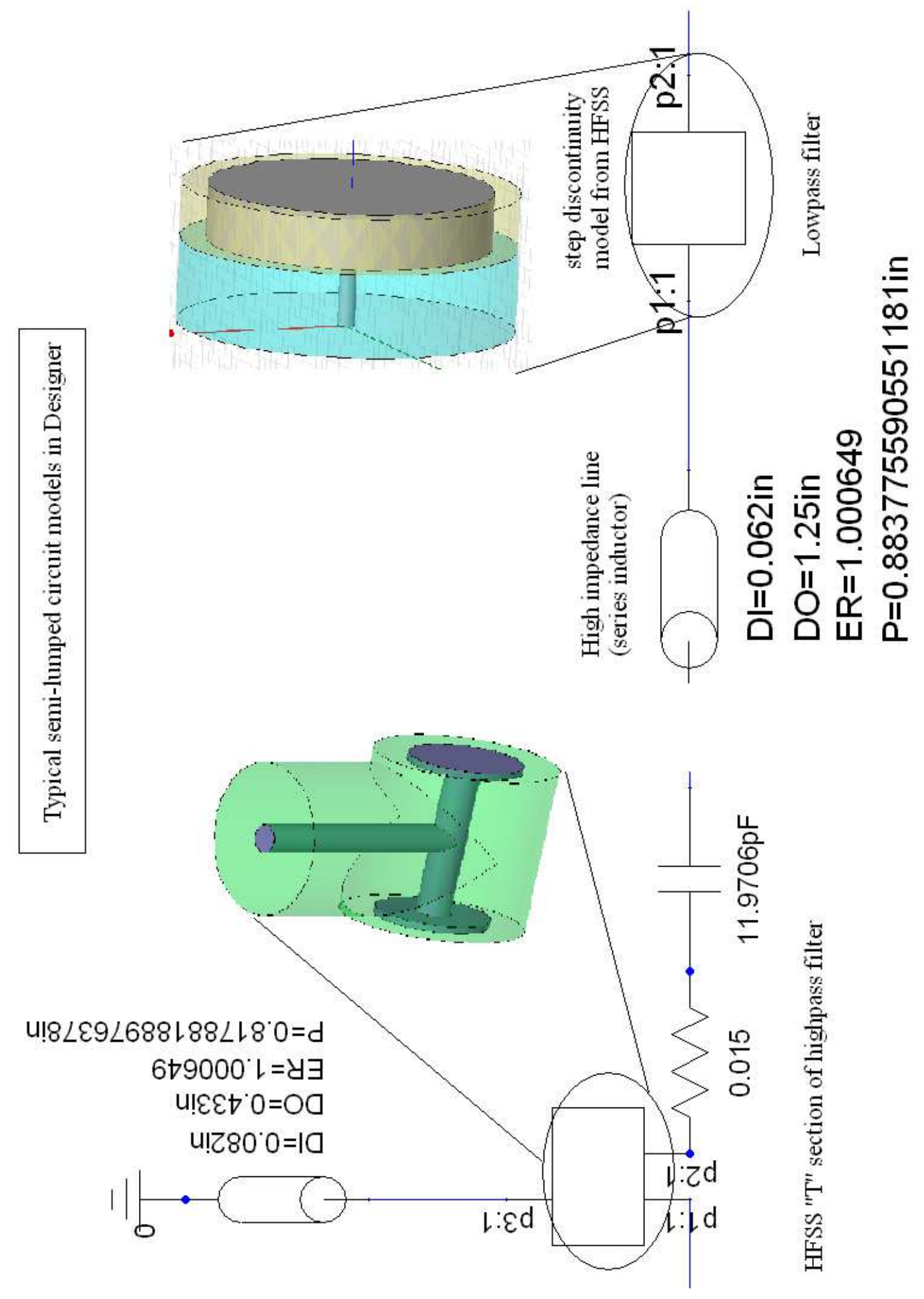




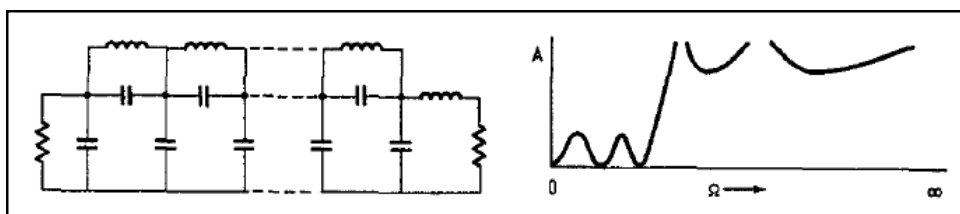

(a)
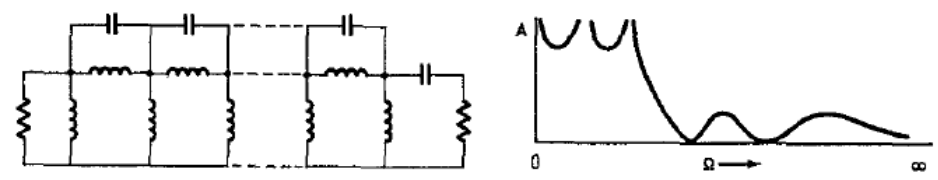

(b)

Fig. 1. Elliptic function prototype filter networks and attenuation characteristics: (a) prototype low-pass, and (b) prototype high-pass.

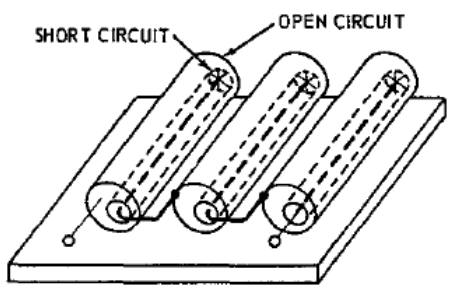

(a)
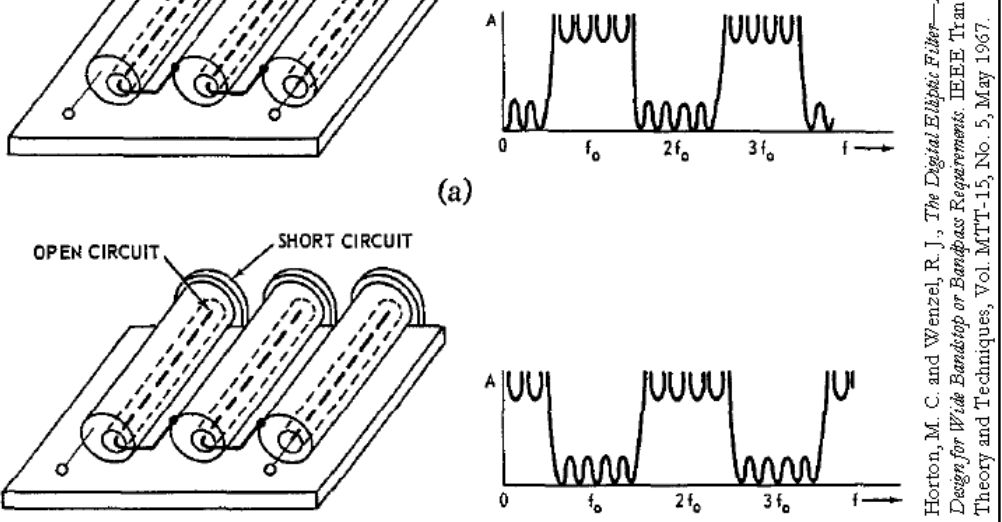

(b)

Fig. 2. Digital elliptic microwave filter configurations and responses for (a) distributed bandstop designs, and (b) distributed bandpass designs.
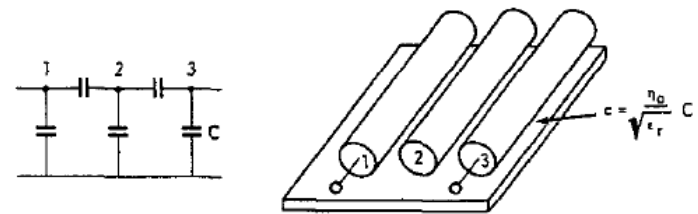

(a)
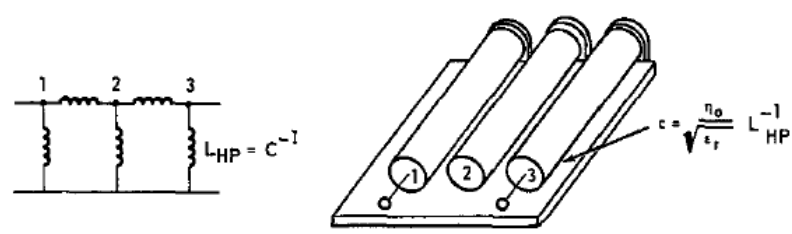

(b)

Fig. 3. Parallel conductor distributed representations of transformed lumped element prototype networks: (a) capacitive, and (b) inductive. 
Digital Elliptic Diplexer

(MathCad 11.0 Worksheet) (method of Wenzel)

$$
\begin{array}{ll}
\mathrm{fc} 1:=0.41010^{9} & \text { the } 3 \mathrm{~dB} \text { frequency crossover } \\
\mathrm{fc} 2:=1.85 \cdot 10^{9} & \mathrm{Z} 0:=50 \quad \text { era }:=1.000649 \text { (air) ert }:=2.1 \\
\mathrm{f} 0:=\frac{\mathrm{fc} 1+\mathrm{fc} 2}{2} & \text { the center frequency }(\lambda / 4)
\end{array}
$$

from $(\mathrm{T} 1) \quad \Omega \mathrm{c}:=\tan \left(\frac{\pi \mathrm{fc} 1}{2 \cdot \mathrm{f0}}\right) \quad$ fAs $1:=50010^{6} \quad \mathrm{fAs} 2:=320 \cdot 10^{6}$

$$
\mathrm{kL}:=\frac{\Omega \mathrm{c}}{\Omega \mathrm{As} 1} \quad \Omega \mathrm{As} 1:=\tan \left(\frac{\pi \cdot \mathrm{fAs} 1}{2 \cdot \mathrm{f} 0}\right) \quad \Omega \text { As } 1=0.834
$$

Therefore: $\Omega \mathrm{c}=0.641 \quad \mathrm{~kL}=0.769$

from table 2: $\quad \mathrm{N}:=6 \quad$ and $\mathrm{k}=0.8, \mathrm{As}=51 \mathrm{~dB}$ at $\Omega \mathrm{As}=1.2318(639 \mathrm{MHz})$

Then: $\quad i:=0 . .6$

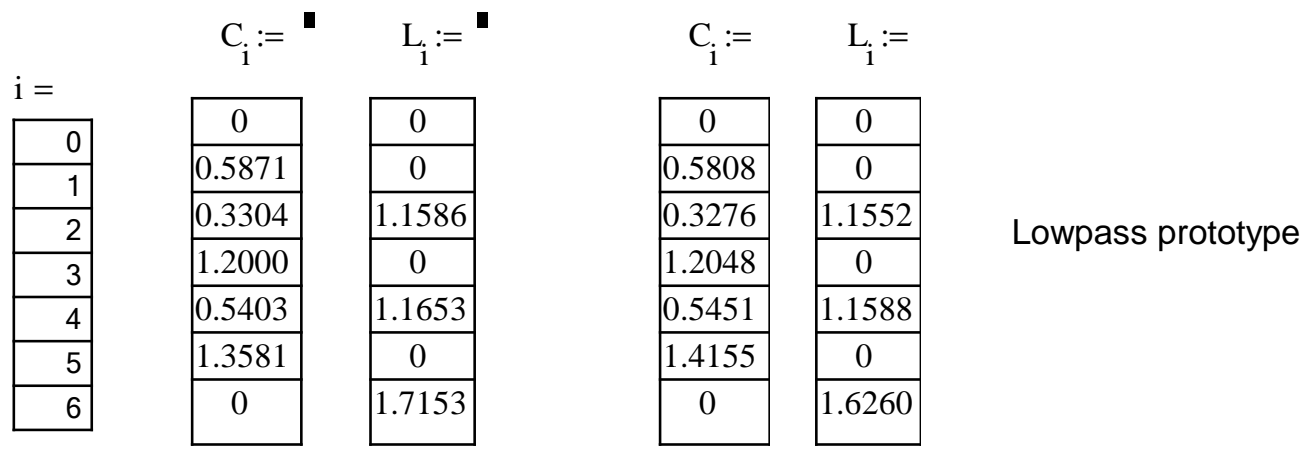

(initial values) (optimized values from Designer)

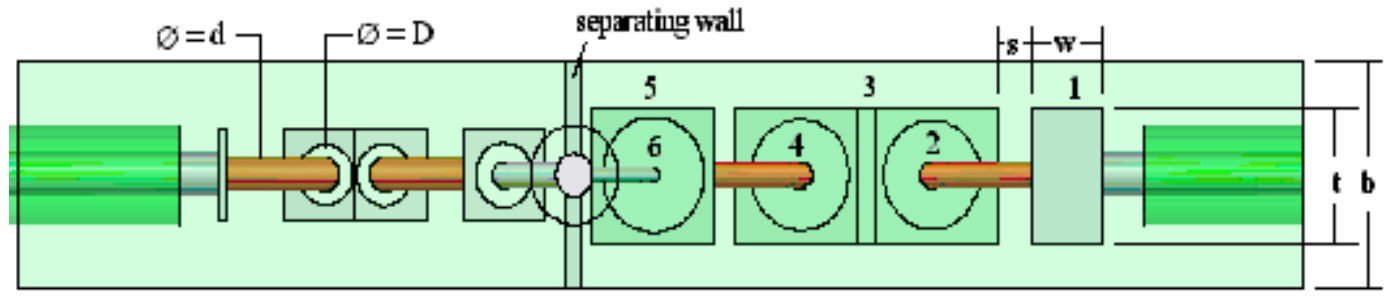




$$
\mathrm{f} 0=1.13 \times 10^{9}
$$

$$
\operatorname{frep}(\Omega):=\frac{2 \cdot \mathrm{f0}}{\pi} \operatorname{atan}(\Omega \mathrm{c} \cdot \Omega)
$$

$$
\operatorname{frep}(1.2)=4.716 \times 10^{8}
$$

$$
\text { CLPchart }_{i}:=\frac{376.7}{\sqrt{\text { era }} \cdot \mathrm{Z} 0} \cdot \frac{\mathrm{C}_{\mathrm{i}}}{\Omega \mathrm{c}}
$$

$$
\text { (LP = Lowpass })
$$

\section{(MathCad 11.0 Worksheet)}

(equation for static capacitances of elements)

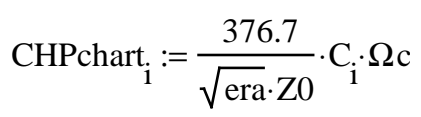

$$
\text { (HP = highpass) }
$$

$$
\begin{aligned}
& \text { CLPchart }_{1}= \\
& \text { CHPchart }_{i}= \\
& \begin{array}{|r|}
\hline 0 \\
\hline 2.803 \\
\hline 1.581 \\
\hline 5.815 \\
\hline 2.631 \\
\hline 6.832 \\
\hline 0 \\
\hline
\end{array} \\
& \text { tLP }:=0.6 \quad \text { tHP }:=0.4 \quad b \quad:=0.75 \\
& \mathrm{sLP}_{\mathrm{i}}:=\quad \mathrm{CfLP}_{\mathrm{i}}:= \\
& \begin{array}{|c|}
\hline 0 \\
\hline .165 \\
\hline 0 \\
\hline 100 \\
\hline
\end{array} \\
& \begin{array}{|c|}
\hline 0 \\
\hline .360 \\
\hline 0 \\
\hline .225 \\
\hline
\end{array} \\
& \text { for } \operatorname{tLP}=0.6 \\
& \text { CFolp := } 1.30 \quad \text { (fringing capacitance between enclosure and outer } \\
& \text { element) } \\
& \text { for } s w / 2=0.5 \quad \text { (distance between enclosure and outer element) } \\
& \mathrm{sHP}_{\mathrm{i}}:=\quad \mathrm{CfHP}_{\mathrm{i}}:=
\end{aligned}
$$

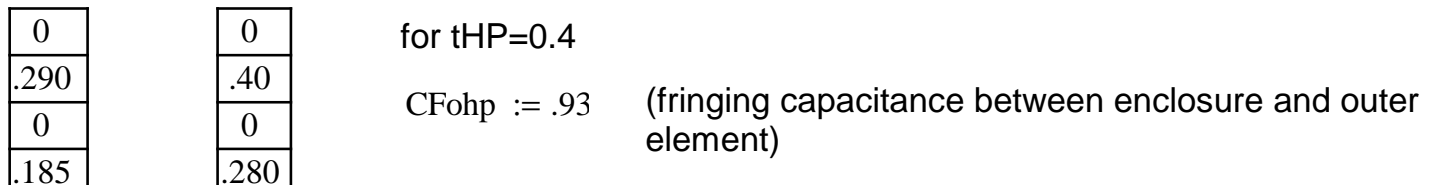

$$
\begin{aligned}
& \text { for } s w / 2=0.7 \text { (distance between enclosure and outer element) }
\end{aligned}
$$




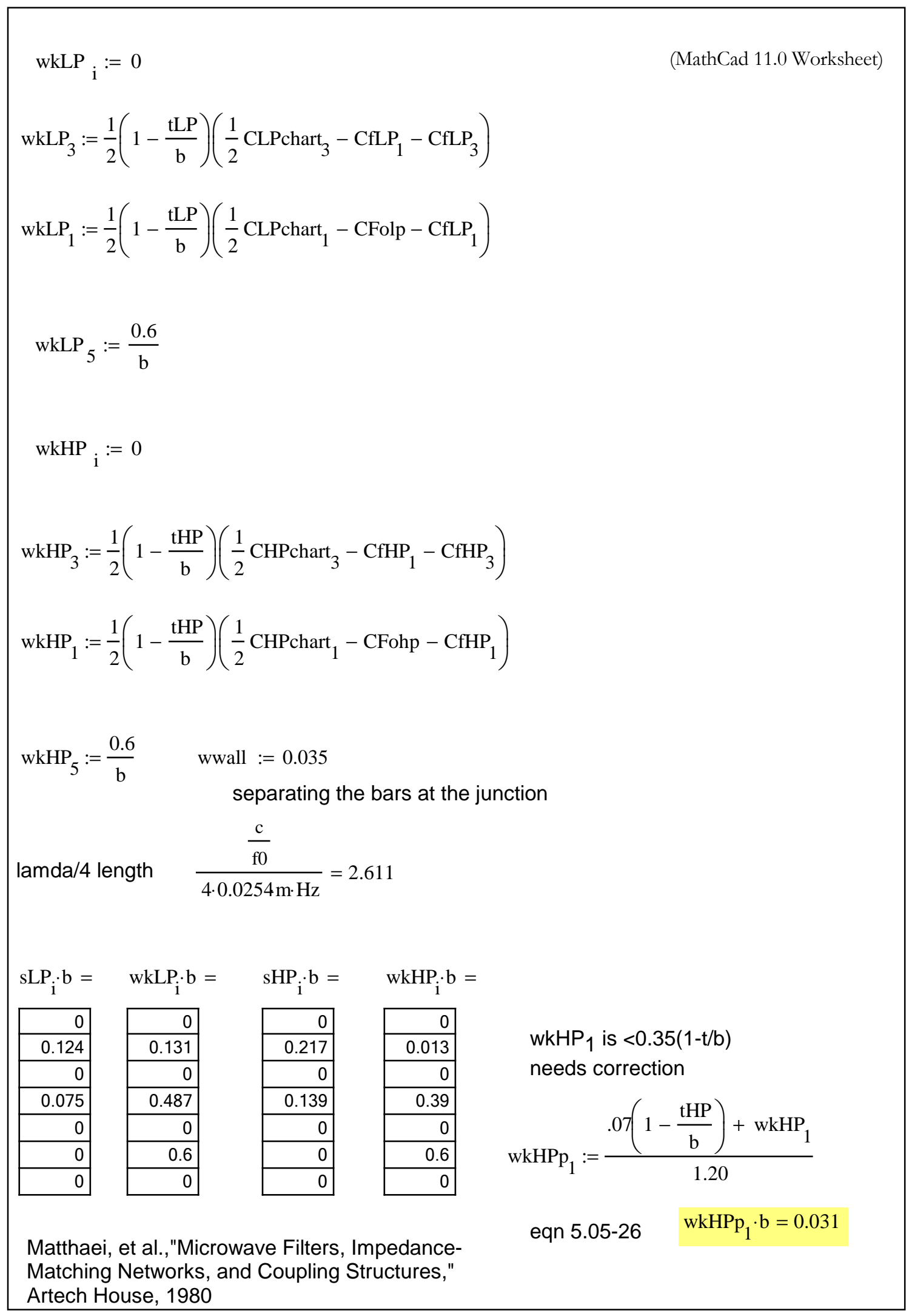




$$
\mathrm{Zlp}_{\mathrm{i}}:=\mathrm{Z0} \cdot \frac{\mathrm{L}_{\mathrm{i}}}{\Omega \mathrm{c}} \quad \mathrm{Zhp}_{\mathrm{i}}:=\mathrm{Z} 0 \cdot \mathrm{L}_{\mathrm{i}} \cdot \Omega \mathrm{c}
$$

\begin{tabular}{|c|c|}
\hline $\mathrm{Zlp}_{\mathrm{i}}=$ & $\mathrm{Zhp}_{\mathrm{i}}=$ \\
\hline 0 & 0 \\
\hline 0 & 0 \\
\hline 90.127 & 37.017 \\
\hline 0 & 0 \\
\hline 90.407 & 37.132 \\
\hline 0 & 0 \\
\hline 126.857 & 52.103 \\
\hline
\end{tabular}

(characteristic impedances of internal stubs)

$\mathrm{D}:=.1$

Given

$$
=\frac{2 \cdot 10^{-7} \cdot c \cdot \frac{s}{m}}{\sqrt{\varepsilon}} \cdot \ln \left(\frac{D}{d}\right)
$$

$\operatorname{Dia}(\varepsilon, \mathrm{d}, \mathrm{Zc}):=\operatorname{Find}(\mathrm{D})$

$$
\mathrm{k} 3:=2,4 . .6
$$

$$
\text { Dia (era, .083, Zlp } \left.\mathrm{k} 3_{\text {( }}\right)
$$

$\operatorname{Dia}\left(\mathrm{ert}, .075, \mathrm{Zhp}_{\mathrm{k} 3}\right)$

\begin{tabular}{|l|}
\hline 0.373 \\
\hline 0.375 \\
\hline 0.689 \\
\hline
\end{tabular}

\begin{tabular}{|l|}
\hline 0.183 \\
\hline 0.184 \\
\hline 0.264 \\
\hline
\end{tabular}

(LP)

(HP)

$\operatorname{Dia}\left(\right.$ era, $\left..045, \mathrm{Zlp}_{6}\right)=0.374$ 


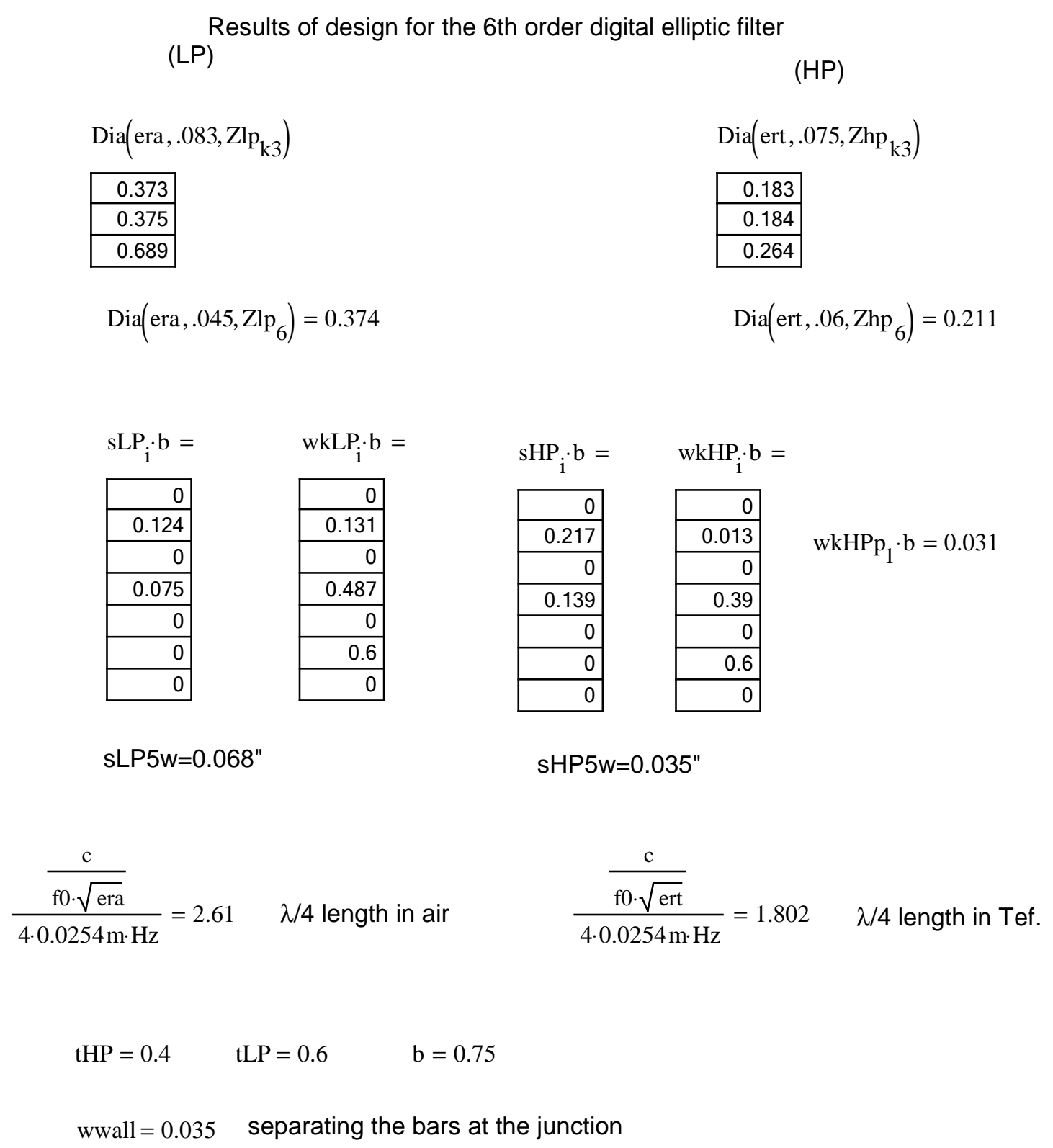
(LP)

(HP)

$\operatorname{Dia}\left(\mathrm{era}, .083, \mathrm{Zlp}_{\mathrm{k} 3}\right)$

Dia(ert, .075, Zhp k3 $)$

0.373

0.375

0.689

\begin{tabular}{|l|}
\hline 0.183 \\
\hline 0.184 \\
\hline 0.264 \\
\hline
\end{tabular}

$\operatorname{Dia}\left(\right.$ era, $\left..045, \mathrm{Zlp}_{6}\right)=0.374$

$\operatorname{Dia}\left(\right.$ ert, .06, Zhp $\left._{6}\right)=0.211$

$\mathrm{sLP}_{\mathrm{i}} \cdot \mathrm{b}=$

$w k_{i} \cdot b=$

$\mathrm{sHP}_{\mathrm{i}} \cdot \mathrm{b}=$

${ }^{w k H P} \cdot \mathrm{b}=$

\begin{tabular}{|r|}
\hline 0 \\
\hline 0.124 \\
\hline 0 \\
\hline 0.075 \\
\hline 0 \\
\hline 0 \\
\hline 0 \\
\hline
\end{tabular}

\begin{tabular}{|r|}
\hline 0 \\
\hline 0.131 \\
\hline 0 \\
\hline 0.487 \\
\hline 0 \\
\hline 0.6 \\
\hline 0 \\
\hline
\end{tabular}

\begin{tabular}{|r|}
\hline 0 \\
\hline 0.217 \\
\hline 0 \\
\hline 0.139 \\
\hline 0 \\
\hline 0 \\
\hline 0 \\
\hline
\end{tabular}

$\mathrm{wkHPp}_{1} \cdot \mathrm{b}=0.031$

sLP5w=0.068"

sHP5w=0.035"

$\frac{\frac{\mathrm{c}}{\mathrm{f} 0 \cdot \sqrt{\mathrm{era}}}}{4 \cdot 0.0254 \mathrm{~m} \cdot \mathrm{Hz}}=2.61 \quad \lambda / 4$ length in air

$\frac{\frac{\mathrm{c}}{\mathrm{f} 0 \cdot \sqrt{\mathrm{ert}}}}{4 \cdot 0.0254 \mathrm{~m} \cdot \mathrm{Hz}}=1.802 \quad \lambda / 4$ length in Tef.

$\mathrm{tHP}=0.4 \quad \mathrm{tLP}=0.6 \quad \mathrm{~b}=0.75$

wwall $=0.035$ separating the bars at the junction

(MathCad 11.0 Worksheet) 


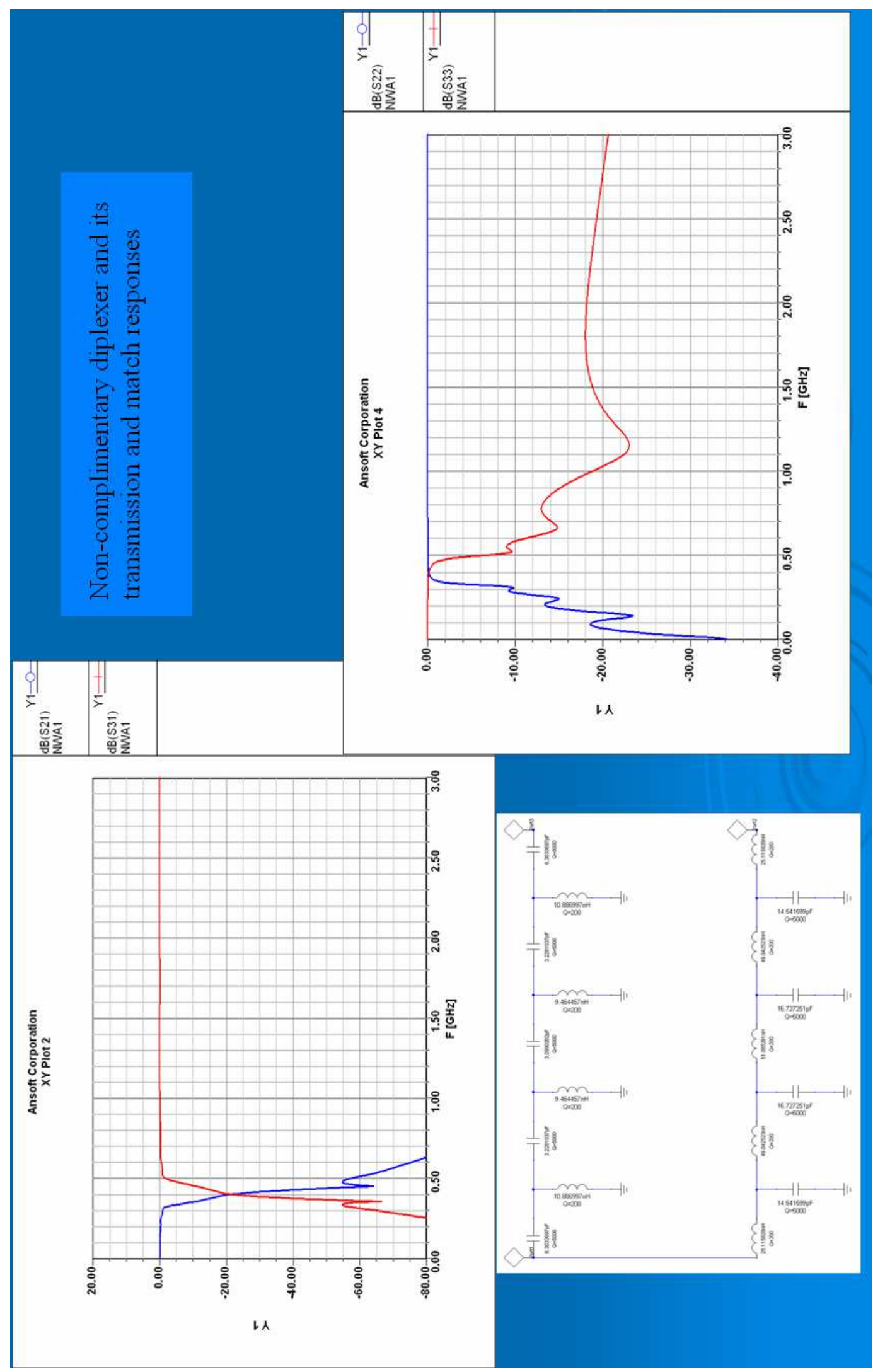




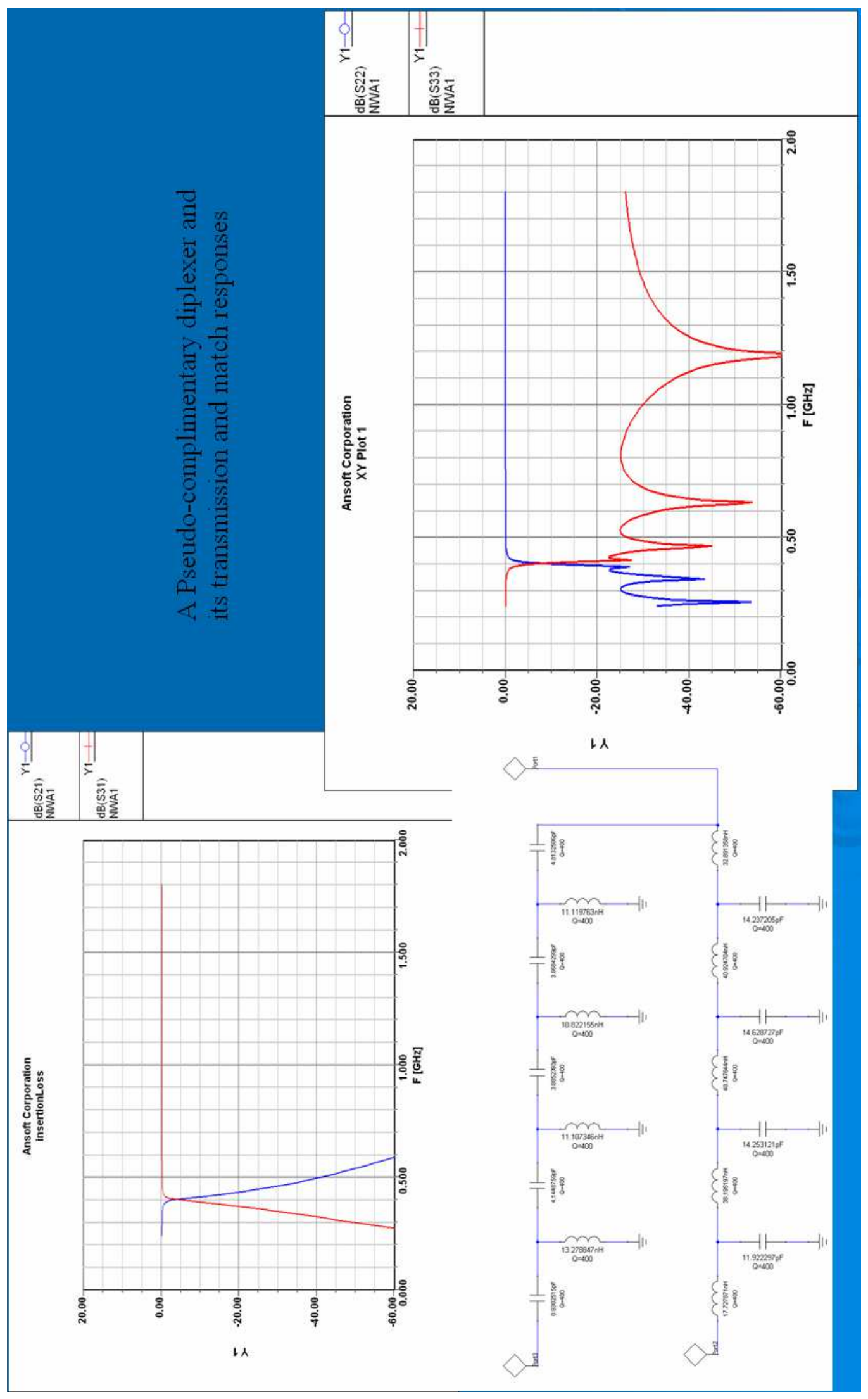

